\title{
Standardisation and applications of bronchoalveolar lavage cytology
}

Citation for published version (APA):

De Brauwer, E. I. G. B. (2000). Standardisation and applications of bronchoalveolar lavage cytology. [Doctoral Thesis, Maastricht University]. Datawyse / Universitaire Pers Maastricht. https://doi.org/10.26481/dis.20001214eb

Document status and date:

Published: 01/01/2000

DOI:

10.26481/dis.20001214eb

Document Version:

Publisher's PDF, also known as Version of record

\section{Please check the document version of this publication:}

- A submitted manuscript is the version of the article upon submission and before peer-review. There can be important differences between the submitted version and the official published version of record. People interested in the research are advised to contact the author for the final version of the publication, or visit the DOI to the publisher's website.

- The final author version and the galley proof are versions of the publication after peer review.

- The final published version features the final layout of the paper including the volume, issue and page numbers.

Link to publication

\footnotetext{
General rights rights.

- You may freely distribute the URL identifying the publication in the public portal. please follow below link for the End User Agreement:

www.umlib.nl/taverne-license

Take down policy

If you believe that this document breaches copyright please contact us at:

repository@maastrichtuniversity.nl

providing details and we will investigate your claim.
}

Copyright and moral rights for the publications made accessible in the public portal are retained by the authors and/or other copyright owners and it is a condition of accessing publications that users recognise and abide by the legal requirements associated with these

- Users may download and print one copy of any publication from the public portal for the purpose of private study or research.

- You may not further distribute the material or use it for any profit-making activity or commercial gain

If the publication is distributed under the terms of Article $25 \mathrm{fa}$ of the Dutch Copyright Act, indicated by the "Taverne" license above, 
Standardisation and applications of

bronchoalveolar lavage cytology 
(O) EIGB De Brawer, Mastricht 2000, The Netherlands

ISBN $90-5278-289-X$

\section{Cover Design:}

Hendrik De Brauwer, based on a photograph of encapsulated budding yeasts in BAL fluid.

Vormgeving en druk:

Datawyse / Universitaire Pers Maastricht 


\section{Standardisation and applications of bronchoalveolar lavage cytology}

\section{PROEFSCHRIFT}

ter verkrijging van de graad van doctor aan de Universiteit Maastricht, op het gezag van de Rector Magnificus, Prof. dr. A.C. Nieuwenhuijzen Kruseman, volgens het besluit van het College van Decanen, in het openbaar te verdedigen op donderdag 14 december 2000 om 16.00 uur

$$
\text { door }
$$

Els Ingrid Godelieve Bert De Brauwer geboren op 20 september 1967 te Hasselt

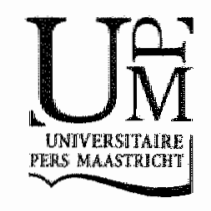




\section{Promotor}

Prof. Dr. C.A. Bruggeman

Co-promotoren

Dr. M. Drent

Dr. J.A. Jacobs

\section{Beoordelingscommissie}

Prof. Dr. M.P. van Dieijen-Visser (voorzitter)

Prof. Dr. R.P. Baughman (Pulmonary Critical Care Division, Cincinnati, USA)

Dr. M.F. Peeters (Sint Elisabeth Ziekenhuis, Tilburg)

Prof. Dr. G. Ramsay

Prof. Dr. E.F.M. Wouters 
Aan mijn ouders

Voor Ger, Astrid en Clara 



\section{Contents}

List of abbreviatons

CHAPTER $\mathbb{1}$

General introduction

CHAPTER 2

Cytocentrifugation conditions affecting the differential cell count in bronchoalveolar lavage fluid

CHAPTER 3

Differential cell analysis of cytocentrifuged bronchoalveolar lavage fluid samples affected by the area counted

CHAPTER 4

Bronchoalveolar lavage fluid differential cell count: how many cells should be counted?

CHAPTER 5

Test characteristics of Acridine Orange, Gram and May-Grünwald-Giemsa stains for the detection of intracellular organisms in bronchoalveolar lavage fluid

CHAPTER 6

Correlation of leukocyte esterase detection by reagent strips and the presence of neutrophils: a study in bronchoalveolar ॥avage fluid

CHAPTER ?

Detection of non-infectious conditions mimicking pneumonia in the intensive care setting: usefulness of bronchoalveolar lavage fluid cytology

CHAPTER 8

Summary and general discussion

Samenvatting

Dankwoord

Curriculum Vitae

List of Publications 


\section{List of abbreviations}

$\begin{array}{ll}\text { AM } & \text { Alveolar macrophage } \\ \text { ANOVA } & \text { Analysis of variance } \\ \text { AO } & \text { Acridine orange } \\ \text { ARDS } & \text { Adult Respiratory Distress Syndrome } \\ \text { ATS } & \text { American Thoracic Society } \\ \text { BAL } & \text { Bronchoalveolar lavage } \\ \text { BOOP } & \text { Bronchiolitis obliterans with organising pneumonia } \\ \text { C } & \text { Number of cells counted } \\ \text { CCS } & \text { Cytocentrifugation spot } \\ \text { cfu } & \text { Colony forming units } \\ \text { CSD } & \text { Crescent-shaped distribution } \\ \text { df } & \text { Degrees of freedorn } \\ \text { D-analysis } & \text { Decision-analysis } \\ \text { D-study } & \text { Decision-study } \\ \text { EAA } & \text { Extrinsic allergic allveolitis } \\ \text { EMS } & \text { Expected mean sums of squares } \\ \text { EOS } & \text { Eosinophil } \\ \text { ERS } & \text { European Respiratory Society } \\ \text { F } & \text { Female } \\ \text { G-theory } & \text { Generalizibility-theory } \\ \text { GENOVA } & \text { Generalised analysis of variance } \\ \text { H. influenzae } & \text { Haemopbilus influenzae } \\ \text { HPF } & \text { High power field } \\ \text { GG adj.F } & \text { Greenhouse-Geisser adjusted F-ratio } \\ \text { ICCA } & \text { Intraclass correlation coefficients for interobserver } \\ & \text { agreement } \\ \text { ICGR } & \text { Intraclass correlation coefficients for reproducibility } \\ \text { ICO } & \text { Intracellular organisms } \\ \text { ICU } & \text { Intensive care unit } \\ \text { IFA } & \text { Immuno-fluorescence assay } \\ \text { ILD } & \text { Interstitial lung diseases } \\ \text { IPF } & \text { Idiopathic pulmonary fibrosis } \\ \text { L.pneumophila } & \text { Legionella pneumtophila } \\ \text { LE } & \text { Leukocyte esterase } \\ \text { LHR } & \text { Likelihood ratio } \\ \text { Lym } & \text { Lymphocyte } \\ \text { M } & \text { Man } \\ \text { Mc } & \text { Mast cell } \\ \text { MGG } & \text { May-Grünwald-Giemsa } \\ & \end{array}$




$\begin{array}{ll}\text { min } & \text { Minute } \\ \text { ND } & \text { No data } \\ \text { NS } & \text { Not significant } \\ \mathrm{O} & \text { Observer } \\ \mathrm{p} & \text { Probability } \\ \text { P.carimi } & \text { Pnemmocystis carinit } \\ \mathrm{P} & \text { Plasma cell } \\ \text { PCR } & \text { Polymerase chain reaction } \\ \text { PMN(s) } & \text { Polymorphonuclear neutrophil(s) } \\ \text { Q } & \text { Quadrant } \\ \text { QF } & \text { Quasi-F ratio } \\ \text { REMLS } & \text { Restricted maximum likelihood } \\ \text { rpm } & \text { Revolutions per minute } \\ \text { S } & \text { Specimen } \\ \text { SAR } & \text { Sarcoidosis } \\ \text { SD } & \text { Standard deviation } \\ \text { SEP } & \text { European Society of Pneumonology } \\ \text { TCC } & \text { Total cell count } \\ \text { VAP } & \text { Ventilator-associated pneumonia }\end{array}$





\section{General introduction}

1. Background

2. Technical aspects of bronchoalveolar lavage

2.1. Premedication and local anaesthesia

2.2 Site of lavage

2.3 Fluid used for bronchoalveolar lavage

2.4 Methods to instil and recover the fluid

2.5 Volumes of fluid to be used

3. Laboratory processing of bronchoalveolar lavage: Bronchoalveolar lavage fluid cytology

3.1 Cytocentrifugation

3.2 Choice of stains

3.3 Cellular components of the bronchoalveolar lavage fluid

3.4 Microscopy

4. Diagnostic value of bronchoalveolar lavage fluid cytology

4.1 Diagnostic value of bronchoalveolar lavage fluid cytology in the assessment of ventilator-associated pneumonia

4.1.1 Assessment of the bronchoalveolar lavage fluid quality

4.1.2 Bronchoalveolar lavage fluid cytology in the prediction of ventilator-associated pneumonia

4.1.3 Detection of non-infectious lung conditions

4.2 The role of bronchoalveolar lavage fluid cytology in the management of non-infectious lung diseases

5. Aims of the study, outlines of this thesis 
Bronchoalveolar lavage (BAL) is a procedure in which the bronchoalveolar region of the respiratory tract is lavaged or washed with an isotonic salt solution. It is a method for sampling cells and solutes from a large area deep within the tissue of the lung. BA.L has emerged to be useful both in fundamental research and for clinical purposes. ${ }^{1-6}$

Bronchoalveolar lavage in human was first used at Yale in 1922 as a therapeutic tool, e.g. in the management of phosgene poisoning and as a means of removing abundant secretions. ${ }^{1}$ Therefore, the rigid bronchoscope was developed. The rigid bronchoscope was used as a conduit for lung lavage till the early 1960s. ${ }^{712}$ About 1967, the flexible bronchofiberscope conceived by Dr. Shigeto Ikeda was introduced. ${ }^{13,14}$ The ability to safely visualise and biopsy bronchial lesions, combined with bronchial brushings and washings for cytologic and bacteriologic sampling virtually eliminated the need for rigid bronchoscopy and substantially reduced the need for open lung biopsy or mediastinoscopy in the diagnosis of lung cancer and interstitial lung diseases (ILD). Fiberoptic bronchoscope, as the instrument is called, and BAL fluid analysis have provided information a bout the cellular and noncellular components of the alveolar epithelial lining fluid. Moreover, BAL fluid analysis has improved the diagnosis of opportunistic infections, and has provided insights into the diagnosis and pathogenesis of ILD. ${ }^{2,15}$ However, the role of BAL fluid analysis in the assessment of lung disease activity and follow-up of ILD is still controversial. ${ }^{16}$

\subsection{Premedication and local anaesthesia}

Most centres use sedating compounds such as diazepam or meperidine together with atropine as premedication for fiberoptic bronchoscopy. Local anaesthesia is usually accomplished by local applicarion of lidocaine: 1) spray aerosol for the nasal, oral, pharyngeal and laryngeal area; 2) direct instillation via the bronchoscope for anaesthesia of the trachea, carina and bronchi. ${ }^{17}$

\subsection{Site of lavage}

A standard site of sampling is recommended unless the affected area is not generalised throughout the lungs but localised. From an anatomical point of view, the middle lobe or lingula are the most convenient lobes to be lavaged. ${ }^{18}$ The lower lobes are difficult to occlude or wedge with the bronchoscope, and more lavage fluid is necessary to obtain a satisfactory recovery. In general, results obtained at one site are thought to be representative for the whole lung. Depending on the 
nature of the disease and its heterogeneity, lavage of more than one site will reduce sampling errors. In patients with localised lesions, such as inflammatory inflltrates, malignant lesions, etc., it is recommended that the area of greatest abnormality, as seen on the chest radiograph, should be chosen as the preferred site for performing the BAL. 17

\subsection{Flwid used for bronchoalveolar lavage}

A pyrogen-free saline solution (isotonic $0.9 \% \mathrm{NaCl}$, suitable for intravenous use) is preferred. Lavage fluid should be warmed to body temperature $\left(37^{\circ} \mathrm{C}\right)$. However, most groups when performing BAL for diagnostic or research purposes have used fluid at room temperature. $2,15,19-23$

\subsection{Methods to instil and recover the fuid}

After complete inspection of the airways, a fiberoptic bronchoscope is gently impacted, or 'wedged', into a segmental or subsegmental bronchus. The fluid is instilled into the subsegment through the working channel. 20,24 Subsequently, the fluid is aspirated and recovered with the help of a suction trap to which mechanical suction is applied. ${ }^{20}$ The suction pressure during aspiration will be kept to a minimum (25-100 $\mathrm{mmHg}$ ). After each instillation, the recovered fluid is collected. in the syringe, in a sterile suction flask, in a plastic specimen trap, or in a siliconised vessel. The aliquots are separately recovered in non-adhesive polypropylene containers, which are consecutively numbered. ${ }^{17}$

\subsection{Volume of fluid to be used}

The greatest technical variation in carrying out $B A L$ relates to the volume of fluid used. To reduce variability, workers should employ a standard introduction volume of lavage fluid of minimum $100 \mathrm{ml}$ in adults. The European Society of Pneumonology recommended $200-240 \mathrm{ml}$ divided in four input aliquots. 17 Usually, the total volume infused ranges from 100 to $300 \mathrm{~m}$ using multiple aliquots of 20 to $50 \mathrm{ml} \cdot 18,25$

Previous task force reports have focussed on the clinical indications for BAL and on the technical aspects, dealing mainly with the evaluation of cells and other cytological features in BAL, 5,26-28 More recently, the European respiratory Society (ERS) Task Force Report provided a comprehensive review of the current status of techniques for the measurement of acellular components in thuman BAL. 
fluid samples. ${ }^{29}$ All these reports provide guidelines and recommendations to define standard procedures for the general treatment of BAL fluid.

\subsection{Cytocentrifugation}

Slides for microscopy are prepared by cytocentrifugation. This process involves a low-speed centrifugation of the BAL fluid with deposition of the cells onto a microscope slide. Cytocentrifugation increases the diagnostic threshold of the microscopic detection of organisms by up to 2 logs as compared to conventional centrifuge prepared smears. 30 In addition to this quantitative benefit, cytocentrifuged preparations reveal organisms and host cells with well-preserved morphology and high resolution, which facilitates the recognition of intracellular bacteria. Moreover, cytocentrifuged preparations facilitate uniform staining of slides and the microscopist needs to examine only a 6 - mm diameter spot on the slide. The adjustable cytocentrifugation parameters include time, speed and acceleration rate. For optimal recovery of tiny objects such as bacteria, the maximal speed of 2.000 revolutions per minute ( $\mathrm{rpm}$ ), which equals a g-value $x$ 300 , has been recommended. ${ }^{31,32}$. Fowever, these extreme operating conditions damage larger and vulnerable cells resulting in stretching or tearing of the cell borders. The combination of a low acceleration rate and a speed of $650 \mathrm{rpm}$ ( $g$-value $\times 40$ ) results in both a preserved cell morphology and a good recovery of micromorganisms, 27

\subsection{Chotce of stams}

Obviously, numerous stains are available and there exists little consensus on which stain is the preferable one to use. The choice not only depends on the cost and the time available for testing, but also on the technical expertise and experience of the laboratory staff, on the facilities of automatic staining and on the ability to batch specimens. Regardless of the method selected, concurrent staining of control slides should be performed.

The Gram and the May-Grünwald-Giemsa (MGG) stains are routinely performed on all submitred BAL fluid samples. ${ }^{33}$ In addition, slides of each BAL fluid specimen are stained with the fluorescent auramine-rhodamine dye for visualisation of acid-fast bacteria. Optional stains are performed when clinically indicated, or when microscopic findings on Gram or MGG stained preparations incite further exploration of confirmation.

Several considerations made us to elect the MGG stain over the Papanicoulaou stain as the stain of choice for standard cytological examination of the BAL fluid specimens. Romanovsky stains such as the MGG stain render nuclear features in less detail as compared to Papanicoulaou stains and are less suitable for the detection of malignancy and viral inclusion bodies. They are however excellent for identification of leukocytes and obviously stain 
extracellular substances such as mucus. Slides for MGG stainings are allowed to air-dry and are fixed for 10 minutes by an overlay of absolute methanol. For a clear background, it is important that the methanol used as fixative is completely water-free. Rapid substitutes for traditional Romanovsky stains are available, such as the Wright's stain and the Diff-Quick stain (Scientific Products, McGraw, 111, U.S.A.). However, using larter stain is not possible to stain mast cells. ${ }^{34}$

Additional stains include the Perls' stain, the Acridine Orange stain, the Leukophor stain and the methenamine silver nitrate stain. Further, immunofluorescence tests for the detection of Pnewmocystis carinit and Legronella pneumophila are available.

A Perls' stain for haemosiderin visualisation is recommended when blue-green granules or brownish bulky particles are seen in macrophages or polymorphonuclear neutrophils (PMNs), or when BAL fluid samples from immunocompromised hosts are processed. The chromogen potassium ferrocyanide combines with trivalent iron to give an intense blue colour. On staining for iron, alveolar macrophages and PMNs that have ingested red blood cells or red cell degradation products display a positive reaction that ranges from a faint homogenous blue discoloration of the cytoplasm to an intense blue-staining of bulky intracytoplasmatic material.

Acridine Orange is a fluorochrome that preferentially binds to nucleic acids of bacteria at low pH. Staining with Acridine Orange is simple to perform, and allows differentiation of bacteria and fungi (which show a bright orange fluorescence) from background material and mammalian cells (which fluoresce green to yellow). ${ }^{35}$

\subsection{Cellular components of the bronchoalveolar lavage fluid}

Cells present in BAL fluid samples of healthy controls comprise alveolar macrophages ( 80 to $90 \%$ of the total cell count), lymphocytes (5 to $10 \%)$, PMNs ( 1 to $2 \%$ ), eosinophils and mast cells ( 1 to $2 \%$ ). These percentages may vary due to confounding factors, of which cigarette smoking is the most important. ${ }^{26,36,37}$ Cells that are normally not present in BAL fluid samples include squamous and bronchial epithelial cells, plasma cells and malignant cells.

\section{Alveolar macrophages}

Normally, BAL fluid consists of predominantly alveolar macrophages. ${ }^{26,37}$ Alveolar macrophages are mononucleated cells that range from $10 \mu \mathrm{m}$ to $40 \mu \mathrm{m}$ in diameter. Their cytoplasm is pale and abundant, and in most cases it is equally proportioned around the nucleus. It may contain phagocytised materials such as carbon, haemosiderin, cell fragments or debris. The nucleus is round to oval. Multinucleated macrophages are occasionally seen but they do not imply infection or foreign body reaction. The chromatin is granular to reticular, and creases 

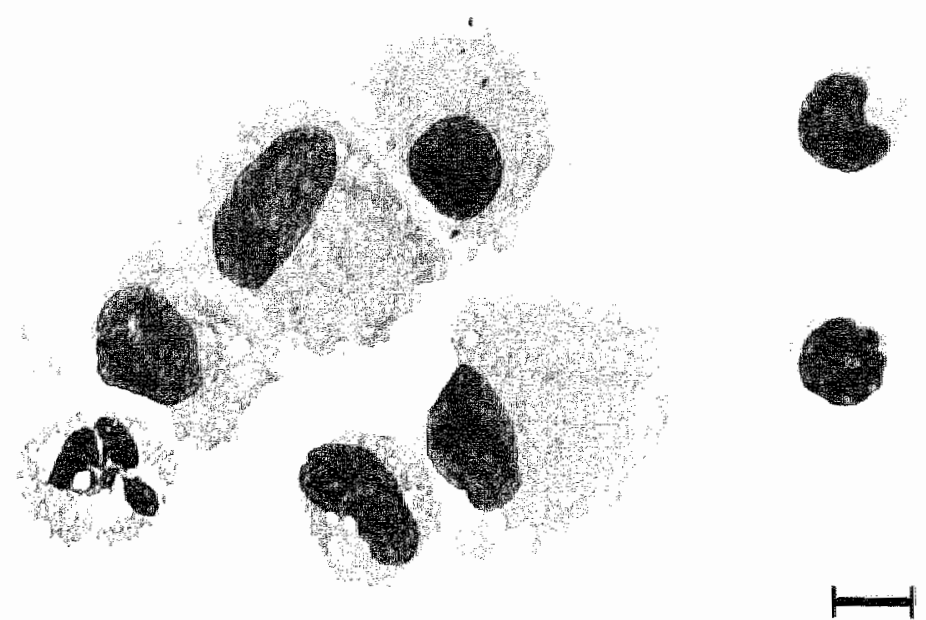

Figure 1. May Grunwald Giemsa stain, high power magnification, one polymorphonuclear neurrophil (lower lefr comer), two lymphocyres (right, and five alweolar macrophages (center).
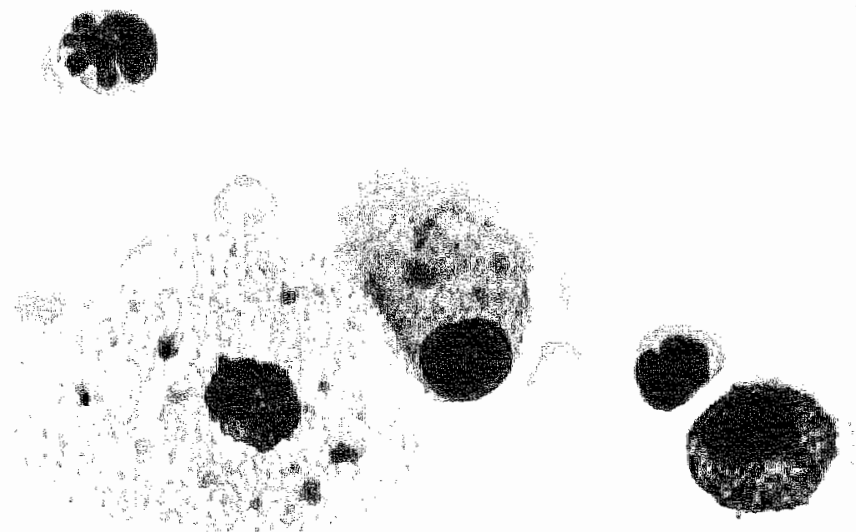

Figure 2. May-Crünwald-Giemsa stain, high power magnification, one foamy alvedar macrophage llower left comer). The cyroplasm of foamy alveolar macrophages show clar and complete vactolisation. A normal alveolar macrophage (right) lies adjacent to the foamy alweolar macrophage. 
and nucleoli may be observed (figure 1 and 2). Foamy alveolar macrophages are macrophages that display clear and complete cytoplasm vacuolisation (figure 2). Although usually non-specific, this finding may be a part of the diagnostic picture in aspiration pneumonia or in drug-induced pulmonary disease, particularly in drug-induced pneumonitis caused by amiodarone. ${ }^{38}$

\section{Lymphocytes}

Mature lymphocytes are the smallest nucleated cells in the BAL fluid. They display a high nuclear:cytoplasmatic ratio, and sometimes only a bare nucleus may be discerned. The nuclear shape is round to intended. The chromatin is dense and homogenous and stains deep blue-purple. Nucleoli are not observed in mature lymphocytes. An eccentric rim of scanty, sky blue cytoplasm is clearly delineated at one side and it occasionally contains a few azurophilic granules (figure 1). Increased numbers of mature lymphocytes are seen in BAL fluid samples of patients with sarcoidosis. ${ }^{39}$ Activated lymphocytes are, from a morphological point of view, similar to the "atypical lymphocytes" observed in blood films of patients with viral infections and drug hypersensitivity. 40 In contrast to immature lymphocytes, activated lymphocytes contain mature coarse red-purple nuclear chromatin and their cytoplasm is more abundant. Compared to mature lymphocytes, activated lymphocytes are larger. They may show irregular cell borders and the cytoplasm may be vacuolated and foamy. The cytoplasm's colour ranges from pale blue (with a deeper blue cytoplasm near the cell border) to intensely basophilic. The nucleus may be slightly to moderately intended, and is sometimes stretched along the length of the cell. The nuclear chromatin is granular and condensed, similar to the chromatin of plasma cells. Distinguishing activated lymphocytes from small alveolar macrophages may be difficult. ${ }^{41}$

\section{Polymorphonuclear neutrophils}

The PMNs average a diameter of 12 to $15 \mu \mathrm{m}$. Their nucleus is irregular and consists of two to five (median three) lobes that are connected by delicate fila= ments. The nuclear lobes have coarse blocks of chromatin. The cytoplasm itself is colourless, but it is packed full of tiny granules which stain pink to red with the MGG stain (figure 1). In long-standing inflammation, necrobiotic neutrophils may be seen. These cells show loss of nuclear chromatin pattern, with coalescence of the nucleus into a single or multiple small droplets that stain intensely basophilic. Elevations of the BAL fluid PMN count may occur in several clinical conditions, and the relative numbers of PMNs are associated with disease severity in disorders such as $P$. carinii pneumonia, idiopathic pulmonary fibrosis, sarcoidosis, ARDS and ventilator-associated pneumonia, $42-44$ 


\section{Eosinopbils}

Eosinophils show bilobed nuclei rather than the more complexly lobulated nuclei of neutrophils. They have a dark, granular nuclear chromatin. Their distinct, uniformly sized and bright orange granules are larger than those of the neutrophil and cause them to stand out even at low magnification. The number of eosinophils in BAL fluid may be increased in patients with asthma, drug-induced lung disease, acute or chronic eosinophilic pneumonia, extrinsic allergic alveolitis, idiopathic pulmonary fibrosis and $P$. carini pneumonia. 45,46

\section{Mast cells}

Mast cells in BAL fluid are larger than the basophils that are seen in blood films. Their cytoplasm is filled with small, reddish-purplish granules that often obscure the oval, centrally located nucleus. They are rarely seen in BAL fluid samples and may require special stains for visualisation. Their number may be increased in the BAL fluid of asthmatic patients, patients with bronchiolitis obliterans or farmer's lung disease. $6,47,48$

\section{Epithelial cells}

The presence of squamous epithelial cells points to oropharyngeal contamination of the BAL fluid. These cells are recognised as large, flat cells and occur singly or in sheets. Their nuclei are comparatively small and uniformly round and the chromatin may be very dense. The cytoplasm appears dark or palle blue, and the cell borders are distinctly sharp. Pale squamous epithelial cells may be overlooked in MGG stained preparations, but they are readily visible on Gram stained slicles. Squamous epithelial cells may be covered by oral bacteria.

Bronchial epithelial cells include ciliated cells and mucus-secreting goblet cells, the formers are most frequently observed. Ciliated bronchial epithelial cells are columnar cells with a basally located nucleus, a pale cytoplasm with a distinctive end plate and a tuft of cilia, on which bacteria may be discerned. The nuclear chromatin is reticular, and up to two nucleoli may be seen (figure 3). During the process of cytocentrifugation and staining, a high number of bronchial epithelial cells may be damaged. ${ }^{49}$ Cell degeneration is evidenced by nuclear swelling and poorly discemible cell borders. The presence of the end plate and the reticular, basally located nucleus is however typical morphological features that may help to recognise these cells. Detached cilia appear as faint, slightly curved filaments. They stain Gram-negative and hence may be mistaken for Gram-negative rods. ${ }^{50}$ Mucus-secreting goblet cells are more difficult to recognise. Similar to ciliated cells, goblet cells are pale, elongated cells with a basally located nucleus. The cytoplasm extends above the nucleus in a shape like that of a wine goblet. The mucin stains red in MGG stained preparations. 


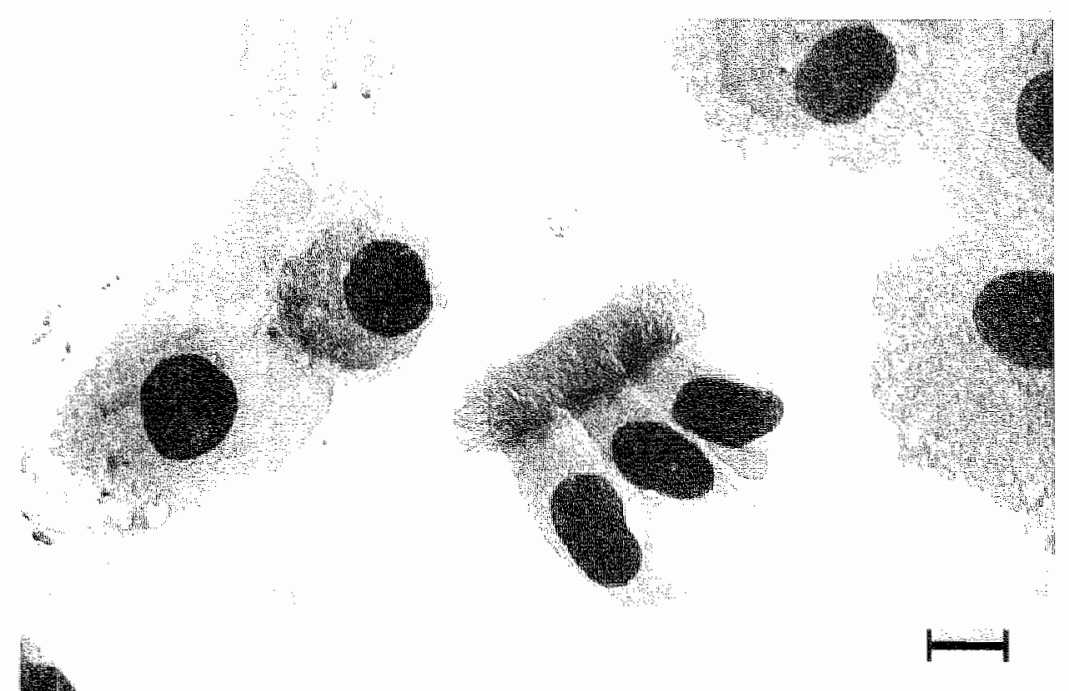

Figure 3. May-Grünwald-Giemsa stain, high power magnification. Three bronchial epithelial cells (center). They are colomnur cells with a basally located nucleus and cilia at the apical site.

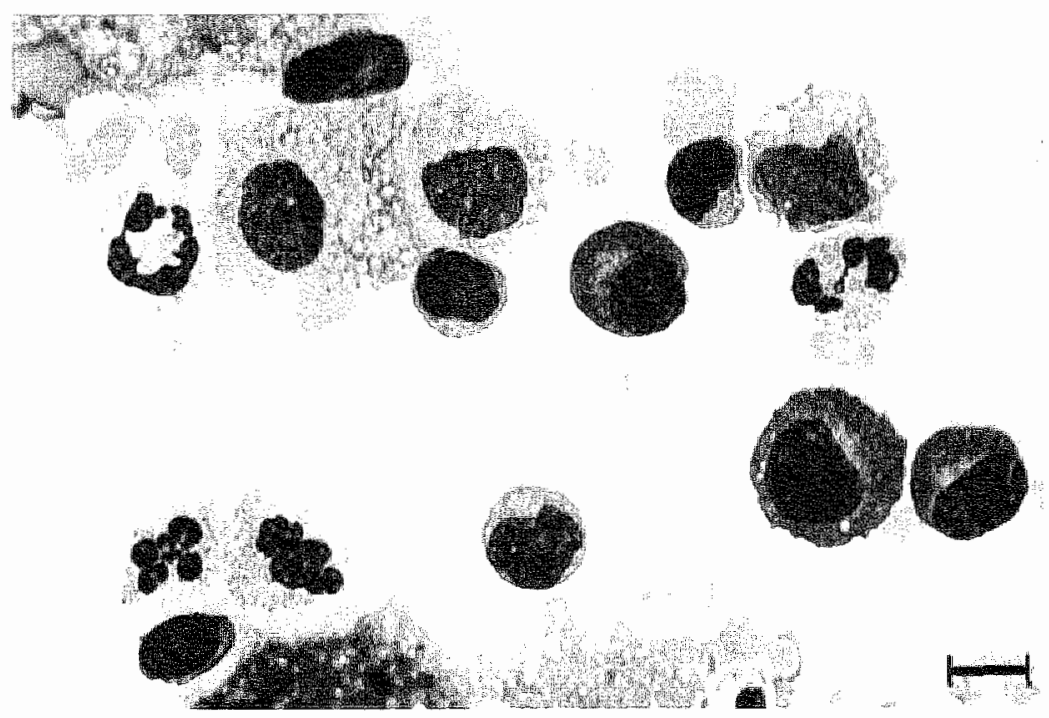

Figure 4. May-Grünald-Giemsa stain, high power magnification. Four plasma celis (rwo lower right comer, one center, one upper lefficomer). Plasma cells have a round ro oval wedeus that mostly lies excentric. The cytoplasm atains basophilic, wirh a perinuclear zone adjacent to the nucleus. 


\section{Type II pneumocytes}

Type II pneumocytes, also referred to as alveolar lining cells, are round or cuboidal cells with a vacuolated cytoplasm. In healthy persons, alveolar lining cells are either not recovered by BAL or are morphologically indistinguishable from macrophages. By contrast, reactive rype II pneumocytes may easily be recognised because they shed as cohesive cellular clusters that are occasionally arranged as gland like fragments. They present as large cells, with a high nuclear:cytoplasm ratio. Their nuclei are large, round to oval, with occasional irregularities in the contour, and the cytoplasm is deeper blue than the cytoplasm of the alveolar macrophages. Reactive type II pneumocytes may resemble malignant cells. They may be seen in BAL fluid samples of patients with the Adult Respiratory Distress Syndrome (ARDS), cytotoxic chemotherapy or radiation therapy. $51,52,53$

\section{Plasma cells}

Normally, plasma cells are not present in BAL fluid specimens. ${ }^{54}$ Their diameter ranges from 8 to $20 \mu \mathrm{m}$. They have a round to oval nucleus that frequently lies excentric. Dense clumps and granules of chromatin are observed, but no nucleoli are present. The cytoplasm stains intensely basophilic, with a perinuclear clear zone adjacent to the nucleus (figure 4). In some cells, vacuoles may be seen. An increase in the number of lymphocytes, the presence of activated lymphocytes and plasma cells may point to a drug-induced pulmonary disease or extrinsic allergic alveolitis. Furthermore, plasma cells can be found in BAL fluid samples obtained from patients suffering from malignant lymphoma, non-Hodgkin or Hodgkin lymphomas. ${ }^{38,54}$

\subsection{Microscopy}

On MGG stained preparations, the differential cell counts are performed on consecutive nucleated cells, excluding epithelial cells. PMN, eosinophil, mast cell, lymphocyte and alveolar macrophage numbers are reported as a percentage of the numbers of cells counted. Squamous and bronchial epithelial cells are separately recorded and expressed as a percentage of the numbers of cells counted. The presence of damaged cells, red blood cells and intercellular debris is recorded semi-quantitatively using a standardised score. Cells containing micro-organisms (infected cells) are enumerated on MGG stained preparations. Both alveolar macrophages and PMNs may contain phagocytised micro-organisms and the enumeration of both cell types must be considered. The quantification of infected cells is expressed as a percentage of the numbers of cells counted. 


\subsection{Diagnostic value of broncboalveolar lavage fluid cytology in the assessment of ventilator-associated pnemmonia}

In patients suspected of ventilator-associated pneumonia (VAP), BAL fluid cytology provides criteria for specimen rejection and offers valuable arguments to the diagnosis of infectious pneumonia as well as to an alternative diagnosis. In our hospital, quantitative cultures of BAL fluid are the standard method for the microbiological diagnosis of VAP. 31 Quantitative cultures of BAL fluid express the BAL fluid microbial burden in colony forming units per millilitre (CFU/mI). As the dillution of the lung secretions in the BAL fluid is 10 -to 100 fold, a colony count of $10^{4}$ cfu/ml represents a bacterial load of $10^{5}$ to $10^{6} / \mathrm{ml}$ in the collection site, which is indicative of bacterial pneumonia. 35 Conversely, a BAL fuid colony count below the $10^{4} \mathrm{cfu} / \mathrm{m} /$ threshold points to oropharyngeal contamination. This theoretical concept has been validated in numerous clinical studies, and quantitative culture of BAL fluid specimens is consequently recommended as the reference method in the diagnosis of VAP. 56,57

\subsubsection{Assessment of the bronchoalveolar lavage fluid quality}

The presence of squamous epithelial cells is indicative for contamination by oropharyngeal flora, and most authors consider BAL fluid samples with $1 \%$ of these cells as invalid for quantitative culture. ${ }^{58,59}$ Ciliated cells and goblet cells represent bronchial tract contamination, and rejection criteria of $5 \%$ and $1 \%$ bronchial epithelial cells have been proposed. ${ }^{58,59}$ Many ventilated patients have tracheobronchitis and bronchial epithelial cells are easily overlooked when they are damaged or unevenly distributed over the cytocentrifuge spot.

\subsubsection{Bronchoalveolar lavage fluid cytology in the prediction of ventilator-associated pneumonia}

BAL fluid cytological parameters that have been studied as predictive of VAP include the total cell count, the differential cell count., and the number of infected cells. The total cell count has been demonstrated to be significantly higher in BAL fluid samples from patients with VAP compared to those obtained from non-infected patients, 60,61 However, there remains a considerable overlap between the pneumonia and the non pneumonia group, precluding accurate distinction. As the total cell count of the BAL fluid also depends upon technical variables during bronchoscopy, and for this reason the use of the total cell count is recommended as an additional quality control, i.e. low total cell counts $(<60.000$ cells/ml) are considered as indicative of technically invalid BAL fluid samples. 62 


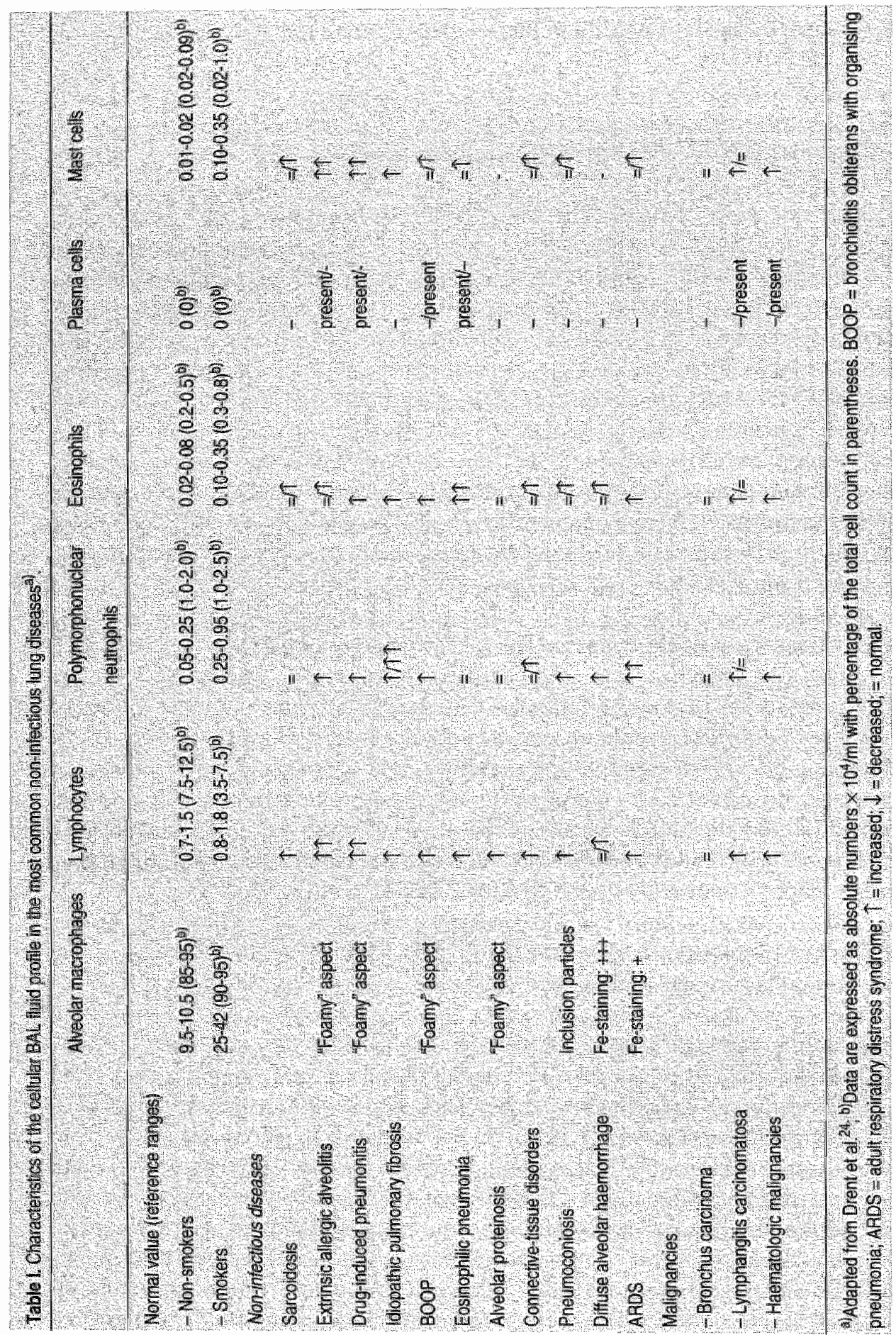


Most studies reported that the percentage of BAL fluid PMNs was significantly higher in patients with VAP as compared to those without pneumonia. ${ }^{63,62}$ An attempt to convert this information into a discriminatory test was not successful, as no useful threshold could be defined. ${ }^{59}$ Further, the number of PMNs also increases in pulmonary processes that are inflammatory but non-infectious, such as in the early phase of the ARDS. ${ }^{64}$ Therefore, the BAL fluid PMN percentage is more useful in its negative prediction, i.e. a low PMN count (or, a high number of macrophages), is a valuable argument for exclusion of VAP. ${ }^{65}$ This has been clearly shown by Kirtland and co-workers who found that a percentage of $<50 \%$ PMNs had a $100 \%$ negative predictive value for VAP as defined by histological criteria. ${ }^{66}$

Infected cells are also more frequently found in BAL fluid samples of patients with VAP than in patients without VAP. The cut-off walues for infected cells cited in the literature range from $2 \%$ to $25 \% .61,67$ These differences may depend upon the patient population studied, the stain used and the cell type enumerated, but few data are available on the technical aspects of this test. The reported cut-off values display a high specificity combined to a lower sensitivity. Most of the studies used quantitative BAL fluid cultures as the validating standard for VAP. The accepted culture cut-off point of $10^{4} \mathrm{cfu} / \mathrm{ml}$ has originally been proposed in a concern to avoid underdiagnosis of VAP, and consequently implicates a number of false-positive pneumonias. ${ }^{68}$ Moreover, several authors used an exclusion criterion of $5 \%$ ciliated cells and this may be too relax to rule out bronchial contamination. 59,62 Consequently, the current "gold" culture standard for VAP is probably too sensitive, explaining at least in part for the lower sensitivity of the infected cell counts. Using the quantitative bacteriological burden of the BAL fluid (and not just the culture threshold) as an endpoint for comparison, Meduri and co-workers found that the percentages of PMNs and infected cells were related to the severity of pneumonia and accurately expressed the degree of local inflammation. ${ }^{68}$ Conflicting results have been reported with regard to the influence of prior and current antibiotics on the recovery rate of infected cells. Dotson and Pingleton reported a decrease in the recovery rate, but this was not confirmed by Souweine and co-workers. ${ }^{69,70} \mathrm{As}$ up to one third of patients suspected of VAP are receiving antibiotics prior to bronchoscopy, this issue should be further studied, with special attention to the influence of antibiotics that are not or only partially effective against the putative pathogen. ${ }^{61}$ In view of all these interferring factors, cut-off points for infected cells need to be established in the local clinical setting. A cut-off value that provides the better sensitivity with a $100 \%$ specificity needs to be preferred, as this figure contributes most to the positive predictive value, i.e. confirmation of VAP. 


\subsubsection{Detection of non-infectious lung conditions}

Non-infectious conditions such as alveolar haemorthage, drug-induced pulmonary toxicity, ARDS, or aspiration of gastric contents may have a clinical presentation similar to that of VAP.71 Cytological findings such as the presence of activated lymphocytes, plasma cells, > 5\% eosinophills, a preponderance of "foamy" macrophages and reactive type II pneumocytes may set the clinician on the trail to the diagnosis of such a condition. A number of $>20 \%$ haemosiderin macrophages has been demonstrated to be indicative for alveolar haemorrhage. 72 Diffuse alveolar bleeding may occur in patients suffering from systemic vasculitis, collagen vascular diseases, Goodpasture's syndrome or in patients with thrombocytopenia, chest trauma, congestive heart failure, and mitral regurgita$\operatorname{tion}^{73,74,52}$

\subsection{The role of bronchoalveolar lavage fuid cytology in the management of} non-infections lung diseases

BAL fluid cytology provides unique information about ILD and other non-infectious diseases. Table I gives an overview of the differences in BAL fluid cell profile for the most common non-infectious lung diseases.

Few years ago, Drent and co-workers demonstrated that the predominant inflammatory cells obtained by BAL (alveolar macrophages, PMNs, easinophils and lymphocytes) may distinguish between three common interstitial lung diseases, i.e. sarcoidosis, extrinsic allergic alveolitis and idiopathic pulmonary fibrosis. ${ }^{37}$ Their observations were subsequently converted into a validated computer progam that enables prediction of the diagnosis of one of these diseases, using information provided by the BAL fluid analysis. ${ }^{37}$ This computer program offers an attractive adjunct to patient care: the three interstitial lung diseases under consideration have similar clinical presentations but may now be distinguished from each other by bronchoscopy with BAL, obwiating the need for more invasive diagnostic procedures. The BAL fluid data that are used for this computer program include the volume recovered, the total cell count and the percentages of alveolar macrophages, lymphocytes, PMNs and eosinophils. Demographic data that are needed are the patient's gender, age, and smoking status. Using a polychotomous logistic regression model, the computer program provides the most reliable diagnosis of the three interstitial diseases and expresses the calculated chance ${ }^{37}$ Recently, an updated version was developed which enables to distinguish disorders of an bacterial infectious origin and the three frequent ILD mentioned above. ${ }^{75}$ 


\section{AIMS OF THE STUDY}

BAL fluid analysis has prowided an insight into the inflammatory mechanisms in a wide range of diseases that affect the lung. In particular, BAL fluid cytology has been appreciated as an additional tool in establishing or ruling out pulmonary infections or ILD. Guidelines and recommendations - dealing with the evaluation of cells are available, and most of them have concentrated on technical aspects of BAL. Leading guidelines are those published by the "Task Group on BAL" of the European Society of Pulmonology and the guidelines of the American Thoracic Society 17,76 However, the processing of BAL fluid is still not completely standardised. Furthermore, there is an increasing demand for better quality control. Differences in BAL fluid processing appeared to be one of the main obstacles to universal acceptance of BAL in the clinical serting. Therefore, the most important aim of this study was to improve the clinical utility of cellular BAL fluid analysis. It complies with some relevant aspects of the processing of BAL fluid and additional cellular analysis.

Normally, processing of BAL fluid includes the analysis of total and differential cell counts. Cytocentrifugation of BAL fluid samples can be considered as a routine laboratory procedure that reveals sufficient preparations of the cell suspensions and enables a reliable differential cell count. Alterations in cytocentrifugation has been demonstrated to affect the recovery rate of microorganisms and underestimate the number of certain cell types present in BAL. fluid. ${ }^{77,78}$ In chapter 2, therefore, the effect of the cytocentrifuge Shandon Cytospin 3 centrifugation conditions, e.g. speed, acceleration rate and duration, on the results of the differential cell count of BAL fluid samples was assessed.

It has become apparent that the cytocentrifugation findings from different groups, e.g. different laboratories, not always are similar. It was hypothesised that the reproducibility and interobserver agreement might be influenced by the area of the cytocentrifuge spot used for cell counting. To test this hypothesis, in chapter 3 , the reliability of the differential cell counts of BAL fluid samples in diferent areas of the cytocentrifuge spot was evaluated.

Recommendations regarding the number of cells to be enumerated by the "Task Group on BAL" of the European Sociery of Pulmonology (300 to 500) and the guidelines of the American Thoracic Society (200 to 500) are quite similar. However, the number of cells enumerated in various studies ranges from 200 to 1000. Moreover, the impact of the number of cells counted on the reliability of the differential cell count in BAL fluid was not evaluated systematically. In chapter 4, the number of each cell type to be enumerated to guarantee a reliable counting was investigated.

The enumeration of intracellular organisms (ICO) in cells recovered by BAL is a valuable tool in the diagnosis of pulmonary infections. However, discrepancy appears in the staining methods used and the number of cells counted for enumeration of $1 \mathrm{CO}$. In chapter 5 , the test characteristics, such as reproducibility and 
interobserver agreement for different staining methods, e.g. Acridine Orange stain, Gram stain and May-Grünwald-Giemsa stain, were evaluated. Additionally, an attempt was made to determine the number of cells to be counted to achieve a reliable enumeration of $1 \mathrm{CO}$.

Besides bacterial cultures and monitoring biochemical changes of BAL fluid obtained from patients with suspected pneumonia, assessment of the toral and differential cell count appeared to be of practical additional value. In this context, the number of polymorphonuclear neutrophils (PMNs) was found to be sensitive to distinguish between disorders of infectious and non-infectious aetiology. However, this widespread clinical application of BAL fluid cytology is limited by the fact that this relies upon trained technicians. In chapter 6 , the usefulness of a simpler method of quantification of PMNs in a clinical setting was evaluated. A commercially awailable reagent strip was tested for its ability to detect and measure PMNs in BAL fluid samples. Therefore, the semi-quantitative categories generated by this strip were compared with the corresponding microscopic enumerated PMN count.

In chapter 7 , in order to evaluate the additional practical diagnostic value of cellular analysis of BAL fluid of patients on the ICU, BAL fluid samples obtained from patients with suspected VAP were reviewed. The usefulness of BAL fluid cellular analysis results in distinguishing infectious and non-infectious conditions, as well as the diagnostic power of these results in case of a disorder of non-infectious aetiology, was evaluated. Finally, chapter 8 contains a summary and the impact of the study on future research regarding BAL fluid cellular analysis.

\section{REFERENCES}

1. Ge IB, Fich RB. Bronchoalveolar lavae. Thorax 1980,35:1-8.

2. Reyrolds Hr. Bronchoalveolar lavage. Am Rev Respir Dis 1987; 135:250-263.

3. Walters EH, Gardiner PV. Bronchoalveolar lavage as a research tool. Thorax $1991: 46: 613-618$.

4. Baughman RP. Bronchoalveolar lavage, Ist edr., St. Louis, Mobsy Year Book, 1992.

5. Klech H, Hutter C, Costabel U, eds. Clinical guidelines and indications for bronchoalveolar lavage: feport of the European Sociery of Pneumonology Tasik Group on BAL. Eur: Respir Rov $1992,2: 47-127$

6. Costabel U, Zaiss AW, Guzman J. Sensivivity and specificity of BAL findings in sarcoidosis. Sarcoitosis 1992; 9 (Supp) 1):211-214.

7. Patterson E. History of bronchoscopy and esophagoscopy for foreign body. La ryngoscope $1926 ; 36: 157,175$

8. Jackson C. Bronchoscopy: past, present and future. N Engl I Med 928; 199; 759-763.

9. Vincenre G. Sobre une technica simplificada en la terapeutics intrapulmonary. Rev Prog Clin 1928 . 
10. Stit $\mathrm{H}$. Bronchial lavage for disinfection and immumisarion of the bronchial tree. J Med Cincinari Acad 1934;14:576-579.

11. Ramirez RJ, Kiefer RF Jr, Ball WC. Bronchopulmonary lavage in man. Ann Intem Med $1965 ; 63: 819-828$.

12. Falk GA, Okinaka AJ, Siskin GW. Immunoglobulins in the bronchial washings of patients with chronic obstructive pulmonary disease. Am Rew Respir Dis 1972;105:14-21.

13. Ikeda S, Yanai N, Ishikawa S. Flexible bronchofiberscope. Keio J Med 1968;17:1-16.

14. Ikeda S. Flexible bronchofiberscope. Ann Otol. Rhinol Laryngol 1970;79:916-919.

15. Hunninghake $G W$, Gadek JE, Kawanami $O$, Ferrans VJ, Crystal RG. Inflammatory and immune processes in human lung in health and disease: evaluation by bronchoalveolar lawage. Am J Pathol 1979;97:149-206.

16. Baughman RP. Is bronchoalveolar lavage clinically useful for every day practice in interstitial lung disease? J Bronchol 1999;6:211-216.

17. Klech H, Pohl W. Technical recommendations and guidelines for bronchoalveolar lavage (BAL): report of the European Society of Pneumonology Task Group on BAL. Eur Respir J $1989 ; 2: 561-585$.

18. Haslam PL, Baughman RP. ERS task force report on acellular components in BAL. Eur Respir Rev 1999;9:25-27.

19. Haslam $P$, Turton $C$, Heard $B$, et al. Bronchoalveolar lavage in pumonary fibrosis. Comparison of cells obtained with lung biopsy and clinical fearure. Thorax 1980;35:9-18.

20. Reynolds HY, Fulmer JD, Kazmierowsky JA, Roberts WC, Frank MM, Crystal RG. Analysis of cellular and protein content of bronchoalveolar lavage fluid from patients with idiopathic pulmonary fibrosis and chronic hypersensitivity pneumonitis. J Clin Invest 1977;59:165-175.

21. Daniele RP, Elias $J A$, Epstein PE, Rossman MD. Bronchoalveolar lavage: role in the pathogenesis, diagnosis, and management of interstitial lung disease. Ann Intern Med 1985;102:93-108.

22. Venet $A$, Clavel $F$, Israel-Biet D, Rouzioux $C$, Dennewald $G$, Stern MV, et al. Lung in acquired immune deficiency syndrome: infecrious and immunological status assessed by bronchoalveolar lavage. Bull Eur Physioparhol Respir 1985;21:535-543.

23. Rossi GA. Bronchoalveolar lavage in the investigation of disorders in the lower respiratory tract. Eur J Respir Dis 1986;69:293-315.

24. Drent $M$, Jacobs JA, Wagenaar SiSc. Bronchoalveolar lavage. Eur Respir Mon $2000_{4}^{*}$ it press.

25. Baughman RP, Renmard SI. Bronchoalveolar lavage general approaches tocorrect for variability of dillution and lung permeability. Eur Respir Rev 1999;9:28-31.

26. BAL Cooperative Group Steering Committee. Broncholaveolar lavage constituents in healthy individuals, idiopathic pulmonary fibrosis, and selected comparison groups. Am Rev Respir Dis 1990;141:169-202.

27. Capron F, Perrot JY, Szekeres G, Cauler S. Technique du liquide de lavage bronchoalvéolaire dans un laboratoire central d'anatomie et cytologie pathologiques. Ann Pathol 1990;10:278-281. 
28. Baselski VS, El-Torky M, Coalson JJ, Griffin JP. The standardisation of criteria for processing and interprening laboratory specimens in patients with suspected ventilaror-associated pneumona. Chest 1992;102:571-579.

29. Haslam PL, Baughman RB, Eds. Report of the European Respiratory Sociery Task Force. Eur Respir Rev 1999;9.

30. Perry JL. Utility of cytocentrifugation for direct examination of clinical specimens. Clin Microbiol Newsletter 1995;17/5upp!. 4);29-32.

31. Shanholtzer CJ, Schaper PJ, Peterson LR. Concentrated gram stain smears prepared with a cytospin centrifuge. J Clin Microbiol 1982;16:1052-1056.

32. Chapin-Rolyertson $\mathrm{K}$, Dahlberg SE, Edberg SC. Clinical and laboratory analyses of cytospin-prepared gram stains for recovery and diagnosis of bacteria from sterile body fluids. J Clin Microbiol 1992;30:377-380.

33. Jacobs $J A, D e$ Brauwer EIGB. BAL. fluid cytology in the assessment of infectious Iung disease. Hosp Med 1999;60:550-555.

34. Ronai Z, Bauer PC, Wang YM, Costabel U. Nachweis von Mastzellen in der bronchoalveolären mit verschiedenen Färbungen. Pneumol 1993;47:456-457.

35. Latier BA, Reller LB, Mirretr $S$. Comparison of acridine orange and gram srains for detection of micro-organisms in cerebrospinal fluid and other clinical specimens. $J$ Clin Microbiol 1981;14:201-205.

36. Laviolette M. Lymphocyte fluctuation in bronchoalveolar lavage fluid in normal volunteers. Thorax 1985;40:651-656.

37. Drent $M$, Nierop van MAMF, Gerritsen FA, Wouters EFM, Mulder PGH. Computer program using BALF analysis results as diagnostic tool in interstitial lung diseases. Am J Respir Crit Care Med 1996;153:736-741.

38. Rosenow EC III, Martin WJ II. Drug-induced interstitial hung disease. Nn: Schwarz MI, King Te (eds.). Interstitial lung disease. $2 d$ edirion, 1993.

39. Zaman SS, Elshami A, Gupta PK. Bronchoalveolar lavage cytology in pulmonary sarcoidosis. Acta Cytol 1995;39:1117-1123.

40. O'Connor BH. A colour atlas and instruction manual of peripheral blood cell morphology. Williams \&: Wilkins, Baltimore 1984.

41. Baughman R, Strohofer $\$$, Kim K. Variation of differential cell counts of bronchoalveolar lavage fluid. Arch Pathol Lab Med 1986;110:341-343.

42. Azoulay E, Parrot A, Flahault A, Cesari D, Lecomte I, Rour P, et al. AIDS-related Preamocystis carmii pneumonia in the era of adjunctive steroids: implication of BAL. neutrophilia. Am J Respir Crit Care Med 1999;160:493-499.

43. Drent M, Jacobs JA, Vries de J, Lamers RJS, Liem IH, Wouters EFM. Does the cellular bronchoalveolar lavage thid profile reflect the severity of sarcoidosis? Eur Respir J $1999 ; 13: 1338-1344$.

44. Weiland JE, Davis WR, Holter JF, Mohanmed JR, Dorinsky PM, Gadek JE. Lung neutrophils in the adult respiratory distress syndrome. Am Rev Respir Dis 1986;133:21.8-225.

45. Allen JA, Davis WB, Pacht ER. Diagnostic significance of increased bronchoalveolar lavage Huid eosinophils. Am Rey Respir Dis 1990;142:642-647. 
46. Fleury-Feith J, Tran Van Whieu J, Picard C, Escudier E, Bemaudin JE. Bronchoalyeolar lavage eosinophilia associated with Pwenwoysts carinh preumonitis in ADS patients: comparative study with non-AIDS patients. Chest 1989:95:1198-1201.

47. Foresi A, Bertorelli G, Pesci A, Chetra A, Oliwieri D. Inflammatory markers in BAL and bronchial biopsy in asthma during remission. Chest 1990;98:528-535.

48. Pesci $A$, Bertorelli $G$, Olwieri $D$. Mast cells in bronchoalveolar lawage fluid and in transbronchial biopsy specimens of patients with farmer's Iung disease. Chest $1991 ; 100: 1197-1202$.

49. Taskinen $\mathrm{E}$, Tukuainen $\mathrm{P}$, Renkonen $\mathrm{R}$. Bronchoalveolar lavage: influence of cytologic methods in the cellular picture. Acta Cytol 1992;36:680-686.

50. Stanley MW, Mrak RE, Bardales RH. Detached single cilia: another potential pseudomicrobe seen in bronchoalveolar lavage specimens. Diagn Cytopathol 1995;13: $225-228$.

51. Grotte D, Stanley MW, Swanson PE, Henry-Stanley J, Scorr D. Reactive type II pneumocytes in bronchoalveolar lavage fluid from Adult Respiratory Distress Syndrome can be mistaken for cells of adenocarcinoma. Diagn Cytopathol 1990;6:317-322.

52. Stover DE, Zaman MB, Hajdu SI, Lange M, Gold J, Armstrong D. Bronchoalveolar lavage in the diagnosis of diffuse pulmonary infiltrates in the immunosuppressed host. Ann Intern Med 1984; 101:1-7.

53. Ness MJ, Rennard SI, Vaughn WP, Ghafouri MA, Linder JA. Detection of candida antigen in bronchoalveolat lavage fluid. Acta Cytol 1987,32:347-352.

54. Drent $\mathrm{M}$, Velzen-Blad van $H$, Diamant $M$, Wagenaar SiSc, Donckerwolcke-Bogaert $M$, Bosch van den JMM. Differential diagnostic value of plasma cells in bronchoal we olar lavage fluid. Chest 1993; 103:1720-1724.

55. Baselski VS, Wunderink RG. Bronchoscopic diagnosis of pneumonia. Clin Microbiol Rev $1.994 ; 7: 533-558$.

56. Ewig S. Diagnosis of wentilator-associated pneumonia: non-routine tools for routine practice. Eur Respir I 1996:9:1339-1341.

57. Fagon JY, Chastre JC, Wolf M, Gervais C, larer-Aubas S, Stéphan F et all. Invasive and non-invasive strategies for management of suspected ventilator-associated pneumonia. Ann Intern Med 2000;132:621-630.

58. Gerbaux P, Ledoray V, Boussuges A, Molenat F, Jean P, Sainty JM. Diagnosis of nosocomial pneumonia in mechanically vertilated patients. Am J Respir Crit Care Med $1998 ; 157: 76-80$.

59. Aubas 5, Aubas P, Capdevila X, Darba H, Roustan JP, Du Cailar J. Bronchoalweolar latvage for diagnosing bacterial pneumonia in mechanically ventilated patients. Am J Respir Crit Care Med 1994;149:860-866.

60. Pugin J, Auckenthaler R, Mili N, Janssens JP, Lew PD, Suter PM. Diagnosis of ventilator-associated pneumonia by bacteriologic analysis of bronchoscopic and nonbronchoscopic "blind" bronchoalveolar lavage fluid. Am Rev Respir Dis 1991;143: 1121.1129. 
61. Alaouchiche B, Jaumain H, Dumontet C, Morin J. Farly diagnosis of ventilator-associated pneumonia: is it possible to define a cutoff value of infected cells in BAL fluid. Chest 1996:110:1558-1565.

62. Timsir JF, Misset B, Goldstein FW, Vaury P, Carlet J. Reappraisal of distal diagnostic testing in the diagnosis of ICU-acquired pneumonia. Chest 1995;108:1632-1639.

63. Sole-Violan J, Castro de FR, Rey A, Martin-Gonzáles JC, Cabrera-Navarro P. Usefulness of microscopic examination of intracellular organisms in lavage fluid in ventilator-associated pneunonia. Chest 1994; 106:889-894.

64. Nakos G, Kitsiouli EL, Tsangaris I, Lekka ME. Bronchoalveolar lavage fluid characteristics of early intermediate and late phases of ARDS: alterations in leukocytes, proteins, PAF and surfactant components. Intensive Care Med 1998;24:296-303.

65. Cobben NAM, Drent M, Jacobs JA, Schmitz MPJ, Mulder PGH, Henderson RF, er all Relaw tionship between enzymatic markers of pulmonary cell damage and cellular profile: a study in bronchoalveolar lavage fluid. Exp Lung Res 1999;25:99-111.

66. Kirtland SH, Corley DE, Winterbauer RH, Springmeyer SC, Casey KR, Hampson NB, et al. The diagnosis of ventilator-associated pneumonia: a comparison of histologic, microbiologic, and clinical criteria. Chest 1997;112:445-457.

67. Chastre J, Fagon JY, Soler P, Bornet M, Domart Y, Troullet JL, et all. Diagnosis of nosocomial bacterial pneumonia in intubated patients undergoing ventilation: comparison of the usefulness of bronchoalweolar lawage and the protected specimen brush. Am J Med $1988 ; 85: 499-506$.

68. Meduri GU, Wunderink RG, Leeper KV, Beals DH. Management of bacterial pneumonia in ventilated patients. Chest 1992;101:500-508.

69. Dotson RG, Pingleron $S K$. The effect of antibiotic therapy on recovery of intracellular bacteria from bronchoalveolar lavage in suspected wentilator-associared nosocomial pneumonia. Chest 1993;103:541 546 .

70. Souweine B, Veber B, Bedos JP, Gachot B, Dombret MC, Regnier B, et al. Diagnostic accuracy of protected specimen brush and bronchoalveolar lavage in nosocomial pneumonia: impact of previous antimicrobial treatments. Crit Care Med 1998;26:236-244.

71. Timsit Jf, Chevret $S$, Valcke J, Misset B, Renaud B, Goldstein IVW, at al. Mortality of nosocomial pneumonia in ventilated patients: infuence of diagnostic tools. An J Respir Crit Care Med 1996;154:116-123.

72. Lassence de A. Alveolar haemorthage. Am J Respir Crir Care Med 1995;151:157-163.

73. Schnabel A, Reuter M, Csemok E, Richter C, Gross WL. Subclimical alveolar bleeding in pulmonary vasculitides: correlation with indices of disease activity. Eur Respir I $1999 ; 14: 118-124$.

74. Scully RE, Mark EJ, McNeely WF, McNeely BU. Case records of the Massachusetts general hospital. N Engl J Med 1995;332:1566-1572.

75. Drent M, Jacobs IA, Cobben NAM, Costabel U, Wouters EFM, Mulder PGH. Predicting computer program using bronchoalveolar lavage fhid analysis results: an update. Subraitted.

76. Goldstein R. Clinical role of bronchoalveolar lavage in adults wirh pulmonary disease. Am Rev Respir Dis 1990;142:481-486. 
77. Mordulet-Dambrine M, Arnoux A, Stanis:a Leguern G, Sandron D, Cluetien J, Huchon G. Processing of lung lavage fluid causes variability in bronchoalveolar cell count. Am Rev Respir Dis 1984;130:305-306.

78. Lam $S$, LeRiche JC, Kijek K. Effect of filtration and concentration on the composition of bronchoallweolar lavage fluid. Chest 1985:87:740-742. 

CHAPTER 2

\section{Cytocentrifugation conditions affecting the differential cell count in bronchoalveolar lavage fluid}

Els De Brauwer

Jan Jacobs

Fred Nieman

Cathrien Bruggeman

Sjoerd Wagenaar

Marjolein Drent 


\section{ABSTRACT}

Objective: lnvestigation of variations in sped, duration and acceleration rate of the Cytospin 3 cytocentrifuge (Shandon Scientific Lrd.) on the differential cell count of bronchoalveolar lavage (BAL) fluid samples.

Study design: BAL fluid samples $(\mathrm{n}=51)$ were cytocentrifuged at various combinations of speed $(500,1200$ and $2000 \mathrm{rpm}$ ), acceleration rate (low, medium and high) and duration ( $5,10,15$ and 20 minutes $)$. The preparations were May-Grünwald-Giemsa stained and differentiated on 500 cells. Data were analysed by mixed model repeated measurements ANOVA.

Results: The mean lymphocyte count was significantly higher at $1200 \mathrm{rpm}$ than at $500 \mathrm{rpm}$, whereas the macrophage count decreased. Between 1200 and $2000 \mathrm{rpm}$, the number of both cell types stabilised. Significantly higher numbers of lymphocytes were recorded at 10 and at 15 minutes of cytocentrifugation than at 5 minutes. The acceleration rate did not influence the differential cell count. Seventeen BAL fluid samples were selected to test the diagnostic impacr of cell danage using a walidated computer program. In one out of 17 samples the predicted diagnosis did not correspond berween two different speeds, i.e. 500 and $2000 \mathrm{rpm}$.

Conctusion: Variations in cytocentrifugarion speed and duration affected the mean lymphocyte and macrophage counts of BAL fluid samples. 


\section{NTRODUCTION}

Bronchoalveolar lavage (BAL) recovers cells and solutions from the lower respiratory tract and the alveolar spaces. Changes in the BAL fluid profile may reflect pathological processes within the lung parenchyma. The quantification of the different cell types has been demonstrated to be of additional value in the diagnostic work-up of pulmonary diseases particularly in interstitial lung diseases (ILD) and suspected infectious diseases. ${ }^{1-4}$

High-quality preparations are mandatory to allow reliable cytological examination. Cytocentrifugation is a widely accepted procedure for making microscopic preparations in both the research setting and in daily clinical practice. The Cytospin (Shandon Scientific Ltd., Astmoor, England) is one of the most widely utilised cytocentrifuges and currently the Cytospin 3 is marketed. The cytocentrifuge has three adjustable conditions, i.e. speed, duration and acceleration rate. ${ }^{5}$

There is evidence that alterations in cytocentrifugation conditions may affect the recovery rate of micro-organisms and parasites such as Pnemocystis carinii. ${ }^{6,7}$ Moreover, the process of cytocentrifugation has been demonstrated to underestimate the number of lymphocytes, and it has been assumed that differences in cytocentrifugation influence the magnitude of this underestimation. 8,9

Until now, however, the effects of different cytocentrifugation conditions on cell recovery have not yet studied systematically. Therefore, the aim of the present study was to investigate the effect of the Shandon Cytospin 3 cytocentrifugation conditions, e.g. speed, acceleration rate and duration, on the results of the differential cell count of BAL fluid samples.

\section{MATERIALS AND METHODS}

\section{Materials}

BAL fluid samples obtained from patients with suspected pneumonia or ILD were used. Exclusion criteria were a recovery less than $20 \mathrm{ml}$, the presence of $\geq 1 \%$ squamous epithelial cells or $\geq 5 \%$ ciliated cells on microscopic examination, or the presence of excessive amounts of mucopurulent exudate or red blood cells obscuring cell identity. ${ }^{10-13}$

\section{Bronchoalveolar lavage}

BAL was performed during fiberoptic bronchoscopy, as reported previously. ${ }^{1,2}$ After premedication $(0.5 \mathrm{mg}$ atropine intramuscular and sometimes $5-10 \mathrm{mg}$ diazepam orally) and local anaesthesia of the larynx and bronchial tree (lidocaine $0.5 \%), \mathrm{BAL}$ was performed by standardised washing of the middle lobe, lingula or 
involved lobe with four aliquots of $50 \mathrm{ml}$ sterile $0.9 \% \mathrm{NaCl}$ at $37^{\circ} \mathrm{C}$. The $\mathrm{BAL}$ fluid samples were transported to the laboratory within 1.5 minutes after collection and analysed within one hour upon arrival in the laboratory.

\section{Bronchoalveolar lavage fluid laboratory analysis}

The volume of the recovered BAL fluid was recorded. The first fraction, representing the bronchial fraction, was discarded and the remaining fractions were pooled for further analysis. The total cell count was performed in a Fuchs Rosenthal hemocytometer chamber. All nucleated cells were counted. Cytocentrifugation was done with the Shandon Cytospin 3 apparatus (Shandon Scientific Ltd., Astmoor, England), using uncoated pre-cleaned slides (MenzelGlaser, Emergo, Landsmeer, The Netherlands) and white filter cards (Shandon no. 190005). In order to obtain standardised and easy-to-read monolayer preparations, the number of drops per smear was adjusted in relation to the total cell count. ${ }^{14}$ Preparations were made at varying cytocentrifugation conditions (table I):

Design 1, variations in cytocentrifugation speed: to study the effect of variations in cytocentrifugation speed, BAL fluid samples were cytocentrifuged at speeds of 500 revolutions per minute (rpm), $1200 \mathrm{rpm}$ and $2000 \mathrm{rpm}$ for 10 minutes and the low acceleration rate.

Design 2, variations in acceleration rate and speed: for evaluation of the effect of the acceleration rate, BAL fluid samples were cytocentrifuged at low, medium and high acceleration rates. This was done at speeds of $500 \mathrm{rpm}$ and $2000 \mathrm{rpm}$, for 10 minutes.

Design 3, variations in duration of cytocentrifugation and speed: the effect of duration of cytocentrifugation was investigated by cytocentrifugation of $\mathrm{BAL}$ fluid samples at 5, 10,15 and 20 minutes, combined to speeds of $500 \mathrm{rpm}, 1200$ $\mathrm{rpm}$ and $2000 \mathrm{rpm}$, and at a low acceleration rate.

The preparations were air-dried and May-Grünwald-Giemsa (MGG) stained, as previously described. ${ }^{13}$ Subsequently, the MGG stained preparations were examined by one observer at a magnification of $\times 1,000$ using oil immersion. Differential cell counts were performed on 500 nucleated cells in a circular pattern around the centre of the cytocentrifuge spot. ${ }^{13}$ The numbers of cells were recorded after $100,200,300,400$ and 500 cells counted. The cell types were expressed as the mean per 100 cells counted.

\section{Bronchoalveolar lavage fluid cytomorphology}

To explain the differences in differential cell count observed spun at varying cytocentrifugation conditions, the cytomorphology of $10 \mathrm{BAL}$ fluid samples cytocentrifuged at 500,1200 and $2000 \mathrm{rpm}$ was investigated. Firstly, the number of free nuclei was counted on 500 nucleated cells and expressed as a mean per 500 cells counted. Secondly, the quality of the preparations was recorded blindly using 
a standardised semi-quantitative score (i.e. negative: none per high power field $(\mathrm{HPF}),+:<1$ per $\mathrm{HPF},++: \geq 1$ per HPF). The morphologic chatacteristics scored were cell damage (i.e. pycnotic nuclei, strongly vacuolated cytoplasm, tearing and stretching of cell borders) and free nuclei, derived from lymphocytes, as well as from macrophages. $8,12,15$

\section{Bronchoalveolar lavage fluid diagnostic inpact}

Finally, the diagnostic impact of differences in differential cell count was analysed. The BAL fluid samples with $>5 \%$ difference in absolute number of lymphocytes between the different cytocentrifugation speeds was selected. For these BAL fluid samples, a validated computer program based on a polychotomous logistic regression model was used to predict the diagnosis. ${ }^{2}$ In this program, the variables used to discriminate among sarcoidosis, idiopathic pulmonary fibrosis and subacute extrinsic allergic alveolitis are the yield of recovered BAL fluid, total cell count, percentage of alveolar macrophages, lymphocytes, polymorphonuclear neutrophils (PMNs) and eosinophils, together with some demographical data, e.g. sex, age and smoking status yes or no.

The different cell counts obtained at various cytocentrifugation speeds were entered into the computer program and the different diagnosis was compared.

\section{Statistical analysis}

Data for each design were analysed by mixed model repeated measurements ANOVA (analysis of variance) using "speed", "acceleration rate" and "duration of cytocentrifugation" as fixed factors, while "samples" and "number of hundreds counted" (up to 500 ) were considered as random factors. Overall differences within fixed factors were at first calculated by using Quasi-F ratios for each mean effect and for possible interaction effects (design 2 and 3 only). To correct spluericity deviations in the variance-covariance matrix of repeated measurements with each fixed factor, the Greenhouse-Geisser adjusted F ratio for each mean effect (or for the interaction of effects) was calculated as a second step in the analysis of variance. Due to the fact thar it was not possible to compure these adjustments of the F ratio for the Quasi-F ratios, given the computer programs available, it was decided that a more specific analysis of the differences in means of the fixed factors was only warranted, if both overall tests (Quasi-F ratio and Greenhouse Geisser adjusted Fratio) had p-values lower than 0.05 . If this was the case, Helmert and reversed Helmert contrasts berween means of fixed factors were used in such a way, that specific difference between means could be tested pairwise and in an orthogonal manner. Again, pairwise differences were considered to be statistically significant, if the $\mathrm{p}$-value turned out to be less than 0.05 . For computing Quasi-F ratios the GENOVA program was used, for the adjusted F ratios and other descriptive statistics SPSS $\sim \mathrm{pc}$, version 6.1 was used. 
The data of the counted free nuclei of $10 \mathrm{BAL}$ fluid samples at three different speeds were analysed by repeated measurements ANOVA. Particularly, a multivariate trend test as well as a univariate trend test was done. The overall test was corrected for non-sphericity by the Greenhouse-Geisser adjusted F-ratio. In addition to this, a non-parametric test was performed as the low numbers may prohibit ANOVA tests.

\section{RESULTS}

In table I the three study designs are summarised and the numbers of BAL fluid samples studied in each design are listed. Fifty-one BAL fluid samples obtained from 51 parients were used in the present study.

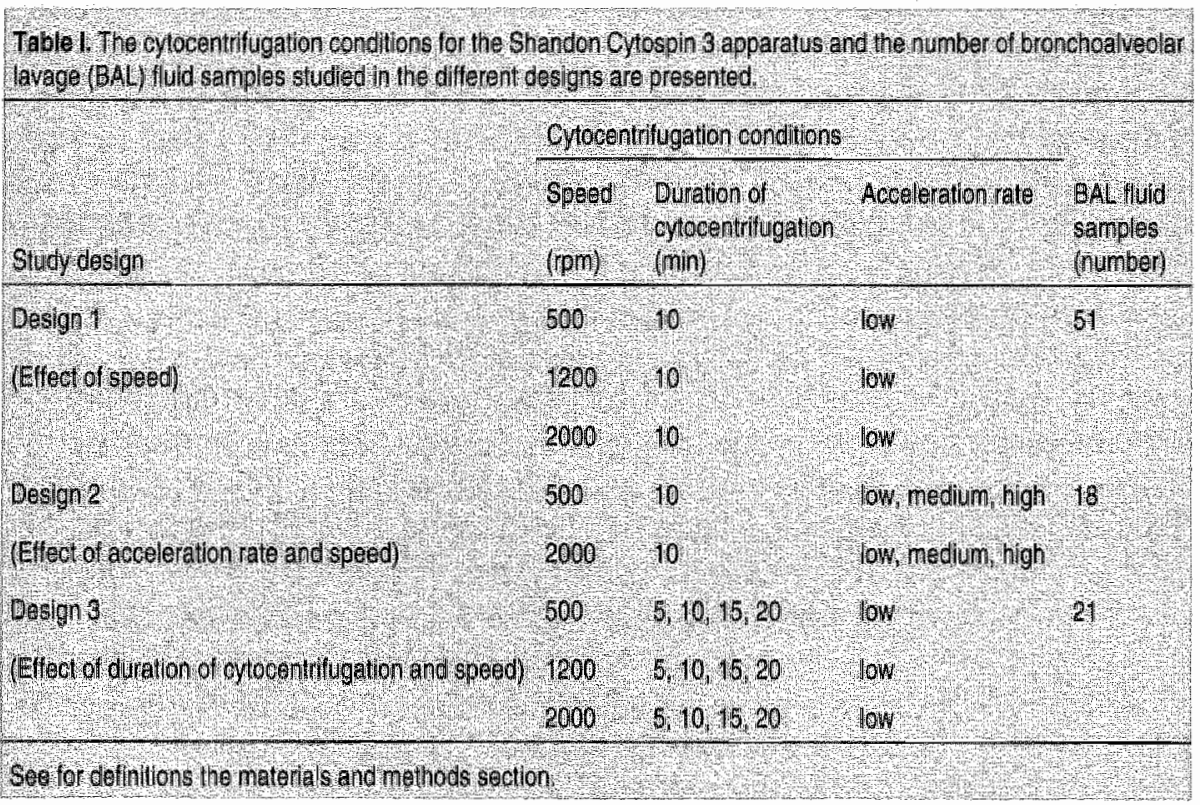

Table II lists the statistically significant results of the enumeration of the lymphocytes and alveolar macrophages for the three study designs. Variations in speed affected the lymphocyte as well as the macrophage counts in all three study designs. Acceleration rate (design 2) did not influence counting of any cell type. Alternations in duration of cytocentrifugation influenced the lymphocyte counts (design 3). No interactions were found between speed and acceleration rate, nor between speed and duration of cytocentrifugation (designs 2 and 3). None of the remaining cell types (PMNs, basophils and eosinophils) demonstrated statistically significant overall tests. 


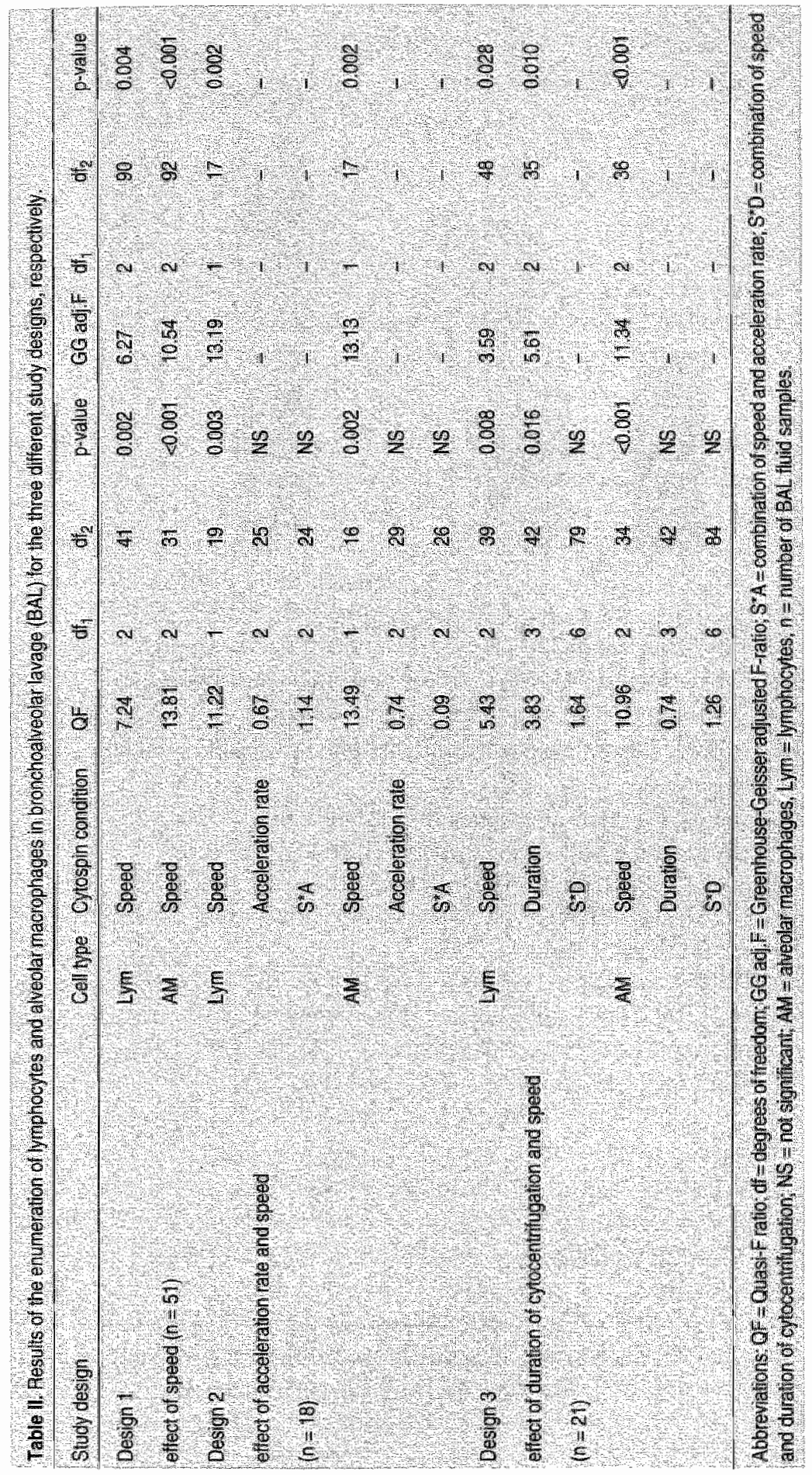




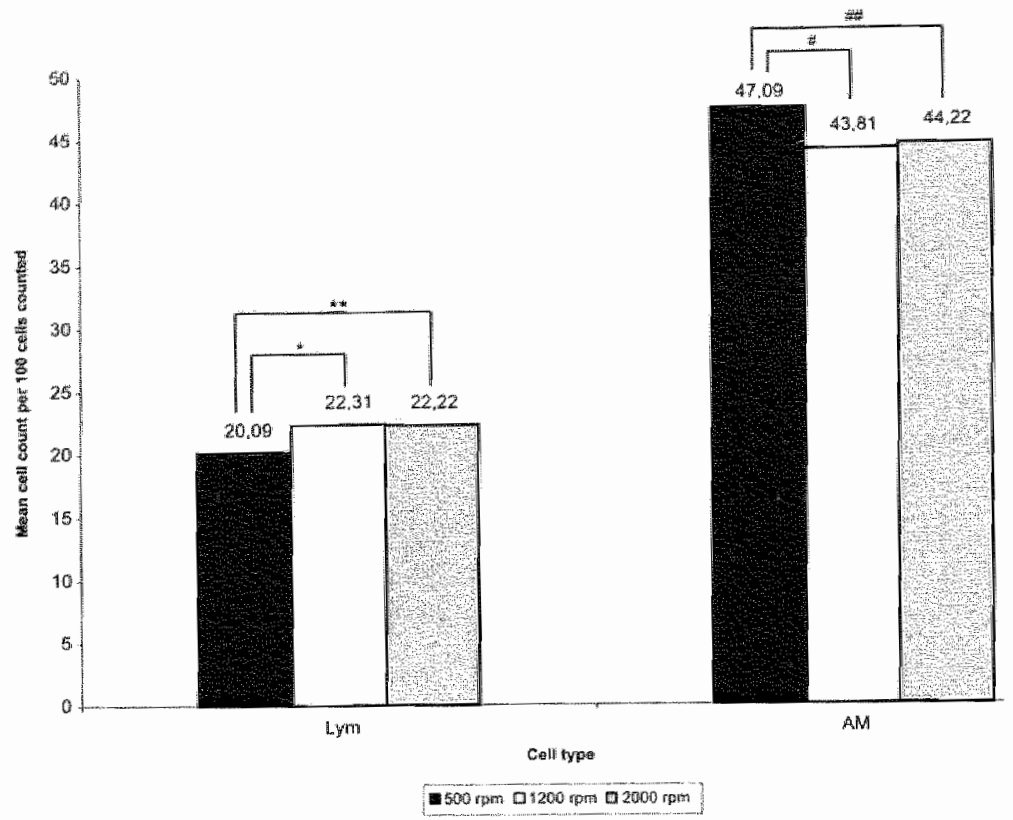

Figure 1. Cytocentrifugation speed and the enumeration of the different cell rypes in 51 bronchoalweolar lavage fluid samples (study design 1). Lym = Iymohocytes, $A M=$ alveolar macrophages; $p<0.004 ; " p=0.01 ; p<0.001$; $\mathrm{p}<0.001$.

Figure 1 shows the effect of variations in cytocentrifugation speed assessed in study design 1. Only cell types with statistically significant differences are presented. The lymphocyte count, expressed as mean per 100 cells counted, increased from 20.09 at $500 \mathrm{rpm}$ to 22.31 at $1200 \mathrm{rpm}$ and was approximately constant between $1200 \mathrm{rpm}$ and $2000 \mathrm{rpm}$. Conversely, the mean alveolar macrophage count significantly decreased from $500 \mathrm{rpm}$ to $1200 \mathrm{rpm}$, and from $500 \mathrm{rpm}$ to $2000 \mathrm{rpm}$.

In line with the findings observed in study design 1, significant effects obtained in study design 2 (variations in acceleration rate and speed) were found between speeds of 500 and $2000 \mathrm{rpm}$. The mean lymphocyte count increased from 21.60 at $500 \mathrm{rpm}$ to 26.40 ar $2000 \mathrm{rpm}(\mathrm{p}=0.002)$, whereas the mean alveolar macrophage count complementary decreased from 48.93 at $500 \mathrm{rpm}$ to 43.96 at $2000 \mathrm{rpm}\langle\mathrm{p}=0.002\rangle$.

As shown in table III, the results observed in study design 3 (effect of duration and speed) confirmed the significant increase of the number of lymphocytes from $500 \mathrm{rpm}$ to $1200 \mathrm{rpm}$, and the decrease of the number of macrophages from 500 rpm to 1200 rpm as well as from 500 to $2000 \mathrm{rpm}$. 


\begin{tabular}{|c|c|c|c|}
\hline & Speed & & \\
\hline Cell type & 500 poim & $120190 \mathrm{~m}$ & $2000 \mathrm{nn}$ \\
\hline Lyriphogytes & $1081=$ & 23.27 & 2176 \\
\hline Alveolal macriphages & $5187^{\text {th }}$ & 47.57 & 4899 \\
\hline
\end{tabular}

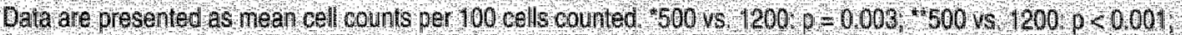
$5000 \mathrm{~s} .2000 \mathrm{p}=0013$

The duration of cytocentrifugation affected the mean lymphocyte counts, which varied between 20.76 at 5 minutes, 22.54 at 10 minutes, 22.12 at 15 minutes and 21.03 at 20 minutes, respectively. The differences between 5 minutes and 10 minutes as well as between 5 and 15 minutes appeared to be statistically significant ( $\mathrm{p}=0.023$ and 0.04 respectively).

At $500 \mathrm{rpm}$ the cell morphology was better preserved than at 1200 and 2000 $\mathrm{rpm}$. The mean number of free nuclei increased significantly from 23.6 at 500 $\mathrm{rpm}$, to 46.5 at $1200 \mathrm{rpm}$, to 73.8 at $2000 \mathrm{rpm}$ ( $\mathrm{plinear}<0.001$ ). As can be seen in figure 2, cell damage was more marked at 1200 and $2000 \mathrm{rpm}$ than at $2000 \mathrm{rpm}$, and slightly more macrophages damaged at high speed conditions than were lymphocytes.

When the data were entered in the computer program of Drent and co-workers, one out of $17 \mathrm{BAL}$ fluid samples yielded a different diagnosis when the counts at $500 \mathrm{rpm}$ and $2000 \mathrm{rpm}$ were considered, i.e. sarcoidosis and extrinsic allergic alveolitis respectively.

\section{DISCUSSION}

During the process of cytocentrifugation, cells are deposited by the cytospin's centrifugal force on the glass slide, and the remaining cell-free fluid is absorbed into a filter path that is positioned between the cytospin chamber and the glass slide. Although cytocentrifugation of BAL fluid specimens generates high-quality monolayer preparations, it is known that this process entails a selective loss of lymphocytes, and this occurs in varying degrees at all cytocentrifugation conditions. ${ }^{8}$ For the Shandon Cytospin 2 instrument, one study reported a higher lymphocyte count after cytocentrifugation at $90 \times g$ than at $23 \times g .{ }^{9}$ Using millipore filter preparations as a "gold standard" for the recovery of lymphocytes, Saltini and co-workers found a relatively higher lymphocyte number at a speed of $800 \mathrm{rpm}$, compared to a speed of $400 \mathrm{rpm} .^{8}$ In line with the findings of these studies, in the present study a higher recovery rate of lymphocytes at the interme- 

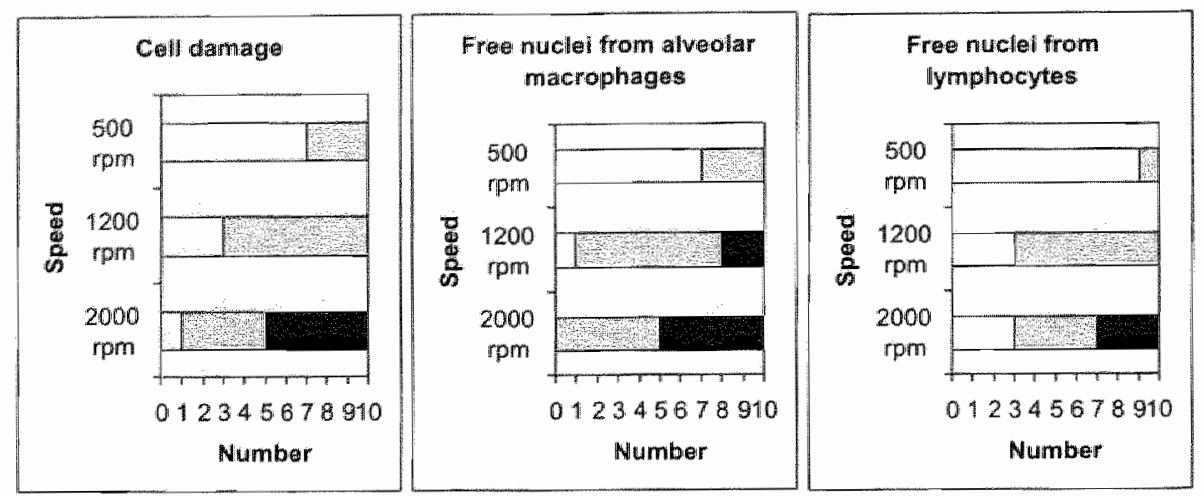

Figure 2. Effect of the cytocentrifugation speed on the cytomorphology of the cytocentrifuged preparations of bronchoalveolar lavage fluid. Negative $\square ;<1$ per. HPF ${ }^{*}$; $>$ or $=1$ per $\mathrm{HPF}^{*}$ - ${ }^{*}$ HPF $=$ high power field; Number = number of BAL fluid samples semi-quantitatively scored according to the criteria mentioned in the materials and methods section.

diate cytocentrifugation speed, than at the lower speed was observed. As anticipated, the high numbers of lymphocytes were accompanied by a complementary decrease in the alveolar macrophage numbers. No further increase in the lymphocyte fraction from $1200 \mathrm{rpm}$ to $2000 \mathrm{rpm}$ was found.

The capillary force of the filter path counteracts the effect of the centrifugal force as it drags small lymphocytes together with the specimen fluid into the filter path. In line with this, Laviolette and comworkers noted the disappearance of ${ }^{51} \mathrm{Cr}$-labelled lymphocytes into the filter path during cytocentrifugation. ${ }^{16}$ To date, alveolar macrophages, which are larger cells, are less prone to this capillary action. Given the constant radius of the cytocentrifuge, the Cytospin's centrifugal force is directly proportional to the quadrate cytocentrifugation speed. Hence, the low cytocentrifugation speed of 500 rpm equals a $g$-value of approximately $\times 30$, and the intermediate $(1200 \mathrm{rpm})$ and high $(2000 \mathrm{rpm})$ speeds equal $\mathrm{g}$-values of $\times$ 160 and $\times 450$ respectively. The relative impact of the filter's capillary force is consequently much smaller at the intermediate and high speed than at the low cytocentrifugation speed. This results in a higher adherence of lymphocytes to the glass slide at the increasing speed. The stabilisation of the lymphocyte fraction at the high-speed cytocentrifugation may be caused by a saturation effect. Furthermore, it is known that at elevated speed distortion of the cellular morphology appears and presumably, also explains the increase of lymphocytes at higher speed. In line with this, we demonstrated that the number of free nuclei differed significantly between low and high speed. In addition, at a higher speed, the cytomorphology of the macrophages was slightly more disturbed than the cytomorphology of the lymphocytes in the present study. 
A peak recovery of the lymphocytes at 10 and 15 minutes duration of cytocentrifugation was found. Excessive duration of centrifugation causes stretching and tearing of the cell borders (Cytospin operator manual), and the resulting cell damage may have been responsible for the lower recovery of lymphocytes at longer duration. ${ }^{5}$ Furthermore, at all cytocentrifugation runs performed at the 5-minutes duration, the BAL cell-free fluid was completely absorbed into the filter path. Therefore, it is not likely that incomplete procession of the BAL fluid specimen, at the short duration of cytocentrifugation, explains the lower recovery of lymphocytes. Presumably, the longer centrifugation durations promote the adherence of the lymphocytes to the glass slide. The Cytospin operator manual recommends a 10-minutes cytocentrifugation duration for obtaining air-dried specimens. ${ }^{5}$ This relative long cytocentrifugation duration favours complete absorption of bloody and mucous BAL fluid specimens, which tend to obstruct the pores of the filter path. In view of the optimal lymphocyte recovery, 10-minutes duration appears to be optimal in the present study.

The cytospin's acceleration rate did not influence the BAL fluid differential cell counts. We recorded the delays at which speeds were reached for the three acceleration rates (data not shown). Taking into account a cytocentrifugation duration of 10 minutes, the differences between these delays were of minor importance, e.g., for the low and the high acceleration rates, the fully loaded cytospin rotor reached the $2000 \mathrm{rpm}$ speed after 22 and 36 seconds respectively.

Although the differences in lymphocyte and alveolar macrophage enumeration for various cytocentrifugation conditions were statistically significant, their significance for immediate patient care remains conjectural. In the present study, the highest differences for the mean absolute number of lymphocyte and alveolar macrophage count achieved a maximum of $5 \%$. For the 51 BAL fluid samples in study design 1 , the maximum absolute difference in lymphocyte counts between the low and high speeds was found to be $17 \%$, and 16 and 5 BAL fluid specimens showed differences in lymphocyte counts of $\geq 5 \%$ and $\geq 10 \%$ respectively. These values are lower than those reported by Saltini and co-workers. ${ }^{8}$ However, it should be noted that in the latter study fetal calf serum was added to the BAL fluid specimens, and this procedure augments the loss of lymphocytes during cytocentrifugation. ${ }^{17}$ Furthermore and to our knowledge, there exist no clear tolerance limits as to the inter-assay variability of the BAL fluid differential cell counts. Recently, Kleykamp et al. found that an inter-laboratory variability of $>$ $10 \%$ in the lymphocyte population of BAL fluid differential cell counts was substantial. ${ }^{18}$ These latter results, together with the demonstrated inter-assay differences in the lymphocyte count resulting in the discrepancy between the computer-predicred diagnosis, and generated by the differential cell counts at 500 rpm and $2000 \mathrm{rpm}$ in one out of 17 cases, point out influence on diagnostic power.

In conclusion, variations of cytocentrifugation speed, as well as time, affect the lymphocyte and alveolar macrophage count. Although the highest lymphocyte recovery was found at $1200 \mathrm{rpm}$, during 10 minutes and low acceleration 
rate, cytocentrifugation at low speed reached the optimal cytomorphology. Standardisation of the technique is recommended. This standardisation is mandatory to achieve high weliable BAL fluid analysis and to make differential cell counts comparable between different laboratories. Reliable, as well as comparable results will improve the diagnostic power of cellular BAL fluid analysis results.

\section{REFERENCES}

1. Drent M, Mulder PGH, Wagenaar SjSc, Hoogsteden HC, Velzen van H, Bosch van den JMM. Differences in BAL fluid variables in interstitial lung diseases evaluated by discriminant analysis. Eur Respir J 1993;6:803-810.

2. Drent M, Nierop wan MAMF, Gerritsen FA, Wouters EFM, Mulder PGH. A computer program using BALF-analysis results as a diagnostic tool in interstitial lung diseases. Am J Respir Crit Care Med 1996;153:736-741.

3. Jacobs JA, De Brauwer EIGB, Ramsay G, Cobben NAM, Wagenaar SjSc, Ven van der AJAM, et al. Detection of non-infectious conditions mimicking pneumoniat in the intensive care setring: usefulness of bronchoalweolar fluid cytology. Respir Med 1999;93:571 -578.

4. Kahn FW, Jones JM. Diagnosing bacterial respiratory infection by bronchoalveolar lavage. J Infect Dis 1987;155(5):862-869.

5. Cytospin 3 cell preparation system operator guide. Shandon scientific Ltd, Astmoor, England 1991:27.

6. Shanholzer CJ, Schaper PJ, Pererson LR. Concentrated gram stain smears prepared with a cytospin centrifuge. J Clin Microbiol 1982;16(6):1052-1056.

7. Gill VI, Nelson NA, Stock F, Evans G. Optimal use of the Cytocentrifuge for recovery and diagnosis of Pnewmocystis carini in bronchoalveolar lawage and sputum specimens. J Clin Microbiol 1988;26(9):1641\%1644.

8. Saltini C, Hance AJ, Ferrans VJ, Basset F, Bitterman PB, Crystal RG. Accurate quantificaron of cells recovered by bronchoalweolarlavage. Am Rev Respir Dis 1984;130:650-658.

9. Mordeler M, Arnoux A, Stanislas G. Sandron D, Chrétien J, Huchon G. Processing of lung lavage fluid causes variability in bronchoalveolar cell count. Am Rev Respir Dis 1984;130; 305-306.

10. Baselski VS, Wunderink RG. Bronchoscopic diagnosis of pneumonia. Clin Microbiol Rev 1994:7 (4):533-558.

11. Henry Stanley MJ. Laboratory processing of BAL fluids. In: Stanley MW. Bronchoalweolar lavage: cytollogy and clinical applications. IGAKU-SHON, New York, USA 1991: 213-223.

12. Chamberlain DW, Braude AC, Rebuck AS. A critical eval uation of bronchoalveolar lawage. Acta Cyrologica $1987 ; 31(5): 599-605$.

13. De Brauwer EIGB, Jacobs JA, Nieman FH, Bruggeman CA, Drent M. Test characteristics of Acridine Orange, Gram and May-Grünwald-Giemsa stains for the detection of intracellular organisms in bronchoalveolar lavage flund. J Clin Microbiol 1999;37:427-429. 
14. Capron F, Perrot J, Szekeres $\mathrm{G}$, Caulet $S$. Technique du liquide de lavage bronchaveolaire dans un laboratoire central d'anatomie et cytologie pathologique. Anm Pathol 1990;10: 278-281.

15. Kobayashi TK, Ueda M, Yamaki T, Yakushiji M. Evaluation of cytocentrifuge apparatus with special reference to the cellular recovery rate. Diagn Cytopathol 1992;8:420-423.

16. Laviolette $\mathrm{M}$, Carreux. M, Coulombe R. Bronchoalveolar lavage cell differential count on microscope glass cover. Am Rev Respir Dis 1988;138:451 457.

17. Willcox $M$, Kervitsky A, Watters LC, King J. TE. Quantificarion of cells recovered by bronchoalveolar lavage. An Rev Respir Dis 1988;138:74-80.

18. Kleykamp BO, Baughman RP. Who should perform bronchoalveolar lavage analysis? Am.J Respir Crit Care Med 1998;157:67. 

CHAPTER 3

\section{Differential cell analysis of cytocentrifuged bronchoalveolar lavage fluid samples affected by the area counted}

Els De Brauwer

Marjolein Drent

Paul Mulder

Cathrien Bruggeman

Sjoerd Wagenaar

Jan Jacobs 


\section{ABSTRACT}

Objective: Variations in the differential cell counts between the quadrants of cyrocentrifuged bronchoalvelar (BAL) fluid preparations were investigated. In addition, the diagnostic impact of these differences was evaluated in interstitial lung diseases (ILD).

Study design: BAL fluid samples obrained from 30 patients suspected of ILD or pneumonia were cytocentrifuged and additionally stained with MayGrünwald-Giemsa stain. Two observers differentiated 200 cells in each quadrant as well as in a circular pattern around the center of the cytocentrifuge spot.

Results: Lymphocytes and alvedar macrophages were not randomly distributed on the cytocentrifuge spot. Ten samples of patients with histologically confirmed ILD were selected to test the diagnostic impact using a validated computer program. The predicted diagnosis did not correspond to the histological diagnosis for one quadrant out of one of these 10 samples (sarcoidosis instead of idiopathic pulmonary fibrosis), whereas the differential cell counts perfomed around the center of the cytocentrifuge spot prowided the correct diagnosis in all cases.

Conclusion: BAL Huid differential cell counts varied between the quadrants of the cytocentrifuge spot. The center of the cytocentrifuge spot appeared to be the most reliabie area. Therefore, cell counting is recommended in a circular pattern around the center of the cytocentrifuge spot. 


\section{INTRODUCTION}

Usefulness of bronchoalveolar lavage (BAL) is appreciated for clinical applications in the fields of interstitial lung diseases (ILD) and opportunistic infections. ${ }^{1-8}$ It is a minimal invasive procedure and associated with virtually no morbidity. $4,5 \mathrm{BAL}$ recovers cells and solutions from the lower respiratory tract and the alveolar spaces. It is thought that changes in lavage fluid and cells reflect pathological changes in the corresponding parenchymal constituents. 4,5

Previously, Drentet al. reported quantitative support for the important role of BAL in the diagnostic work-up of patients suspected of having ILD. ${ }^{8}$ BAL data of a large cohort of patients with sarcoidosis, extrinsic allergic alveolitis and idiopathic pulmonary fibrosis were studied. A logistic regression equation was constructed to provide the most likely diagnosis, which was found to be accurate in $94.5 \%$ of the patients studied as well as in a test population of a different hospital.

However, the BAL procedure is still not completely standardised. Particularly, differences in BAL fluid processing appeared to be one of the main obstacles to universal acceptance of BAL as an established clinical tool. $3,4,9$ Guidelines and recommendations for the BAL procedure and processing of the BAL fluid samples have been published. ${ }^{9}$ The cells obtained can be evaluated by cytological techniques as well as by immunohistochemical procedures. Routine processing includes the analysis of total and differential cell counts. Cytocentrifugation of BAL fluid samples can be considered as a routine laboratory procedure, which reveals sufficient preparation of the cell suspensions and enables a reliable differential cell count. However, differences between various laboratories have been reported. $3-5,9-11$

We hypothesized that the reproducibility and interobserver agreement might be influenced by the area of the cytocentrifuge spot used for cell counting. Therefore, the aim of the present study was to determine the reliability of differential cell counts of BAL fluid samples regarding different areas of the cytocentrifuge spot. Furthermore, the diagnostic impact of these differences, when interpreting the BAL fluid analysis results in ILD was evaluated.

\section{MATERIALS AND METHODS}

\section{Materials}

The indication for the BAL varied. For the most part, a pulmonary infection or a diffuse ILD was suspected. Exclusion criteria were BAL fluid recovery less than 35 $\mathrm{ml}$ and contamination with red blood cells and/or oropharyngeal cells. BAL fluid samples obtained from patients with a confirmed pulmonary infection $(\mathrm{n}=11$; based on culture results $\left.\geq 10^{4} \mathrm{cfu} / \mathrm{ml}\right)$ and samples from patients without signs of 
pulmonary infection $\left(\mathrm{n}=19\right.$; based on quantitative culture results $<10^{3} \mathrm{cfu} / \mathrm{m}$ ) were evaluated. These latter patients suffered from different ILD including sarcoidosis and idiopathic pulmonary fibrosis (IPF). The diagnosis was based, with care on clinical information, chest $X$ ray findings, high resolution $C T_{\text {, }}$ pulmonary function tests, BAL fluid analysis, and, in 10 cases, the diagnosis was histologically proven. The BAL fluid samples obtained from the patients with a histologically confirmed diagnosis were selected to test the diagnostic impact of the differential cell counts in various areas of the cytocentrifuge spot of BAL fluid. preparations.

\section{Bronchoalveolar lavage}

BAL was performed as reported previously during fiberoptic bronchoscopy. ${ }^{8}$ The procedure is briefly described. After premedication $10.5 \mathrm{mg}$ atropine intramuscular and sometimes 5-10 mg diazepam orally), and local anaesthesia of the larynx and bronchial tree (lidocaine $0.5 \%$, BAL was performed by standardised washing of the lobe involved with four aliquots of $50 \mathrm{ml}$ sterile saline $(0.9 \% \mathrm{NaCl})$ at $37^{\circ} \mathrm{C}$. Upon arrival in the laboratory, the volume of the $\mathrm{BAL}$ fluid recovered was recorded. The first fraction (bronchial fraction) was discarded and the remaining fractions were pooled. The total cell count was performed in a haemocytometer chamber (Fuchs Rosenthal). All nucleated cells were counted. Preparations of cell suspensions were made with a cytocentrifuge (Shandon cytospin 3 apparatus, Shandon Scientific Ltd., Astmoor, England). The conditions used were 650 rpm (speed), 10 minutes at a low acceleration. In order to obtain standardised and easy-to-read monolayer preparations, the number of drops per smear was adjusted according to the total cell count. ${ }^{12}$ The preparations were air cdried and subsequently stained according to the May-Grunwald-Giemsa (MGG) staining method. The MGG stain was done using May-Grunwald's Eosine-methylene blue solution (Merck 1424) and Giemsa solution (Merck 9204) as described by Dacie and Lewis. ${ }^{3}$ Additionally, the cytocentrifuge spot was divided into four quadrants. Having the frosted end of the slide in the right hand, the quadrants were numbered as follows: 1) upper left, 2) upper right, 3) lower left and 4) lower right. Two observers evaluated the MGG stained preparations in a double-blinded fashion at a magnification of $\times 1,000$ using an oil immersion objective. The differential cell counts were made in each quadrant as well as in a circular pattern around the center of the cytocentrifuge spot. In each area 200 cells were counted.

\section{Additional materials and methods}

To identify an explanation for the phenomenon of the ir regular distribution of the different cell types on the cytocentrifuge spot further analysis was performed.

Firsty, the presence of a too-low sample volume in the cytospin chamber as a cause of the phenomenon was investigated. BAL fluid samples with a balanced 
Iymphocyte/macrophage ratio were centrifuged. The sediment of the BAL fluid samples was dissolved in $\mathrm{NaCl}$ 0.9\% to final volumes of $100,200,300$ and $400 \mathrm{ml}$ respectively, and each volume having a cell quanticy of 460.000 cells. Differential cell counts were performed in each quadrant on 200 cells.

Secondly, the relationship between the observed crescent-shaped distribution (CSD) and the distribution of the different cell types was investigated. Therefore, five BAL fluid samples with a balanced lymphocyte/macrophage ratio were used. All BAL fluid samples were cytocentrifuged according to the method described above. Cell density was optically measured by use of a metal grid incorporated into the ocular piece of the microscope. Differential cell counts were performed in each quadrant on 200 cells.

Finally, a new Cytospin 3 was introduced in our laboratory near the end of this study. The newly purchased apparatus turned counter clockwise, in contrast with the old Cytospin 3 apparatus, which turned clockwise. The differences of cell distribution on the cytocentrifuge spot of the cytocentrifuged preparations, made by the old and new Cytospin 3, were examined. Ten cytocentrifuged preparations of one BAL fluid sample with a balanced lymphocyte/macrophage ratio were made on both cytospins. Differential cell counts were performed on 200 cells in each quadrant.

\section{Statistical analysis}

Data were analysed using repeated measures. Analysis of Variance ( $\mathrm{rmANOVA)}$ with restricted maximum likelihood (REML) estimation of the model parameters (module $5 \mathrm{~V}$ of the statistical package BMDP). Prior to analysis, all cell counts $x$ were logarithmically transformed as $\ln (x+1)$. This was found to be necessary for symmetrizing the skewed-to-the-right distributions of cell counts. In this study the eight repeared measures per subject are generated by two within-subjects factors: "observer" with two levels and "quadrant" with four levels. Both these factors and their interaction were included as fixed effects in the rmANOVA-model, resulting in a full parametrization of all eight combinations of observer and quadrant. The within subject (co) variance structure of the eight-dimensional residual term was supposed to be of the type "compound symmetry", i.e., all eight variance the same and all 28 covariance the same; this was found to be a reasonable assumption here. This assumption coincides with a random subject effect for each of the 30 subjects. The chi-squared Wald test was applied for significance testing. A p-value of less than 0.05 for each of borth factors and their interaction was considered statistically significant.

Additionally, a validated computer program based on a polychotomous logistic regression model was used to predict the diagnosis of 10 patients with either sarcoidosis or idiopathic pulmonary fibrosis. ${ }^{8}$ The variables used to discriminate among these different disorders were the yield of recovered BAL. fluid, total cell count, percentage of alveolar macrophages, lymphocytes, 
polymorphonuclear neutrophils and eosinophils together with some demographical data, e.g. sex, age, and smoking status yes or no.

\section{RESULTS}

For each cell type present in BAL fluid samples, table I provides the chi-square and p-values of the Wald test calculated for the difference between the two observers $(O)$, the differences between the four quadrants $(Q)$ and the influence of the observer on the quadrant differences $(O . Q)$. From the $\mathrm{p}$-values of the variable $\mathrm{Q}$, it can be concluded that the lymphocytes and alveolar macrophages were not randomly distributed over the different quadrants. In none of the cell types, however, was the $O . Q$ statistically significant. Therefore, observer-related factors did not account for the reported differences in the distribution of lymphocytes and alveolar macrophages.

\begin{tabular}{|c|c|c|c|c|}
\hline Cell type & Variable & DF & Chiscialaire & proluse \\
\hline PWNS & o. & 1 & 0,06 & 0.811 \\
\hline & 2 & 3 & 781 & 0.050 \\
\hline & 00 & 3 & 1,69 & 0.640 \\
\hline Lymphooytes & 0 & M & 127 & $<0,001$ \\
\hline & a & 3 & 14.3 & 0.003 \\
\hline & 00 & 3 & 1.49 & 0.685 \\
\hline AM & 0 & 1 & 304 & 0.081 \\
\hline & 0 & 3 & 73.7 & $\infty 0,001$ \\
\hline & 00 & 3 & 0.63 & 0.889 \\
\hline Eosingphils & 0 & 1 & 0.04 & 0.832 \\
\hline & 0 & 3 & 7.30 & 0.063 \\
\hline & 00 & 3 & 291 & 0.406 \\
\hline
\end{tabular}

A pevalue < 0.05 was considered slatistiealy signiticant PMWS = polymorohonuclear neutrophils, AM = alveolar mociophages.

Table II lists the geometric means of all counts calculated over 30 patients and two observers per cell type and per quadrant. The p-value is one calculated for the quadrant effect of each cell type. The number of lymphocytes gradually increased from quadrant one to four, whereas the number of alveolar macrophages complementary decreased. 


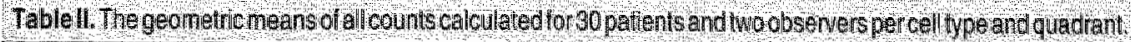

\begin{tabular}{|c|c|c|c|c|c|}
\hline Cellype & ouadran 1 & Quadrant2 & Quadrants & Quadrant4 & provalue \\
\hline PMNS & 14 & 15 & 16 & 15 & 0.050 \\
\hline Lymphocyes & 30 & 32 & 37 & 36 & 0.003 \\
\hline An & 91 & 92 & 77 & 76 & $<0,001$ \\
\hline Easinophis & 2 & 2 & 3 & 3 & 0,063 \\
\hline
\end{tabular}

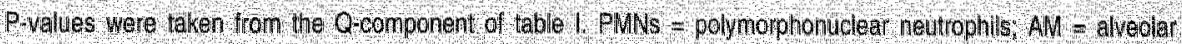
macrophages.

Table III shows the histological diagnosis of ten patients with either sarcoidosis or idiopathic pulmonary fibrosis together with the most likely diagnosis, generated by the computer program. The means of the cell count of the distinct quadrants, as well as the cell counts around the center of the cytocentrifuge spot, are presented. In one BAL fluid sample a discrepancy between the biopsy diagnosis and the predicted diagnosis was found. For this particular case the predicted diagnosis of each quadrant are listed.

Finally, a statistically significant difference in lymphocytes and macrophages per quadrant was found between the old and new cytospin $(\mathrm{p}<0.025)$.

\section{DISCUSSION}

The present data demonstrated that lymphocytes and alveolar macrophages were not randomly distributed on the cytocentrifuge spot of BAL fluid samples. A gradual increase of the number of lymphocytes from quadrant one to quadrant four, at the expense of the number of alveolar macrophages was detected. Furthermore, it was demonstrated that this phenomenon influenced the predicted diagnosis of the distinct quadrants. Certainly, in one case the predicted diagnosis of the quadrants differed with the histologically obtained diagnosis. The incorrect diagnosis was due to variations berween the number of eosinophils and polymorphonuclear neutrophils (PMNs), although both cell types did not differ statistically significantly between the quadrants as calculated over the $30 \mathrm{BAL}$ fluid samples examined. By contrast, the differential cell counts performed in the center of the cytocentrifuge spot and the mean of the cell count of the distinct quadrants pointed to the correct diagnosis in all observations.

This phenomenon is important as BAL fluid analysis is sometimes considered to avoid more invasive techniques used in the diagnostic work-up of patients with ILD. ${ }^{1-6,8}$

To the best of our knowledge, differences in the distribution of different cell types on the cytocentrifuge spot of BAL fluid samples have not been reported 


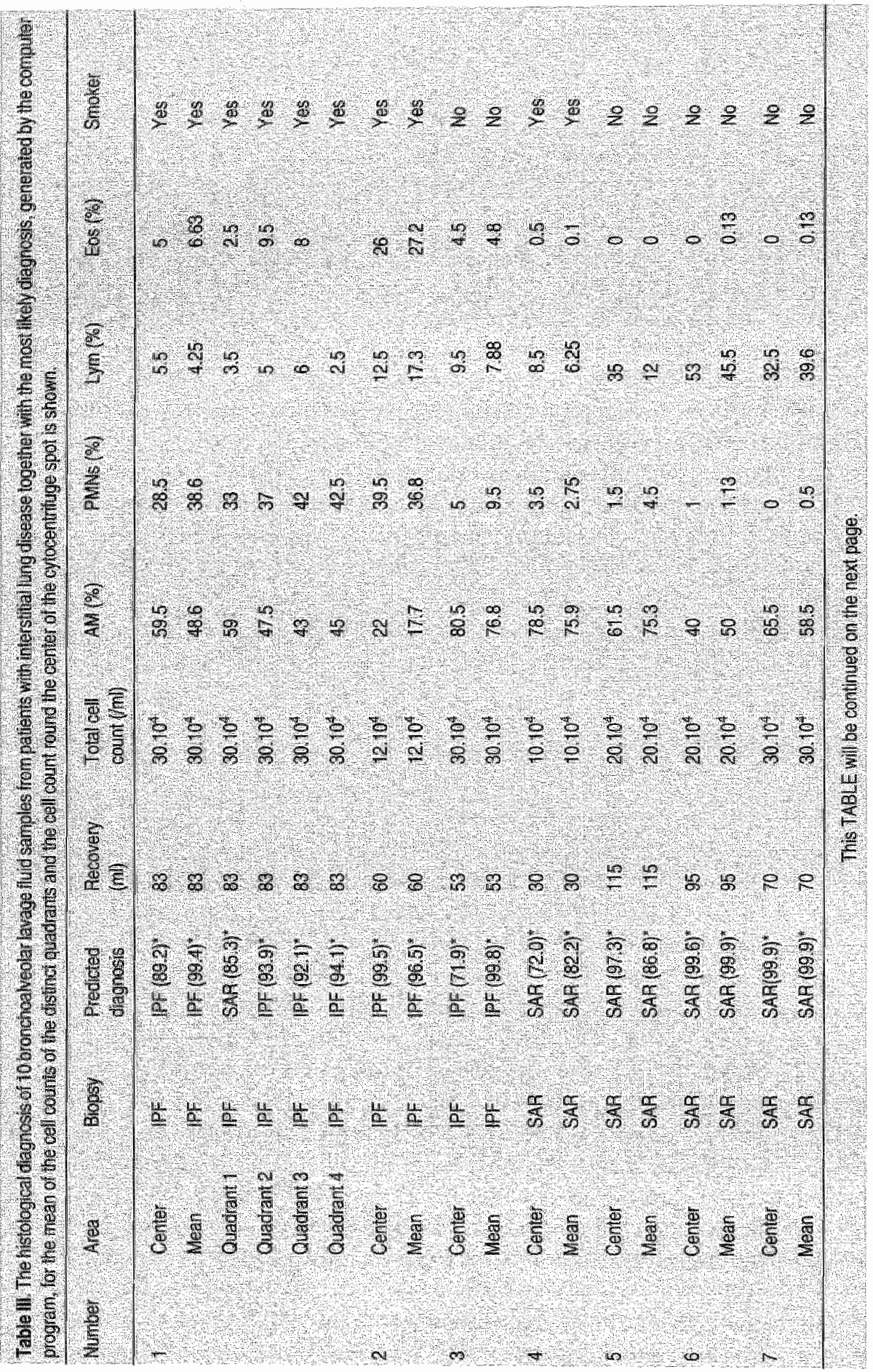




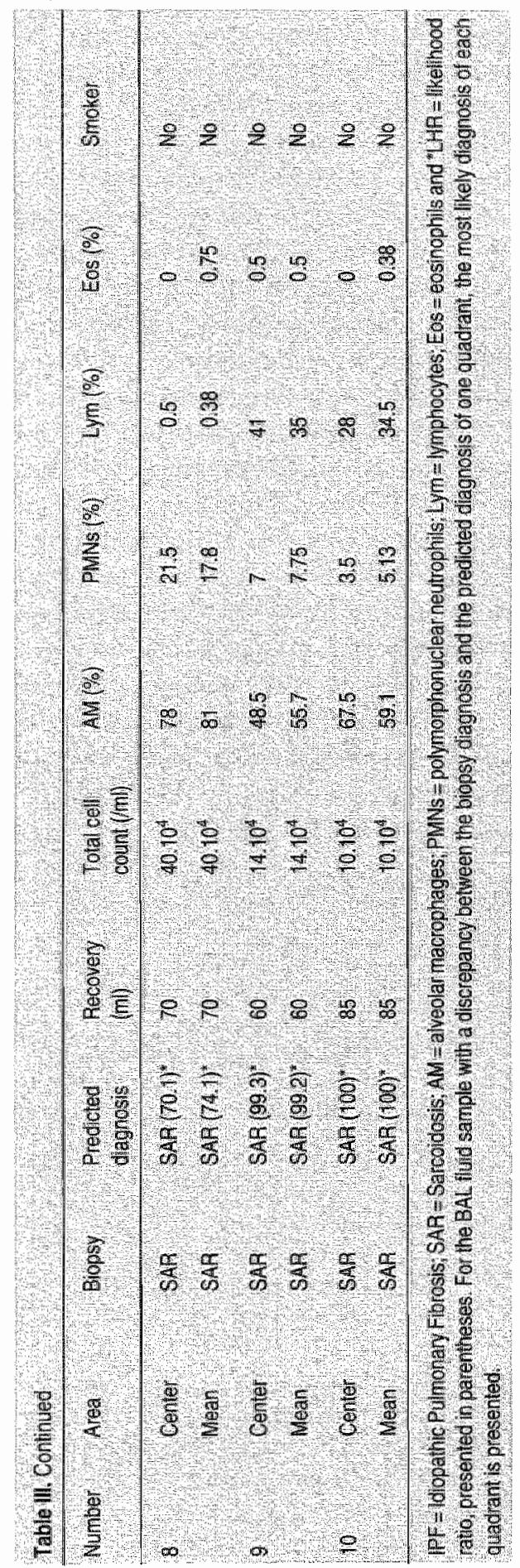


previously. However, several unforeseen problems in the cytocentrifugation process have been described in the past. Most of them deal with quantitative errors in the distribution of the cells. Table IV summarizes these pitfalls.

Boon and co-workers were the first to demonstrate that the cytocentrifugation process might hamper cell recovery. ${ }^{14}$ They demonstrated that long-standing contact between the BAL fluid sample and the filter in the cytospin chamber resulted in a premature diffusion of the sample into the filter of the Cytospin 1 apparatus. This error was subsequently eliminated in the design of the Cytospin 2, as in this apparatus an air bubble prevents contact between the applied fluid and the filter until the cytocentrifugation process starts.

In the present study, the possibility of a too-low sample volume in the cytospin chamber, as a cause of the irregular distriburion, was excluded. Grover and co-workers found that optimal cell recovery was achieved with sample volumes between 200 and $500 \mathrm{ml}$, whereas lower sample volumes resulted in a so-called "bull"s eye distribution" (deposition of the cells on the periphery of the cytocentrifuge spot), with a poor cell recovery. 15 Equal experiments were performed in our laboratory but no relationship was found between the sample volume applied and the degree of difference between the differential cell counts in each quadrant. Moreover, the mumber of drops used per cytocentrifuged preparation for the BAL fluid samples in the present study ranged from two to five, but the differences in cell distribution were similar in all these BAL fluid samples, irrespective of the number of drops used (unpublished data).

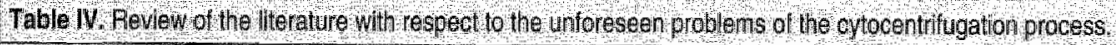

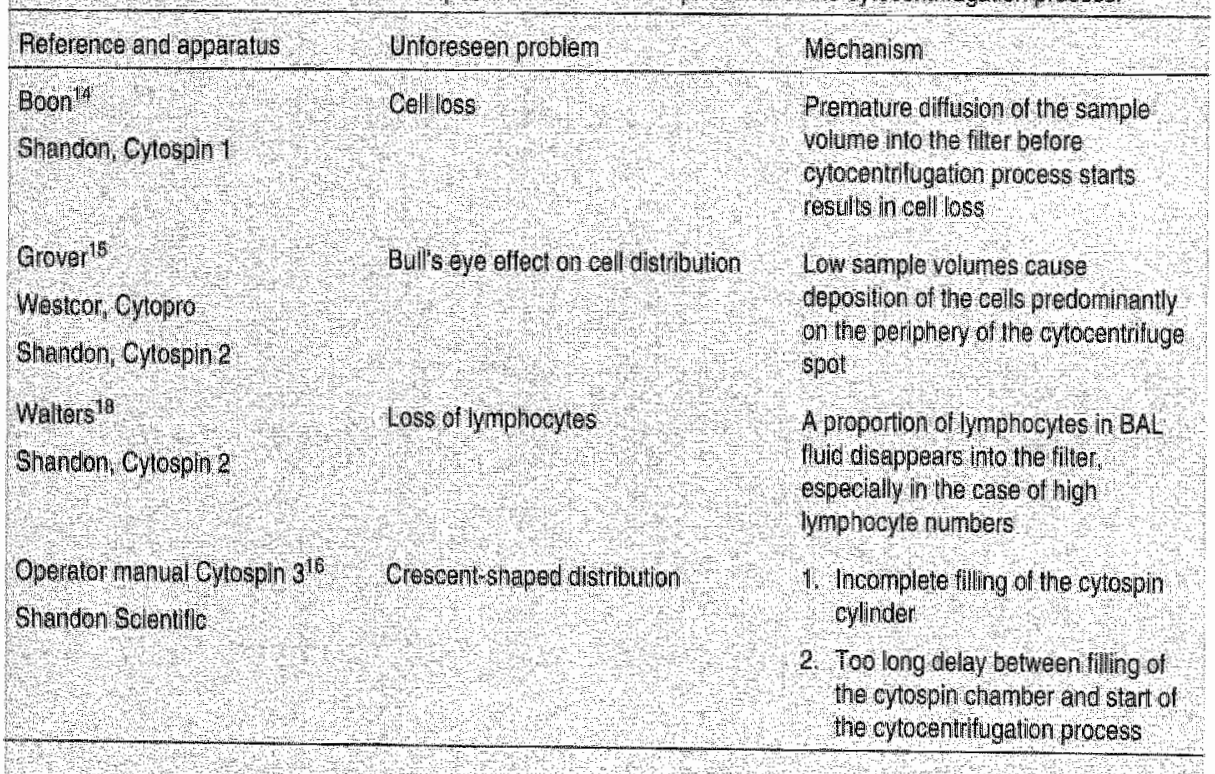


Subsequently, factors related to the cytocentrifugation process accounted for the irregular distribution of lymphocytes and alveolar macrophages. Subtle deviations from the balance and variations in acceleration rates, as factors, possibly related to the irregular cell distribution were eliminated. Furthermore, a crescent-shaped distribution (CSD) of the cells on the majority of the preparations was observed. According to the Cytospin 3 operator manual, this phenomenon was caused either by an incomplete filling of the cytospin chamber, or by a too long delay between sample application and the start of the cytocentrifugation process. ${ }^{16}$ Both factors resulted in the CSD from a combination of capillary and gravity forces. Although we strictly adhered to the Cytospin 3 operating instructions, it was not possible to eliminate this CSD. The CSD tended to occur with an orientation towards quadrant one for the majority of the BAL fluid samplesexamined. Therefore, the relationship between the CSD and differences of the distribution of the cell types in BAL fluid samples with a balanced lymphocytel macrophage ratio was investigated. The quadrant with the highest number of lymphocytes (quadrant 4) disclosed the lowest cell density in each BAL fluid sample examined (results not shown).

A new Cytospin 3 was introduced in our laboratory near the end of this study. The new ly purchased apparatus turned counter clockwise, in contrast with the old Cytospin 3 apparatus, which turned clockwise. The opposite rotation of each cytospin resulted in different cell distribution on the cytocentrifuge spot. In contrast to the cytospin first used, the lowest cell quadrant with the lowest cell density and the highest lymphocyte/macrophage ratio for the new cytospin was quadrant one.

It is tempting to speculate that a combination of centrifugal and gravity forces may explain the uneven distribution of lymphocytes and alveolar macrophages. Laviolette and co-workers demonstrated loss of lymphocytes into the cytospin filter during the cytocentrifugation process. 17 Certainly, the cytocentrifugation resulted in a selective underestimation of the lymphocytes by up to $45 \%$, as the smaller lymphocytes more readily disappear into the filter pores as compared to the larger alveolar macrophages. 18

In the present study, the lymphocytemacrophage ratio in both cytospin preparations was high in the quadrants with the lowest cell density. Therefore, we assumed that the lymphocytes are to be lost into the filter paper while the alveolat macrophages are deposited on the cytocentrifuge spot. Further research is needed using chromium-51-labelled lymphocytes to demonstrate their loss into the filter paper, as conducted by Laviolette and co-workers. ${ }^{17}$

Kleykamp and co-workers studied the differences in differential cell counts between laboratories. 11 There was little resemblance in the test results of both laboratories, and, therefore, comparing BAL fluid results from laboratory to laboratory is disputable. This lack of resemblance in the test results can be atributed to differences in the laboratory processing, such as cell differentiation, of the BAL fluid samples. The necessity for a reference method was suggested. 
For all cases, the predicted diagnosis of the mean of the cell counts of the distinct quadrants and the predicted diagnosis of the differential cell count round the center were identical to the histological one. The differential cell count on 200 cells round the center of the cytocentrifuge spot correctly predicted the diagnosis in the ten BAL fluid samples examined. This route is recommended to avoid possible diagnostic errors. Olson and co-workers recommended a similar method to screen cytocentrifuged urine samples for accurate detection of microorganisms. ${ }^{19}$

In conclusion, lymphocytes and alveolar macrophages were not randomly distributed on the cytocentrifuge spot of BAL fluid samples. Performing cell counts in a single quadrant appeared to influence the interpretation of BAL fluid analysis results in patients suspected of having interstitial lung diseases. Therefore, differential cell counts in a circular pattern round the center of the cytocentrifuge spot is recommended.

\section{REFERENCES}

1. Reynolds HY. Bronchoalveolar lawage. Am Rev Respir Dis 1987;135:250-263.

2. Daniele RP, Elias JA, Epstein PE, Rossman MD. Bronchoalveolar lavage: role in the parhogenesis, diagnosis, and management of interstitial lung disease. Ann Intern Med $1985 ; 102: 93-108$.

3. The BAL Cooperative Group Steering Commitree. Bronchoalveolar lavage constituents in healthy individuals, idiopathic pulmonary fibrosis, and selected comparison groups. Am Rev Respir Dis 1990;141:169-202.

4. Baughman RP. Bronchoalveolar lavage, 1sred., St. Louis, Mobsy Year Book, 1992.

5. Klech H, Hutter C. Clinical guidelines and indication for bronchoalveolar lawage (BAL): Report of the European Society of Pneumology Task Group on BAL. Eur Respir J $1990 ; 3: 937-974$.

6. Du Bois RM. Diffuse lung disease: a wiew for the future. Sarcoidosis Vasc Diffuse Lung Dis $1997 ; 14: 23-30$.

7. Djamin RS, Drent M, Sehreurs AJM, Groen EAH, Wagenaar SjSc. Diagnosis of Pnemnocystis carimi preumonia in HIV positive patients. Bronchoalveolar lavage vs. bronchial brushing. Acta Cytol 1998:42:933-938.

8. Drent M, van Nicrop MAMF, Gerritsen FA, Wouters EFM, Mulder PGH. A computer program using BALF-analysis results as a diagnostic tool in interstitiallung diseases. Am J Respir Crit Care Med 1996;153:736-741.

9. Klech H, Pohl W. Technical recommendations and guidelines for bronchoal weolar lavage (BAL). Eur Respir J 1989:2:561-585.

10. Merchant RK, Schwart DA, Helmers RA, Dayton CS, Hurninghake GW. Bronchoalveolar lavage cellularity. The distribution in normal volunteers. Am Rev Respir Dis $1992 ; 146: 448-453$. 
11. Keykamp BO, Baughman RP. Who should perform bronchoalvedar lavage analysis? Am Respir Crit Care Med 1998;157:67.

12. Capron F, Perror J, Szekeres $G$, Caulet $S$. Technique du liquide de lavage bronchoalvể aire dans un laboratoire central d'anatomie er cytologie pathologiques. Ann Pathol 1990; 10:278-281.

13. Dacie JV, Lewns SM. Preparations and staining methods for blood and bone marrow films. Practical Haematology, Sixth ed., Edinburgh, London, Melbourne, New York, Churchill Livingstone $1984 ; 50-56$.

14. Boon M, Wickel AF, Davoren RAM. Role of the air bubble in increasing well recovery using Cytospin I and II. Acta Cytol 1983;27:699.702.

15. Grover ML, Blee E, Stokes BO. Effect of sample volume on cell recovery in cytocentrifugation. Acta Cytol 1995;39:387-390.

16. Cytospin 3 cell preparation system operator guide. Shandon scientific Ltd., Astmoor, England 1991;27.

17. Laviolette $M$, Carreux $M$, Coulombe R. Bronchoalveolar lavage cell differential count on microscope glass cover. Am Rev Respir Dis 1988;138:451-457.

18. Walters $\mathrm{EH}$, Gardiner PV. Bronchoalveolar lavage as a research tool. Thorax $1991 ; 46: 613-618$.

19. Olson ML, Stanholtzer CJ, Willard KE, Peterson LR. The slide centrifuge gram stain as an urine screening method. Am J Clin Pathol 1991;96:454-458. 

CHAPTER 4

\section{Bronchoalveolar lavage fluid differential cell count: how many cells should be counted?}

Els De Brauwer

Jan Jacobs

Fred Nieman

Cathrien Bruggeman

Marjolein Drent 


\section{ABSTRACT}

Objective: The present study invesrigated the number of cells to be counted in cytocentrifuged bronchoalweolar lavage (BAL) fluid preparations for the most common cell types, in such a way that a predetermined standard in reliability of the enumetation for each cell type is warranted.

Study design: A rotal of 136 BAL fluid samples of patients with suspected. pneumonia or interstitial lung disease was investigated. Differential cell counts were performed on May-Grünwald-Giemsa stained cytocentrifuged preparations, by two observers each differentiating 500 cells. Reliability for the enumeration of ach cell type was expressed as a $\Phi$-value, as calculated in Generalizability Theory.

Results: For polymorphonuclear neutrophils (PMNs), alyeolar macrophages, lymphocytes and eosinophils, an acceptable $\$$-value of $\geq 0.95$ was reached at a count of 300 cells by one observer. The mast cells reached a s-value of only 0.674 at a count of 500 cells by one observer, precluding a reliable count. At the count of 500 cells by one observer, the squamous epithelial cells, the bronchial epitheliat cells and the plasma cells displayed $\Phi$-values of 0.868 , 0.903 and 0.816 respectively.

Conclusion: An extended microscopic screening of BAL fluid preparations is recommended in order to evaluate the presence of these cells. 


\section{INTRODUCTION}

Bronchoalveolar lavage (BAL) allows recovery of cells from the lower respiratory tract and the BAL fluid differential cell count gives important information in the assessment of interstitial lung diseases and pneumonia. ${ }^{1,2}$ For good cell analysis, high-quality microscopic preparations are necessary, and these may be obtained by cytocentrifugation. Cytocentrifuges, such as the Cytospin (Shandon Scientific Ltd., Astmoor, England), are popular in diagnostic laboratory as well as in research settings.

Previously, we demonstrated that the numbers of lymphocytes and alveolar macrophages on cytocentrifuged BAL fluid preparations were influenced by the speed and duration of cytocentrifugation, and that both cell types were not randomly distributed on the cytocentrifuge spot. ${ }^{3,4}$ These observations highlighted the need for standardisation of BAL fluid processing.

Another issue of the BAL fluid differential cell count asks for further study, namely the number of cells to be enumerated. The "Task Group on BAL" of the European Society of Pneumonology recommends a enumeration of at least 300 to 500 cells, in line with the guidelines of the American Thoracic Society (ATS) that mention 200 to 500 cells to be differentiated. ${ }^{5,6}$ Most laboratories comply with these recommendations, but the numbers of cells enumerated in various studies ranges from 200 to 1000 . 7, Moreover, to the best of our knowledge, no study has systematically investigated the relation between the numbers of cells counted and the reliability of the BAL fluid differential cell count.

Therefore, we investigated for each cell type the number of cells to be enumerated to guarantee a predetermined standard in reliability of counting.

\section{MATERIALS AND METHODS}

\section{Study population}

BAL fluid samples of patients with suspected pneumonia or interstitial lung disease were investigated. Exclusion criteria were a recovered BAL. fluid volume less than $20 \mathrm{ml}$, or the presence of excessive amounts of mucopurulent exudate or red blood cells obscuring cell identity.

\section{Bronchoalweolar lavage fluid differential processing}

BAL was performed during fiberoptic bronchoscopy as described previously. 9 Briefly, after premedication, the middle lobe, lingula or involved lobe was washed with four aliquots of $50 \mathrm{ml}$ sterile $0.9 \% \mathrm{NaCl}$ and the samples were immediately transported to the laboratory. After arrival in the laboratory, the volume of the recovered BAL fluid was recorded. The first fraction, representing the bronchial 
fraction, was discarded and the remaining fractions were pooled for further analysis. The total cell count was performed in a Fuchs Rosenthal hemocytometer chamber.

Cytocentrifugation was done with the Shandon Cytospin 3 apparatus (Shandon Scientific Ltd.) using uncoated pre-cleaned slides (Menzel-Gläser, Emergo, Landsmeer, The Netherlands) and white filter cards (Shandon Scientific Ltd., no.19000500). The numbers of drops per cytospin chamber were adjusted to the total cell count. ${ }^{10}$ Cytocentrifugation conditions were as follows: speed: 650 revolutions per minute; duration: 10 minutes; and acceleration rate: low. After drying, the preparations were May-Grünwald-Giemsa stained and subsequently sealed with a coverslip and mounting medium (Histomount, Shandon Scientific Letd.).

\section{Bronchoalveolar lavage fluid differential cell count}

The BAL fluid preparations were examined in a blinded fashion by two observers at a magnification of $\times 1,000$ using oil immersion. Differential cell counts were performed on 500 nucleated cells in a circular pattern around the center of the cytocentrifuge spot. ${ }^{3}$ The differential cell counts were recorded after 100,200 , 300,400 and 500 cells enumerated. The cell types were expressed as the mean per 100 cells counted. The cell types included in the differential cell count were alveolar macrophages, mast cells, eosinophils, lymphocytes, PMNs, plasma cells, bronchial epithelial cells and squamous epithelial cells. Infected PMNs were included within the PMN fraction and were also separately recorded.

\section{Statistical methods}

Variance components to be used in calculating intraclass correlation coefficients for reproducibility and interobserver agreement were estimated. Formulas are based upon G.R. Norman's quasiclassical R coefficients, which are very closely related to the $\rho^{2}$ coefficients in Generalizability theory (or $G$-rheory). ${ }^{11-13}$ From these values, the overall $\Phi$-value was calculated, and this $\Phi$-valne was considered to be acceptable at a threshold level of $\geq 0.95 .^{14}$ Finally, a decision study (or $D$-study) was performed on the $\Phi$-value to estimate how many hundreds of cells must be counted by one observer (or, if necessary, by two observers) in order to obtain a $\Phi$-value of $\geq 0.95$. All data were analysed by SPSS-PC, version 6.1.3, and also by a program for generalised analysis of variance (GENOVA). ${ }^{15}$ 


\section{RESULTS}

A total of 136 BAL fluid samples were included in the study. Table I stmmarises the mean value and standard deviation of each cell type, for both observers and five times hundred cells counted.

Figure 1 displays the $\$$-values in relation to the number of cells counted by one observer, specified for alveolar macrophages, lymphocytes, eosinophils and PMNs. As can be read from this figure, counting of 300 cells generated the threshold $\Phi$-value (i.e, a $\Phi$-value $\geq 0.95$ ) for all these cell types, and counting more than 300 cells consequently resulted in only a minor increase in reliability. For the infected PMNs, the threshold $\Phi$-value was already reached at a count of 200 cells (results not shown).

The $\$$-values of the remaining cell types are listed in table II. For the bronchial epithelial cells, the threshold $\Phi$-value was reached when two observers each counted 500 cells. For the other cell types, i.e. the squamous epithellal cells, the mast cells and the plasma cells, a $\Phi$-value exceeding 0.95 was not reached, neither by differentiating 500 cells by one observer, nor by two observers.

Table 1 . Dfferential cell counts obtained in 136 bronchaliveolat lavage flud samples:

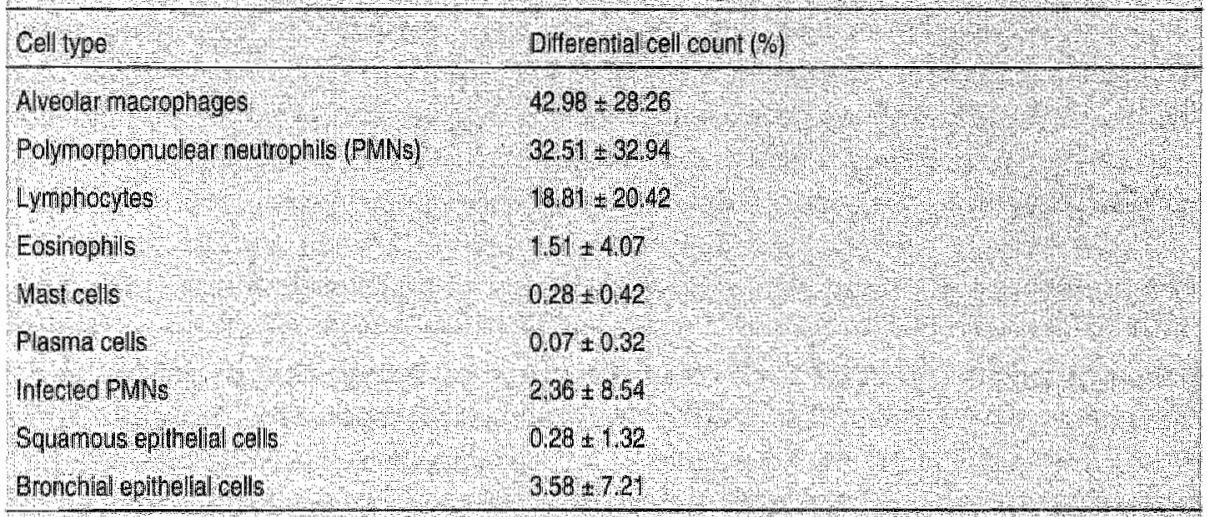

For each cell type mean values \pm SD for counts of 500 cells by each of two obsenvers are llsted

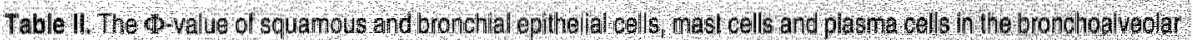
lavage fillow of inential cell count

\begin{tabular}{|c|c|c|}
\hline $\mathrm{Ce} / \mathrm{ppo}+\mathrm{s}$ & $\begin{array}{l}\text { sod cells counted } \\
\text { ond obserke, }\end{array}$ & $\begin{array}{l}2 \times 500 \text { colls counded } \\
\text { wo obsanels }\end{array}$ \\
\hline Squamous epingelialcels & 0868 & 0029 \\
\hline Bromenial ep inelal cels & 0,903 & 9964 \\
\hline Mastoells & 067 & 0804 \\
\hline Plasma cells & 0816 & 0004 \\
\hline
\end{tabular}

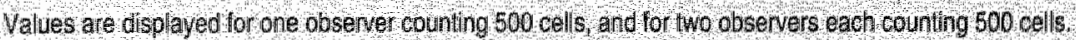




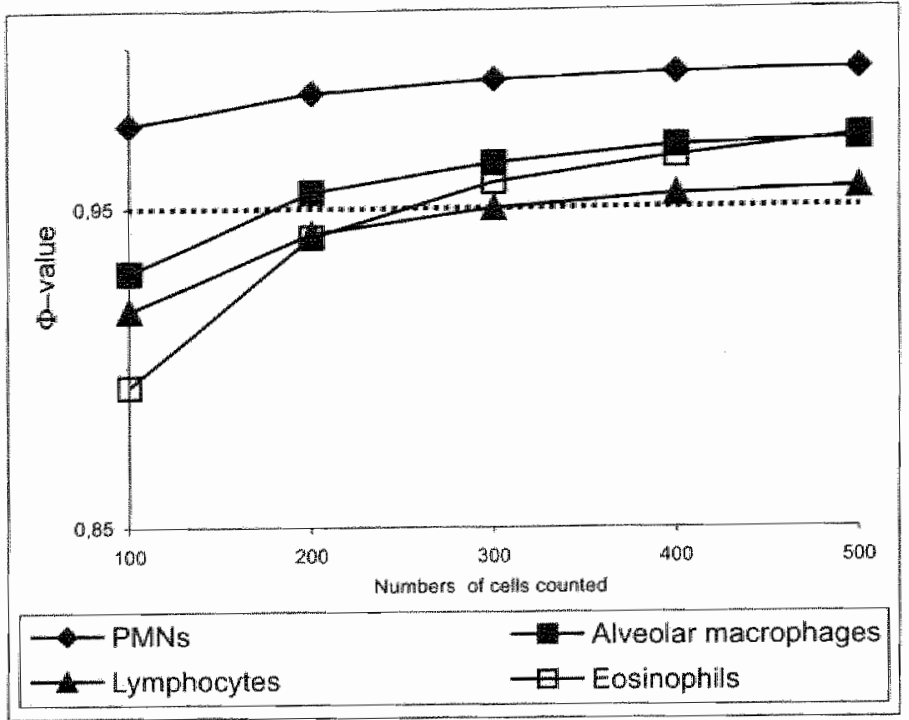

Figure 1 . The $\Phi$-value in relation to the number of cells counted for one observer, as calculated in D-study, is presented. The dotted line represents the acceptable $\Phi$-value of $\geq 0.95$. (PMNs: polymorphonuclear neutrophils).

\section{DISCUSSION}

The present study provided statistical information on the reliability of the BAL fluid differential cell count, with respect to the different cell types. This reliability was expressed as a $\mathbf{Q}$-value, which can be seen as a "combined" reproducibility and agreement coefficient. ${ }^{13}$ The $\Phi$-value and the corresponding Generalizibility theory have been successfully applied in physiological and educational test research as well as in the clinical setting. ${ }^{13}$ previously, we used this approach to study the number of BAL. fluid cells to be enumerated for a reliable estimation of the infected cell count. ${ }^{14}$ For laboratory evaluations such as in the latter study and in the present one, only small differences are tolerated between the various measurements, and therefore we opted for a high standard (i.e. $\Phi$-value $\geq 0.95$ ) as the acceptable threshold. Furthermore, the cytocentrifugation process was carefully standardised, resulting in easy-to-read monolayer preparations that were examined by experienced microscopists. ${ }^{10}$ In this controlled conditions, the number of technical factors that might have been contributed to sampling error can be expected to be limited, and the effect of observer-related factors to be low. For statistical reasons, we included the squamous and the bronchial epithelial cells 
into the differential cell count, although in line with the official recommendations, these cells are separately recorded in the daily practice of our laboratory. 5,10 From the present results, it is clear that counting of 300 to 500 cells, as recommended by Klech and Pohl and by Baselski et al. warrants a reliable estimation of the percentages of alveolar macrophages, lymphocytes, PMNs and eosimophils. ${ }_{2}, 5$

The 200-cell count, which the ATS proposed as the minimum number of cells to be enumerated, only generated a reliable count for the PMNs and the alveolar macrophages. As shown in figure 1, the PMNs performed the best and reached the threshold $\Phi$-value already at a count of 100 cells. This can be explained by the fact that these cells are easy to recognise and because of their high mean number in the present BAL fluid sample collection, which implicates a more precise estimation of their variability. In spite of their low mean number in the present BAL fluid samples, the infected cells exceeded the threshold $\Phi$-value at a count of 200 cells. This is in line with previous findings and may be ascribed to the good morphologic characteristics of both cells and engulfed micro-organisms in MGG stained preparations. ${ }^{14}$ The lymphocytes, and, to a lesser extent, the alveolar macrophages displayed lower $\Phi$-values than the PMNs. As the counting was carefully controlled for technical factors, we presumed that interobserver related factors (agreement) rather than intraobserver related factors (reproducibility) had contributed to the lower $\Phi$-value. Indeed, for both cell types, the values of agreement were lower than those of reproducibility (data not shown). It is well known that large activated $\rrbracket$ ymphocytes are difficult to distinguish from small alveolar macrophages, and we assume that this phenomenon might have accounted for the lower agreement between the two microscopists in the present setting. ${ }^{16}$

Romanovsky-type stains (such as the MGG stain) paint the eosinophil's granules bright orange. These granules, combined to the typical bilobed nucleus, make the eosinophils easily recognisable cells, and they consequently reached acceptable $\Phi$-values in spite of their low mean percentage. By contrast, although mast cells are reported to stain well with the MGG stain, this cell type presently did not reach acceptable reliability, even at counts of 500 cells by each of two observers. ${ }^{17}$ Their poor $\Phi$-walue was equally due to both a low agreement and a low reproducibility. In part, this may be explained by their extremely low mean percentage, with the inherent high variability in estimation. In addition, it is known that degranulated mast cells are morphologically difficult to recognise. ${ }^{18}$ Pathological conditions such as asthma and extrinsic allergic alveolitis are associated with an increase in BAL fluid mast cells. ${ }^{19,20}$ Although in these conditions the variability of the mast cell count tends to decrease in parallel to their increase in number, the presently found low $\Phi$-value urges caution when comparing mast cell percentages from different countings.

The plasma cells were the least numerous cells present in these collection of BAL fluid samples. Although it did not reach the threshold level, their $\Phi$-value was unexpectedly high $(0.816$ when a single observer counted 500 cells, table II), probably by virtue of their typical morphologic appearance. This is important because 
the presence of plasma cells, irrespective of their number, is indicative of diseases such as extrinsic allergic allveolitis or drug-induced pulmonary toxicity. ${ }^{8}$ In BAL fluid samples, plasma cells often occur together with eosinophils and activated lymphocytes. 8,21 When the latter cell types are observed during microscopic examination, it is therefore imperative to screen further for the presence of plasma cells.

The presence of squamous and bronchial epithelial cells points to oral and bronchial contamination respectively. None of both cell types reached the threshold $\Phi$-value, and this was not surprising in view of their low mean percentages. In addition, ciliated bronchial cells are often irregularly distributed over the cytocentrifuge spot, and they tend to occur in small groups. In MGG stained preparations, squamous epithelial cells may be present as faint, pale cells and these cells may be overlooked at the high magnification. For these reasons, it is important to screen the BAL fluid preparations at low magnification (objective $\times 10$ ), in order to recognise singly lying or grouped epithelial cells that otherwise would have escaped detection. ${ }^{10}$

With respect to the diagnostic practice, the present study allowed refinements of the previous recommendations on the numbers of BAL fluid cells to be counted for a reliable differential cell count. With a single observer available (which in daily routine is the most reasonable option), a reliable enumeration of PMNs, infected PMNs, alveolar macrophages, lymphocytes and eosinophils is achieved once 300 cells are counted. Even at a count of 500 cells, the percentage of the other cells can not be ascertained with enough standard of reliability. The low $\Phi$-value of the mast cells precludes reliable counting, and therefore the percentages of mast cells in BAL fluid samples must be interpreted with caution. Furthermore, an extended microscopic screening of the BAL fluid cytocentrifuged preparations is recommended, in order to evaluate the presence of epithelial cells (low magnification) and plasma cells (high magnification).

\section{REFERENCES}

1. Baselski VS, Whinderink RG. Bronchoscopic diagnosis of pneumonia. Clin Microbiol Rev $1994 ; 7: 533-558$.

2. Drent M, Nierop wan MAMF, Gerritsen FA, Wouters EFM, Mulder PGH. A computerprogramme using BALF-analysis results as a diagnostic rool in interstitial lung diseases. Am J Respit Crit Care Med 1996;153:736-741.

3. De Brauwer ElGB, Drent M, Mulder PGH, Bruggeman CA, Wagenaar SjSc, Jacobs JA. Differential cell counts in cytocentrifuged BAL fluid preparations are influenced by the area used for counting. Anal Quant Cyrol Histol 2000; in press.

4. De Brauwer EIGB, Jacobs JA, Nieman F, Bruggeman CA, Wagenaar $5\left\lceil S \mathrm{C}_{n}\right.$. Drent $\mathrm{M}$. Cytocentrifugation conditions affect the differential cell count in bronchoalveolar lavage fluid. Anal Quant Cyrol Histol 2000; in press. 
5. Klech $\mathrm{H}$, Pohl W. Technical recommendations and guidelines for bronchoalveolar lavage (BAL). Eur Respir J 1989;2:561-585.

6. Goldstein RA, Rohatgi PK, Bergofsky EH, Block ER, Daniele RP, Dantzker DR, et al. Clinical role of bronchoalveolar lavage in adults with pulmonary disease. Am Rev Respir Dis $1990 ; 142: 481-486$.

7. Allauchiche $B$, Jaumain $\mathrm{H}$, Dumontet $\mathrm{C}$, Motin J. Early diagnosis of wentilator wassociated pneamonia. Is it possible to define a cut-off value of infected cells in BAL fluid? Chest 1996;110:1558-1565.

8. Drent $M$, Velzen-Blad van $H$, Diamant $M$, Wagenaar $\$ j S c$, Donckerwolck-Bogaert $M$, Bosch van den JMM. Differential diagnostic value of plasma cells in bronchoalveolar lavage fluid. Chest 1993;103:1720-1724.

9. Cobben NAM, Drent M, Jacobs 』A, Schmitz MPJ, Mulder PGH, Henderson RF, et al. Relationship between enzymatic markers of pulmonary cell damage and cellular profile: a study in bronchoalveolar lavage fluid. Exp Lung Res 1999;25:99-111.

10. Jacobs $\mathbb{A}, \mathbb{D}$ e Brawwer EIGB. BAL fluid cytology in the assessment of infectious lung disease. Hosp Med 1999;60:550-555.

11. Shavelson RJ, Webb NM. Generalizability theory: a prinuer. Newbury Park, Sage Publicarions, 1991.

12. Streiner DL, Norman GR. Health measurement scales: a practical guide to their development and use. Oxford, United Kingdom, Oxford University Press, 1991, 2nd ed.

13. Roebroeck ME, Harlaar J, Lankhorst GJ. The application of generalizability theory to reliability assessment: an illustration using isometric force measurement. Phys Ther $1993 ; 73: 386-401$.

14. De Brauwer EIGB, Jacobs JA, Nieman F, Bruggeman CA, Drent M. Test characteristics of Acridine Orange, Gram, and May-Grünwald-Giemsa stains for enumeration of intraceliular organisms in bronchoalveolar layage fluid. J Clin Microbiol 1999;37: 427-429.

15. Crick GE, Brema RL. GENOVA: a generalized analysis of wariance system. Fortran IV computer program and manual. University of Massachusets at Boston Computer Pacilities, Dorchester, Mass., 1982.

16. Baughman R, Strohofer $\mathrm{S}, \mathrm{Kim} \mathrm{K}$. Variation of differential cell counts of bronchoalveolar lavage fluid. Arch Pathol Lab Med 1986;110:341-343.

17. Rónai $Z$, Bauer PC, Wang YM, Costabel U. Identification of masr cells in bronchoalveolar lavage via different stains. Pneumonol 1993;47:456-457.

18. Stamley MW. Qualitative and quantitative cytology in control subjects. Im: Stanley MW, Henry-Stanley MJ, Ider C, Eds. Bronchoalveolar lavage: cytology and clinical applications. New York, Igaku-Shion, 1991:27-65.

19. Foresi A, Bertorelli G, Pesci A, Chetta, Oliveri D. Inflammatory markers in bronchoalveolar lavage and in bronchial biopsy in astma during remission. Chest 1990; 98:528-535.

20. Pesci A, Bertorelli $G$, Olivieri D. Mast cells in bronchoalveolar lavage fluid and in ransbronchial biopsy specimens of patients with Farmer's lung disease. Chest 1991; 100:1197-1202. 
21. Jacobs JA, De Brauwer EIGB, Ramsay G, Cobben NAM, Wagenaar SjSc, Ven wan der AJAM, et al. Detecrion of non-infectious conditions mimicking pneumonia in the intensive care serting: usefulness of BAL fluid cytology. Respir Med 1999;93:571-578. 
CHAPTER 5

Test characteristics of Acridine Orange, Gram and May-Grünwald-Giemsa stains for the detection of intracellular organisms in bronchoalveolar lavage fluid

Els De Brauwer

Jan Jacobs

Fred Nieman

Cathrien Bruggeman

Marjolein Drent

Abbreviated version published in the Journal of Clinical Microbiology 1999;37:427-429 


\begin{abstract}
Objectwe: The purpose of this study was to investigate the test characteristics (reproducibilicy and interobserver agreement) of Acridine Orange ( $\mathrm{OO}$ ), Gram and May-Grünwald-Giemsa (MGG/stains for the enumeration of intracellular organisms (ICO) in bronchoalveolar lavage fluid (BAL fluid) samples and to determine the number of cells to be counted for reliable enumeration of $1 \mathrm{CO}$. Study design: Seventy-seven BAL fluid samples obrained from parients suspected of ventillator-associated pneumonia were cytocentrifuged. The preparations were stained and the ICO were enumerated in a blinded fashion by two observes who counted 500 cells each. Data were analysed using a repeared measurement analysis of variance (ANOVA), Generalizability Theory and Decision-Analysis.

Results: The AO stain displayed the highest intraclass correlarion for reproducibility, the $\mathrm{MGG}$ stain displayed the highest intraclass correlation coefficient for interobserver agrement.

Conclinsion: A Decision-Andysis showed that only the MGG stain had an acceptable $(0$-value $(0.965)$ when al single observer enumerated $1 \mathrm{CO}$ at a count of 200 cells.
\end{abstract}




\section{INTRODUCTION}

The enumeration of intracellular organisms (ICO) in cells recovered by bronchoalveolar lavage (BAL) is a valuable tool in the diagnosis of ventilator-associated pneumonia (VAP) $, 1,5,18,20$ However, there is a discrepancy in the staining methods used in the various studies reported, and in the number of cells counted for enumeration of the ICO. These factors may at least in part explain the different cut-off values of ICO in the diagnosis of VAP. Moreover, to our knowledge no data are reported on test characteristics such as reproducibility and interobserver agreement for the different staining methods used.

As we had cytocentrifuged BAL fluid preparations, we decided to investigate the test characteristics of the Acridine Orange stain (AO), Gram stain and May-Grunwald-Giemsa stain (MGG) for the enumeration of ICO. In addition, we intended to determine the number of cells to be counted for reliable enumeration of $\mathrm{ICO}$.

\section{MATERIALS AND METHODS}

\section{Study population}

BAL fluid samples of mechanically ventilated patients were obtained from January 1996 to March 1997 at the Intensive Care Unit, University Hospital Maastricht, the Netherlands. All patients were suspected of having VAP with respect to clinical features together with radiographic findings; i.e. a new or progressive infiltrate. ${ }^{3}$

\section{Sampling technique}

A fiberoptic bronchoscope (Pentax FB-15H/FB-15X, Pentax Medicals, Japan) was introduced through a special adaptor (swivel connector, Gibeck Respiration, Sweden) and "wedged" into affected segmental or subsegmental bronchus. The fluid was instilled into the subsegment through the biopsy channel of the bronchoscope in four aliquots of $50 \mathrm{ml}$ sterile saline $(0.9 \% \mathrm{NaCl}$, room temperature), then immediately aspirated and recovered. The BAL fluid samples were transported to the laboratory within 15 minutes after collection and analysed within 1 hour upon arrival in the laboratory.

\section{Processing of specimens}

The volume of the recovered BAL fluid was recorded. The first fraction, representing the bronchial fraction, was discarded and the remaining fractions were pooled for further analysis. The total cell count was performed in a Fuchs 
Rosenthal hemocytometer chamber. All nucleated cells were counted. Cytocentrifugation was done with the Shandon Cytospin 3 apparatus (Shandon Scienrific Ltd., Astmoor, England), using the following conditions: speed: $650 \mathrm{rpm}$ (which equals a g-value of approximately $\times 40$ ), time: 10 minutes and acceleration rate: low. In order to obtain standardised and easy-to-read monolayer preparations, the number of drops per smear was adjusted according to the total cell count. ${ }^{4}$ The preparations were air dried, and, if necessary, methanol fixed. Subsequently, preparations were stained with Gram and MGG stains. These preparations were sealed (Xylene substitute mountant, Shandon Scientific Ltd, Astmoor, England) and stored at room temperature. A third preparation was stored at $-30^{\circ} \mathrm{C}$ and stained with the $\mathrm{AO}$ stain at the date of examination.

\section{Staining methods}

The Gram stain was performed according to the conventional method using Crystal violet (Merck 1408, Darmstadt, Germany), Fuchsin (Merck 15937), Potassium iodide (Merck 5043) and Iodine resublimed (Merck 4761).12 The MGG stain was done using May-Grünwald"s Eosine-methylene blue solution (Merck 1424) and Giemsa solution (Merck 9204) as described by Dacie and Lewis. 9 The AO stain was purchased from Difco (Difco, Detroit, MI, USA, product number 3336-75-9) and performed according to the instructions of the manufacturer.

\section{Rejection criteria}

The quality of the cytocentrifuged BAL fluid samples was scored on the MGG stained preparations by one observer. The BAL fluid preparations containing excessive amounts of red blood cells, intercellular debris or damaged nucleated cells were excluded from analysis.

\section{Cytologic aralysis}

The Gram, MGG and AO stained preparations were examined by two observers (first and second author) in a double blind fashion at a magnificarion of $\times 1,000$ using oil immersion. For the AO stain, a Zeiss fluorescence microscope (Carl Zeiss, Oberkochen, Germany) with a filterset 09 487909-0000 (excitation BP450-490, emission LP520) was used. The AO stained preparations were read by both observers at the day that the staining was performed. Differential cell counts were made on the MGG stained cytocentrifuged preparations by examining 500 nucleated cells. For each stain, the number of cells with ICO was counted up to a total of 500 nucleated cells and the number of cells with ICO was expressed as a percentage of all nucleated cells counted. The successive numbers of ICO were noted after counts of $100,200,300,400$ and 500 cells respectively. 


\section{Statistical analysis}

The difference between sample volumes of excluded BAL fluid samples against included ones was calculated using the independent groups Student t-test. The testing of differences in counting over staining methods was done within a mixed model ANOVA design using repeated measurements over number of observers and number of hundreds of counted cells. Because both these factors are "random" and staining method is "fixed", a Quasi-F ratio had to be calculated to obtain a p-value for the differences in methods. For each of the three staining methods a repeated measurements analysis of variance (ANOVA) was calculated using number of observers and number of cells counted in hundreds as random factors. Next, variance components were estimated to be used in calculating intraclass correlation coefficients for reproducibility $\left(\mathrm{ICC}_{\mathrm{R}}\right)$ and interobserver agreement $\left(\mathbb{I C C} C_{A}\right)$. Formulas are based upon G.R. Norman's quasiclassical R measures, which are very closely related to the $\rho^{2}$ measures in Generalizability (or G-) Theory. ${ }^{17,19}$ For a two-way repeated measurements ANOVA design the $I C C_{R}$ for each staining method can be defined as: $\left(\sigma^{2} s+\sigma^{2} s o\right) /\left(\sigma^{2} s+\sigma^{2} s o+\sigma^{2} s c+\right.$ $\sigma^{2} \mathrm{SCO}$, in which $\sigma^{2}$ stands for an estimated variance component, $S$ for specimen, $O$ for number of observers and $C$ for numbers of cells in hundreds. Likewise, the $I C C_{A}$ can be defined as: $\left(\sigma_{S}^{2}+\sigma^{2} S C\right) /\left(\sigma^{2}{ }_{S}+\sigma^{2} S O+\sigma^{2} S C+\sigma^{2} s C O\right)$. Next to these, the "overall" $\Phi$ coefficient was used from $G$-Theory, which can be seen as a combined reproducibility and agreement measure. Finally, a Decision (or D-) study was done on $\Phi$ to investigate how many hundreds of cells are needed to be counted by how many observers (preferably only one) to ascertain a $\Phi \geq 0.95$ on a scale of "zero" (minimum of reproducibility and no agreement at all) to "one" (maximum of reproducibility and total agreement). The measure is defined as $\Phi=$ $\sigma^{2} s /\left(\sigma^{2} s+\sigma^{2} O+\sigma^{2} C+\sigma^{2} O C+\sigma^{2} S O+\sigma^{2} S C+\sigma^{2} s C O\right)$. In D-studies theoretical reproducibility and/or agreement measures are calculated by weighting variance components by the number of observers and/or number of hundreds of cells in the formulas. In this way tables of measures can be made to investigate the most effective combination of numbers to reach a reproducibility/agreement of 0.95 . All data were analysed by SPSS-pc, version 6.1 .3 and by GENOVA, a General-purpose analysis Of Variance program made by J.E. Crick and R.L. Brennan.8

\section{RESULTS}

Seventy-seven BAL fluid samples of 56 patients were included in the study, 31 BAL fluid samples were excluded according to the criteria mentioned. The mean sample volume of the excluded BAL fluid samples was $37.3 \mathrm{ml}$ (range 5 to $100 \mathrm{ml}$ ) while the mean volume of the included BAL fluid samples was $63.7 \mathrm{ml}$ (range 10 to $150 \mathrm{ml} ; \mathrm{p}=0.001$ ). 


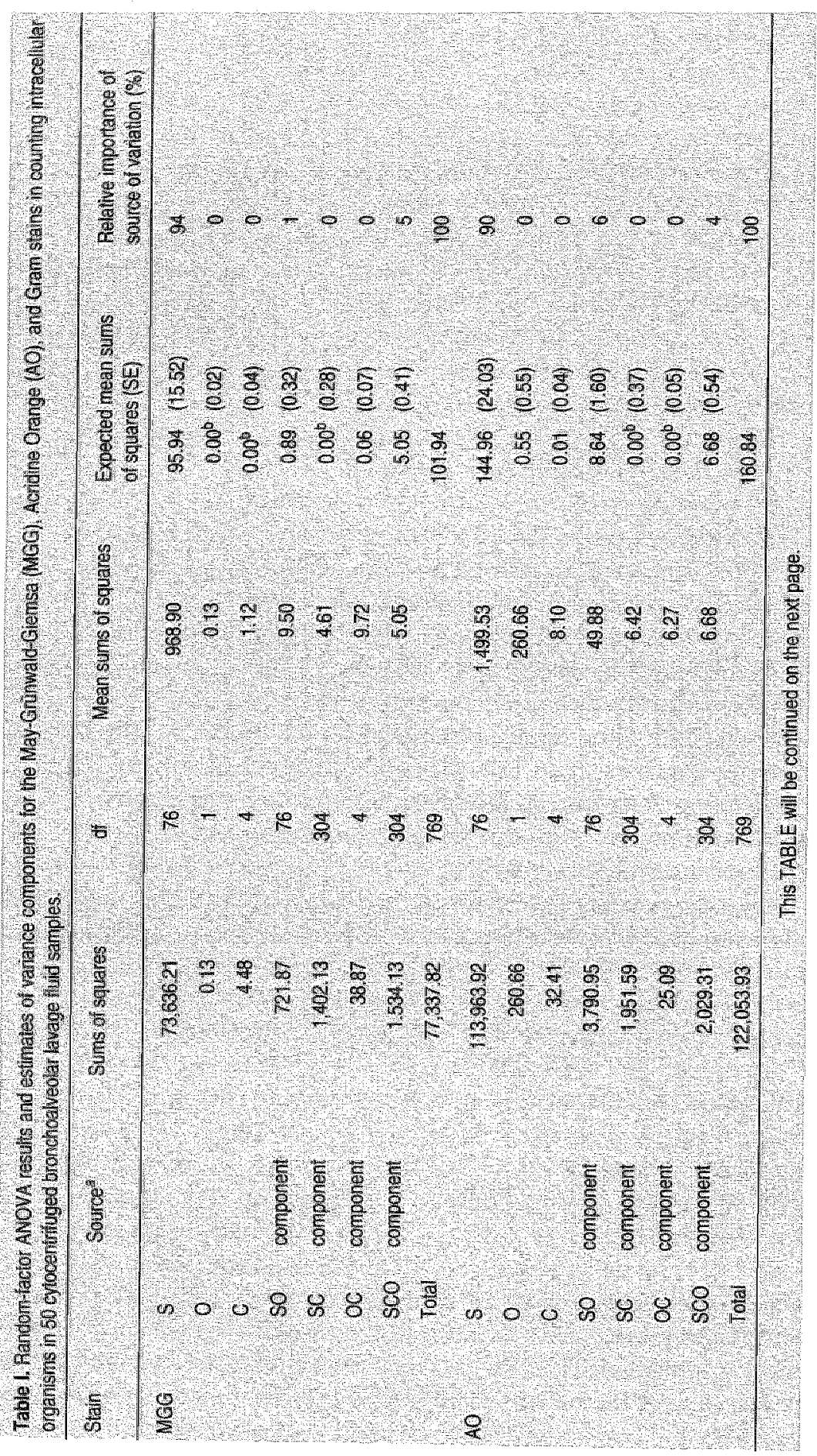




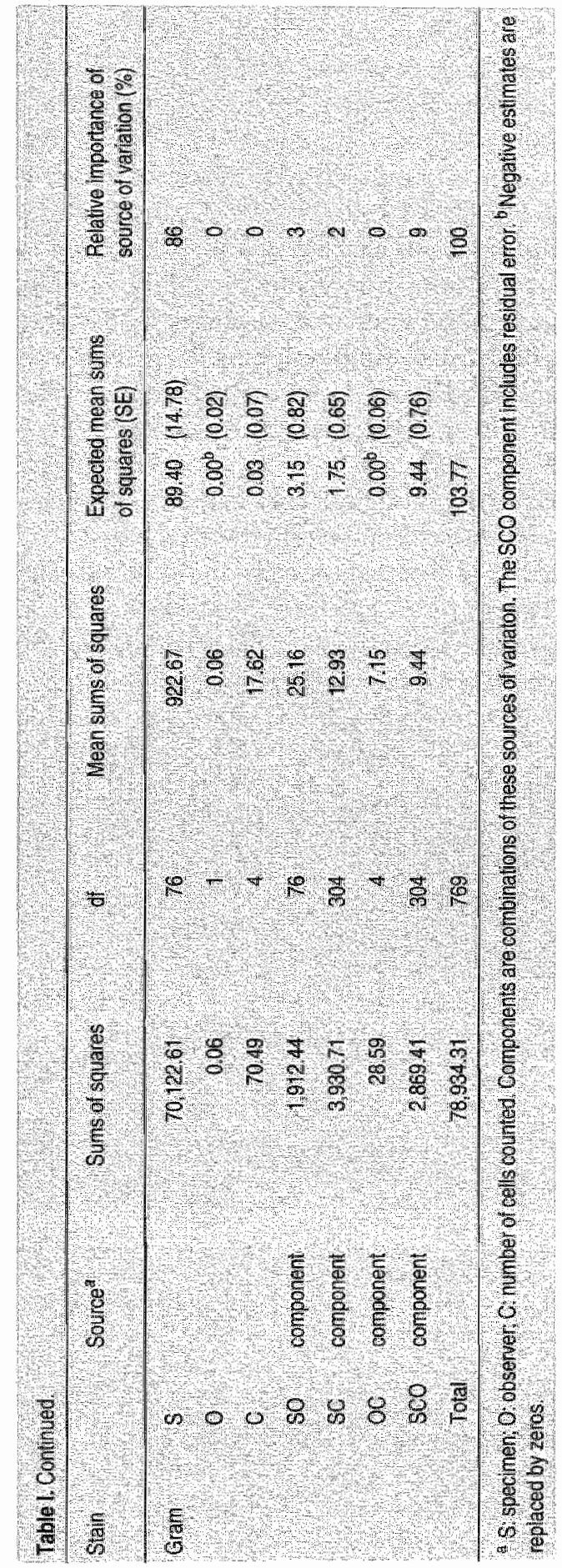


In 50 cytocentrifuged preparations ICO were demonstrated. The AO stain revealed the highest mean number (mean 5.01; range $0-76.2 ; \mathrm{SD}: 12.25$ ), next came the MGG stain (mean 4.27; range $0-54.7$; SD : 9.84) and the Gram stain had the lowest mean number in $\mathrm{ICO}$ counting (mean 4.03 ; range $0-51.9$; SD: 9.61). However, differences in the numbers of $1 \mathrm{CO}$ counted over the three staining methods were not statistically significant (Quasi-F ratio $=1.29$ by 2 and $6 \mathrm{df}, \mathrm{p}>$ 0.25). Table $I$ show the wo-way repeated measurement $A$ NOVA results and the estimates of the variance components for the three staining methods. The expected mean sums of squares are equal to the estimated variance components $\left(E M S=\sigma^{2}\right)$ and next to them the standard errors of each component are given. The percentages in the last column of each table indicate the relative importance of the specimens, the observers, the number of cells and their combinations expressed as variance components in counting $\mathrm{ICO}$.

Table II lists the $\mathrm{KCC}_{\mathrm{R}}$ for one obserwer by number of cells in hundreds specified for the three different staining methods as calculated by D-Analysis.

Next, table III lists the ICCA by number of obserwers and for one hundred cells. specified for all three staining methods.

Figure 1 gives a summary of the D-study i.e. it displays the $\Phi$-values by the number of cells counted, for one observer (figure 1A) and for two observers (figure 1B).

\begin{tabular}{|c|c|c|c|}
\hline Nunber of cells couinted & MGG: & $\mathrm{AO}^{\circ}$ & Grame \\
\hline 11100 & 0.951 & 0.958 & 0.892 \\
\hline $2 \times 100$ & 0.975 & 0970 & 0.643 \\
\hline 3,100 & 0983 & 0.986 & 0.981 \\
\hline $1 \times 100$ & 0987 & 0999 & 0.971 \\
\hline $5 \times 100$ & 2090 & 0.991 & 0996 \\
\hline
\end{tabular}

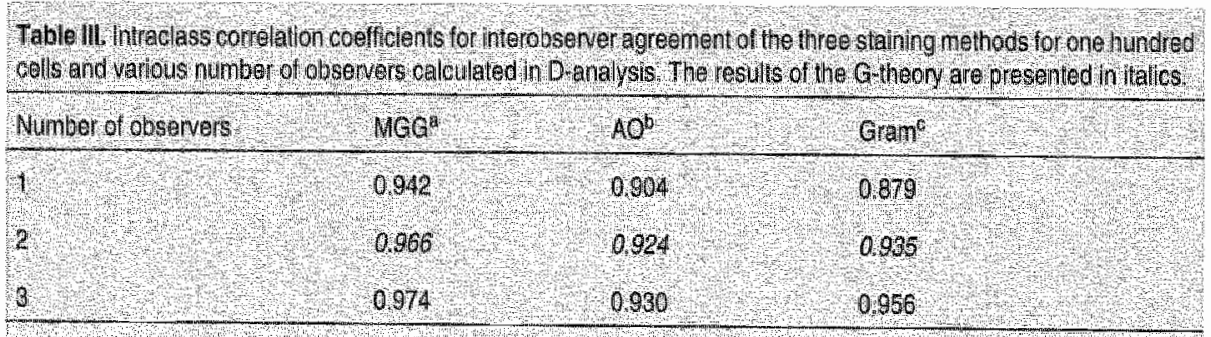

nay-Gunnwald Giensa stain 'Acridine Orange stain "Gram stan. 

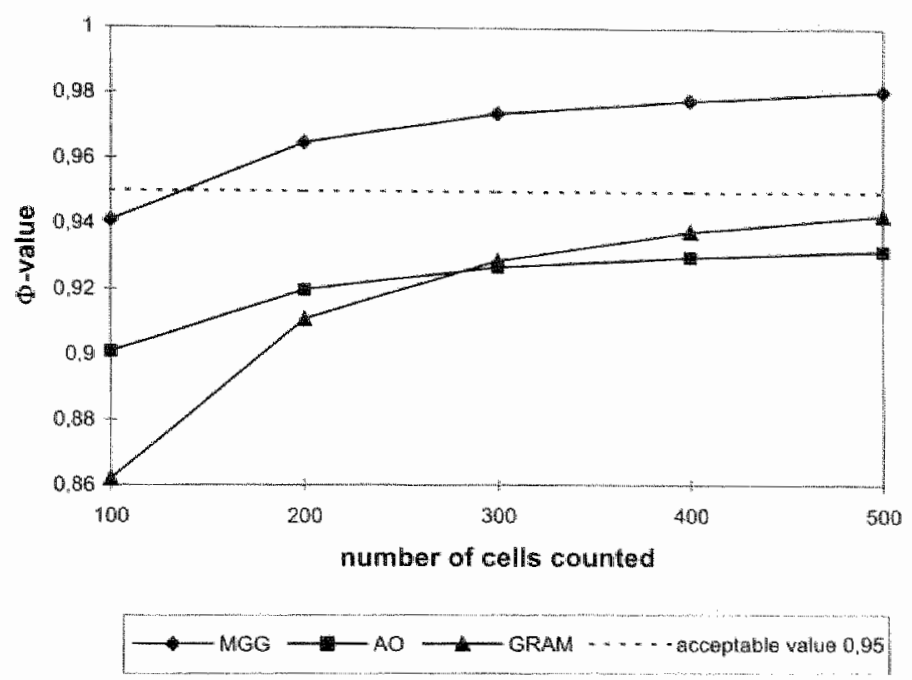

Figure 1A. $\Phi$-values ( $X$-axis) in relation to the no. of cells counted (X-axis) by one observer, as calculated in D-Analysis. Dotted line tepresents the acceptable 1 -value 0.95 . Symbols: = Acridine Orange stain; $\mathbf{A}=$ Gram stain; $=$ May -Grinwald-Giemsa stain.

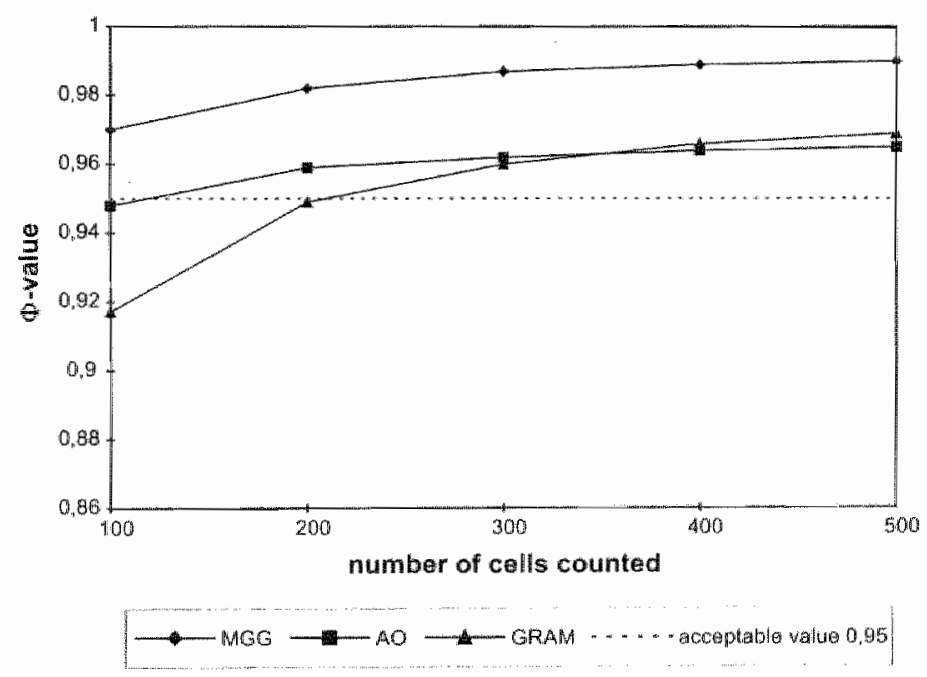

Figure 1B. $\Phi$-values (Y-axis) in relation to the no. of cells counted ( $X$-axis) by two observers, as calculated in D-Analysis. Dotted line represents the acceptable $\Phi$ value 0.95. Symbols: Acridine Orange stain; $\mathbf{A}=$ Gram stain; = May-Grünwald-Giemsa stain. 


\section{DISCUSSION}

The present study assesses the test characteristics (reproducibility and interobserver agreement) of the $A O$ stain, the Gram stain and the MGG stain for the detection of ICO in BAL fluid samples, and establishes the number of cells to be counted for reliable enumeration of $\mathrm{ICO}$. In order to minimise any variation in $1 C O$ recovery due to the cytocentrifugation process, we carefully standardised the operating conditions of the Shandon Cytospin 3. In preliminary studies, we found that the speed of $650 \mathrm{rpm}$ (which equals a g-value of approximately $\times 40$ ) did result in both preserved cell morphology and an optimal recovery of micro-organisms. The study was done in consequence of the lack of consensus on a standardised method for evaluation of ICO in BAL fluid preparations. As can be read from table IV, studies that report on ICO in BAL fluid preparations vary considerably with respect to the stain used and the number of cells counted. $1,5,10,14,15,18,20$ In addition, in any of the studies $l$ isted more than one observer counted the $1 \mathrm{CO}$, and only a few studies mention the cytocentrifugation conditions used. $1,10,15,18$

In the present study, the excluded BAL fluid samples had a low volume. In line with this, others noted that in patients with interstitial lung disease, small BAL fluid volumes were assiociated with unsatisfactory cy tological characteristics. 21

To our knowledge, this study is the first to use the G-Theory for microbiological investigations. G-Theory has already been applied successfully in psychological and educational test research and in Rehabilitation Medicine. ${ }^{16}$ One of the advantages of the $G$-Theory is that important sources of variation (e.g. vartiations in number of observers and/or in number of cells) influencing the results of the investigation can be detected and accounted. However, no recommendations are available regarding the issue how much reproducibility and agreement are satisfactory. As we expected small differences between the three staining methods scored by two experienced observers, we opted for a $\Phi$-value of 0.95 as acceptable. Reproducibility in tems of $I C C_{R}$ differed slightly between the $A O$ stain and the MGG stain but was lower for the Gram stain. For the ICCA, a measure of interobserver agreement, the $\mathrm{MGG}$ stain had the highest value followed by the AO stain and the Gram stain. Factors explaining the tesults can be analysed from the last column of table I. The percentages mentioned in this column list the relative importance of sources of variation in counting $1 \mathrm{CO}$.

For the MGG stain the vast majority (94\%) of variations in counting resides between specimens themselves, and this represents the "natural" variation in numbers of ICO amongst the different study samples. Only one percent of all variance is due to the fact that observers differ in counting the specimens ( $5 O$ component), but there are no estimated differences in counting over each of the hundreds of cells (SC component). Because variations of the highest interaction (SCO component), which can be regarded as a residual error component of the design of this study, are also low ( $5 \%$ ), both ICC $\mathrm{R}$ and ICCA for the MGG stain turn out to be high. 


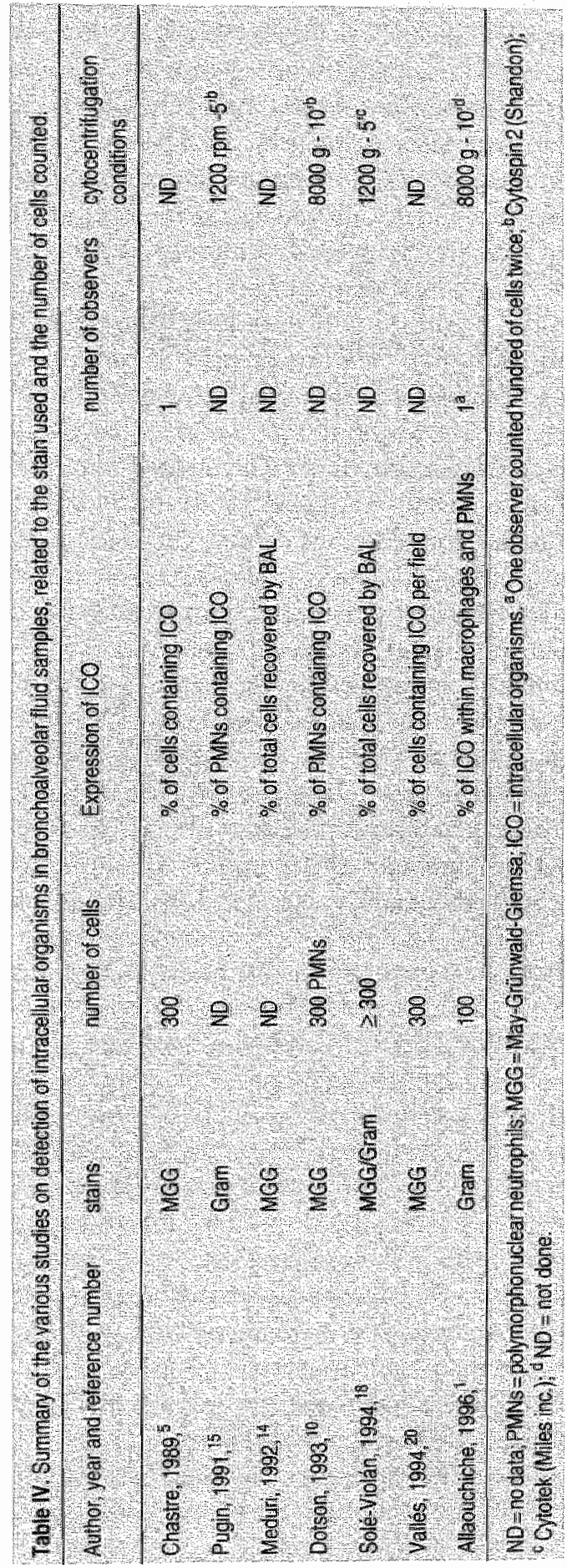


For the $\mathrm{AO}$ stain, differences in counting $\mathrm{ICO}$ between observers account for six percent of all variations, resulting in a lower interobserver agreement (ICC $\mathrm{A}=$ 0.924). The influence of antimicrobial agents on the bacteria may explain at least partially for the differences between the two observers. Bacteria on preparations of three BAL fluid samples appeared as faint, green silhouettes, which were consistently reported as $1 \mathrm{CO}$ by only one observer. Indeed, in retrospect, we found that the three patients under consideration were treated with antimicrobial agents at the time of lavage. We further studied this phenomenon and found that bacteria subjected to subinhibitory concentrations of antimicrobial agents reacted differently with the AO stain: some organisms fluoresced while others did not. If the values of these three specimens were subtracted from analysis, the $S O$ component decreased from six percent to four percent. In addition, on AO stained preparations, cell borders were not always clearly discernible, making distinction between ICO and extracellular organisms difficult. Moreover, Lauer et al. ${ }^{13}$ mentioned that granules from disintegrating leukocytes may be mistaken as cocci.

For the Gram stain, differences in counting ICO between both observers and counting over any number of hundreds of cells form a relatively large part of the variations (three percent and two percent for 50 and $5 \mathrm{C}$ components respectively). Moreover, there is an important SCO component, including residual error of nine percent. These factors are responsible for the relatively low $I C C_{R}$ and ICC $A$ of the Gram stain. The result may be explained by the presence of background (red blood cells and intercellular debris) that intertered with the recognition of micro-organisms. Indeed, the BAL fluid samples with the highest differences in ICO between both observers showed larger amounts of red blood cells and intercellular debris as compared to those specimens with low differences in $\mathrm{ICO}$.

The overall $\$$-coefficient, which combines characteristics of the ICCR and ICCA was studied in a Decision Analysis. From figure $1 \mathrm{~A}$ can be seen that both MGGand Gram stains reach the acceptable $0.95 \Phi$-value when at single observer counts the ICO. As the $\$$-value of the MGG is already reached at a count of 200 cells, this stain appears to be superior for enumeration of ICO in BAL fluid samples. The Gram stain reaches this value only by one obserwer counting 700 cells, while the AO stain (due to its lower ICC ) unavoidably needs two observers counting 200 cells each to reach this p-value (figure 1 B). Additional advantages of the MGG stain over the two other stains include the preserved cell morphology and its ability to detect Pnewmocystis carini. ${ }^{2}$ Moreover, the differential cell count may aid in the recognition of non-infectious disease that may cause pulmonary infiltrates, such as pulmonary haemorrhage, drug-induced toxicity and malignancy. 11,14 On the other hand, the Gram stain findings with regard to bacterial morphology and Gram reaction offer the advantage of early formulation of a directed antimicrobial therapy before the culture results are available. ${ }^{7}$ Although the $\mathrm{AO}$ stain has been evaluated as a sensitive screening technique for difficult to 
read clinical specimens, the lower reliability of this stain does not support its routine use in the enumeration of ICO in BAL fluid samples. 1.3

In conclusion, this study shows that for enumeration of ICO in BAL fluid samples, the MGG stain displays a higher reliability than the Gram and $A O$ stains. With the MGG stain, a reliable enumeration of $1 C O$ can be achieved by one observer counting 200 cells.

\section{REFERENCES}

1. Allaouchiche B, Jaumain $H$, Dumontet $C$, Motin I. Early diagnosis of ventilator-associated pneumonia. Chest 1996;10:1558-1565.

2. Baselski VS, Wunderink RG. Bronchoscopic diagnosis of pneumonia. Clin Microbiol Rev $1994 ; 7: 533-558$.

3. Bonten MJ, Froon AH, Gallard CA, Greve JWM, Leeuw de PW, Drent M, tr all. The systemic inflammatory response in the development of ventilator-associated pneumonia. Am J Respir Crit Care Med 1997; 156:1105-1113.

4. Capron F, Perrot J, Szekeres G, Caulet S. Technique du liquide de lavage broncho-alvéolaire dans un laboratoire central d'anatomie et cytologie parhologiques. Ann Pathol $1990 ; 10: 278-281$

5. Chastre J, Fagon J-Y, Soler P, Domart $Y$, Pierre J, Dombret $\mathrm{MC}$, et al. Quantificarion of BAL cells containing intracelltar bacteria rapidly identifies ventilated patient with nosocomial pneumonia. Chest 1989;95:190-192.

6. Chastre J, Fagon J-Y, Paul S, Marilyn B, Yves D, Trouillet J-L, et al. Diagnosis of nosocomial bacterial pneumonia in incubated patients undergoing ventilation: comparison of the usefulness of bronchaalveolar lavage and the protected specimen bush. Am J Med $1988 ; 85: 499-506$

7. Chastre J, Fagon J-Y. Invasive diagnosing testing should be routinely used to manage ventilated patients suspected of pneumonia. Am J Resp Crit Care Med. 1994:150:570-574.

8. Crick GE, Brennan RL. 1982. In:GENOVA: A generalised analysis of variance system. (Fortran IV computer program and manual), Dorchester, MA, University of Massachusetrs and Bostor, Computer Facilities.

9. Dacie JV, Lewis SM. 1984. Preparations and staining method for blood and bonemarrow films. p. 50-56. Im:Practical Haematology, Sixthed., Edinburgh, London, Melboume, New York, Churchill Livingstone.

10. Dorson RG, Pingleton SK. The effect of antibiotic therapy on recovery of intracellulat bacteria from bronchoalve olar lavage in suspected ventilator-associated nosocomial pneamonia. Chest $1993 ; 103: 541-546$.

11. Drent M, Peters FP, Jacobs JA, Maassen-Brink wan de Kl, Wagenaar SjSc, Wouters EFM. Puhonary infittration associated with myelodysplasia. Ann Oncol 1997;8:905-909.

12. Kruczak-Filipov $P$, Shively RG. 1992. Gram stain procedure, p. 1.5.1-1.5.18. 1\%: H.5., Isenberg, Clinical Microbiology Procedures Handbook, vol. 1. American Society for Microbiology, Washington, D.C. 
13. Lauer AB, Reller LB, Mirrett S. Comparison of Acridine Orange and Gram stains for detection of micro-organisms in cerebrospinal fluid and other clinical specimens. $J$ Clin Microbiol 1.981; 1.4:201-205.

14. Meduri GU, Wunderink RG, Leeper KV, Beals DH. Management of bacterial pneumonia in ventilated patients. Chest 1992;101:500-508.

15. Pugin J, Auckenthaler R, Mili N, Jarssens J-P, Lew PD, Suter PM. Diagnosis of ventilatorassociated pneumonia by bacteriologic analysis of bronchoscopic and non-bronchoscopic "blind" bronchoalveolar lavage fluid. Am Rev Respir Dis 1991;143:1121-1129.

16. Roebroech ME, Harlaar J, Lankhorst GJ. The application of generalizability the ory to reliw ability assessment: an illustration using isometric force measurement. Phys Ther $1993 ; 73: 386-401$.

17. Shavelson RJ, Webb NM. 1991. In: Generalizability Theory, a primer, vol. 1 of measurement methods for the social sciences series. Sage Publications.

18. Solé-Violán J, Rodriguez de Castro F, Rey A, Martin-Gonzalez JC, Carera-Navarro $\mathbb{P}$. Usefulness of microscopic examination of intercellular organisms in lavage fluid in ventilator-associated pneumonia. Chest 1994;106:889-894.

19. Streiner DL, Norman GR. 1995. In: Health Measurement Scales, a practical guide to their development and use, $2^{\text {nd }}$. ed. Oxford University Press.

20. Vallés J, Rello J, Fermandez R, Blanch L, Biagorri F, Mestre J, ev al. Role of bronchoalweolar lavage in mechanically ventilated patients with suspected pneumonia. Eur J Clin Microbiol Infect Dis $1994 ; 13: 549-558$.

21. Walters E, Gardiner P. Bronchoalweolar lavage as research tool. Thorax 1991;46:613-618. 
CHAPTER 6

Correlation of leukocyte esterase detection by reagent strips and the presence of neutrophils: a study in bronchoalveolar lavage fluid

\author{
Jan Jacobs \\ Els De Brauwer \\ Lisette Cornelissen \\ Marjolein Drent
}




\section{ABSTRACT}

Objective: In the present study, we evaluated the leukocyte esterase (LE) area of a reagent strip designed for urinalysis (Multistix 7, Bayer Cooperation) for the semi-quantitative measurement of the percentage of polymorphonuclear neutrophils (PMNs) in bronchoalveolar lavage (BAL) fluid.

Stusdy design: Prospective; the relative PMN counts (obtained by conwentional microscopy and expressed as a percentage of a 500 cell count) of consecutive BAL fluid samples were compared with the corresponding LE categories as read with the Clinitek 50 reader (Bayer Cooperation). LE categories were graded als "negarive", "trace", " $+"$ " "++ " and " +++ ".

Results: A total of 153 BAL fluid samples were included. The mean PMN counts of the "negative LE category $\langle 4.1 \% \pm 4.3, n=43$, and the " +++ "category $(81.8 \% \pm 16.3 \%, \mathrm{n}=37)$ differed significandly from each other and from the mean PMN counts of the other categories. Within the "trace", "*" and " $++*$ " Categories, a considerable overlap of PMN counts was noted. Assignment of a BAL fluid to the "negative" LE category consistently predicted a PMN count below $20 \%$. At a threshold walue of $50 \%$ PMNs, the " +++ LE category predicted the BAL fuid samples to the correct group (PMNs above versus below $50 \%$ with a sensitivity of $70.8 \%$ and a specificiry of $97.1 \%$.

Conclusion: The Multistix 7 reagent strips proved to be useful as a rapid test for semi-quantiattive measurement of the relative PMN counts in BAL fluid. However, the low predictive value for the exchusion of a high PMN count may limit their application. 


\section{INTRODUCTION}

The examination of bronchoalveolar lavage (BAL) fluid is rourinely used in the diagnosis of ventilator-associated pneumonia (VAP) and in the assessment of interstitial lung diseases. Important diagnostic information on these conditions may be obtained from the BAL fluid differential cell count. ${ }^{1-3}$ In particular, the number of polymorphonuclear neutrophils (PMNs) is of interest. For example, the BAL fluid PMN number may distinguish between sarcoidosis parients who demonstrate remission and those having a more severe course of the disease, and it has been demonstrated that a BAL fluid PMN number of $<50 \%$ has a $100 \%$ negative predictive value for histologic pneumonia. ${ }^{4.5}$ However, the widespread clinical application of BAL fluid cytology is limited by the fact that this procedure is expensive and time-consuming, and relies upon specialised technicians. ${ }^{6}$ Furthermore, in most hospitals, facilities for BAL fluid cytology are not a vailable on a 24 hour basis.

Consequently, we were interested in evaluating a simpler, shorter method of quantification of PMNs that would be available to most clinical laboratories. Therefore, we evaluated a commercially available reagent strip (Multistix 7, Bayer Cooperation, Diagnostics Division, Elkhart, IN, USA) for its ability to detect and measure PMNs in BAL fluid samples. The Multistix 7 reagent strip has originally been designed for semi-quantitation of PMNs in urine by an area for detecting leukocyte esterase (LE) enzyme activity.

The aim of this study was to compare the semi-quantative LE categories generated by this reagent strip with their corresponding microscopic PMN counts.

\section{MATERIALS AND METHODS}

\section{Study population}

During a 16-month period (April 1998 - August 1999), BAL fluid samples obtained from patients in the Universiry Hospital Maastricht were collected. The patients included were suspected of having pneumonia or were suffering from different interstitial lung diseases including sarcoidosis, extrinsic allergic alveolitis and idiopathic pulmonary fibrosis.

\section{Sampling technique}

A fiberoptic bronchoscope (Pentax FB-15H/FB-15X, Pentax Medicals, Tokyo, Japan) was introduced through a special adaptor (Swivel connector, Gibeck Respiration, Upplands Väsby, Sweden) and "wedged" into the affected segmental or subsegmental bronchus. The fluid was instilled into the subsegment through 
the biopsy channel of the bronchoscope in four aliquors of $50 \mathrm{ml}$ sterile saline $10.9 \% \mathrm{NaCl}$, room temperature) and immediately aspirated and recovered. The BAL fluid samples were transported to the laboratory within 15 minutes after collection and analysed within 1 hour upon arrival in the laboratory.

\section{Cytological processing of bronchoalveolar lavage fluid specimens}

The wolume of the recovered BAL fluid and its macroscopic appearance were recordled. The first fraction, representing the bronchial fraction, was separated for mycobacterial culture and the remaining fractions were pooled in conical $50 \mathrm{ml}$ non-adhesive polypropylene tubes (Greiner, Product No. 227.261, Alphen aan de Rijn, The Netherlands). The total cell count was performed in a Fuchs Rosenthal hemocytometer chamber. All nucleated cells were counted, and the average value of two successive counts was considered. Cytocentrifugation was done with the Cytospin 3 apparatus (Shandon Scientific Ltd, Astmoor, England) as previously described. ${ }^{7}$ The slides were allowed to air dry, stained with the May-GrünwaldGiemsa dyes, and subsequently sealed with a cover glass by means of a xylene-free mountant (Histomount, Shandon). Differential cell counts were made by examining 500 nucleated cells excluding squamous and bronchial epithelial cells. Cells were counted in a circular pattern around the centre of the cytocentrifuge spot and the differential cell counts including the PMNs were expressed as a percentage of a 500 cell aliquot. ${ }^{8}$

\section{Rejection criteria}

BAL fluid samples were excluded if the recovery was less than $20 \mathrm{ml}$ or if the total cell count was less than $60.000 / \mathrm{ml}$, and if the cytocentrifuged preparations showed excessive amounts of red blood cells, intercellular debris, or damaged cells precluding adequate recognition of different cell types. ${ }^{7,9}$

\section{Reagent strips}

Multistix 7 reagent strips were used for semi-quantitative assessment of the BAL fluid LE activity. Multistix 7 is a seven patch test reagent strip that has been designed to test urine for glucose, ketones, blood, $\mathrm{pH}$, protein, nitrite and leukocytes. The reagent strips were read instrumentally, using the Clinitek 50 Urine Chemistry Analyzer (Bayer Corporation). The performance of the reagent strips was checked against the Chek-stix positive and negative controls (Bayer Corporation) at any time a new package was begun. The procedures were performed as described in the package insert and in the Clinitek 50 operating manual.

Reagent strips were removed from the bottle just immediately before they were used for testing. They were dipped directly and briefly into well-mixed pooled BAL fluid samples. If the BAL fluid specimen depth in the conical tubes was 
less than $5 \mathrm{~cm}$, the specimen was poured into a $10 \mathrm{ml}$ tube. While removing the strips, the edge of the reagent strip was dragged against the rim of the BAL flud container to remove excess fluid. At that time, the "Start" key of the Clinitek 50 reader was pressed. Within the provided $5-10$ seconds delay, the reagent strip was blotted by gently touching the edge to a paper towel. Subsequently, the reagent strip was placed into the trough of the Clinitek 50 reader's test strip table and slid along the table until it touched the end of the trough. Readings were performed automatically and test results were printed by the Clintek 50 reader. The presence of PMNs was graded as "negative", "trace", "+ ", " ++ " and " $+++"$.

To compare the instrumental readings with visual readings, a number of reagent strips was also read against the standards provided on the bottle label, at two minutes after dipping, according to the Multistix 7 package insert.

Further, the effect of increasing reaction times for the reagent strips was studied on four BAL fluid specimens that were diluted with $0.9 \% \mathrm{NaCl}$ until they were read as "+" by the Clinitek 50 reader. Reagent strips were subsequently entered in the Clinitek 50 reader at increasing delays of 30,60 and 120 seconds after dipping.

\section{Statistical evaluation}

For the different LE categories, pairwise comparisons of the mean PMN counts were assessed for significance by the one-way ANOVA posthoc test for multiple comparisons, with Bonferroni's modification.

\section{RESULTS}

During the study period, $153 \mathrm{BAL}$ fluid samples obtained in 134 patients were included. Fourteen BAL fluids were excluded on the basis of insufficient recovered volume or a low total cell count, and 22 samples were excluded because of poor microscopic quality. Half (76/153) of the BAL fluid samples were obtained from patients at the intensive care unit and $57(37.2 \%)$ samples were obtained from patients at the department of pulmonology. The remaining $B A L$ fluid samples $(20 / 153,13.1 \%)$ were recovered from patients in the departments of internal medicine and surgery. Nearly one third $(48 / 153,31.4 \%)$ of the BAL flud samples displayed PMN counts exceeding $50 \%$.

In figure 1 , the semi-quantitative LE categories are plotted against the corresponding numbers of BAL fluid PMNs. As can be seen on this figure, a considerable overlap of individual PMN counts was noted between the LE categories "trace", "+" and "+*". The respective mean PMN counts of these categories did not differ significantly (mean PMN counts $20.2 \% \pm 22.8,27.1 \% \pm 21.5$ and $32.8 \% \pm 21.4$ respectively). However, the mean PMN count of the "negative" LE category $(4.1 \% \pm 4.3, n=43)$ differed significantly from the mean PMN counts of 


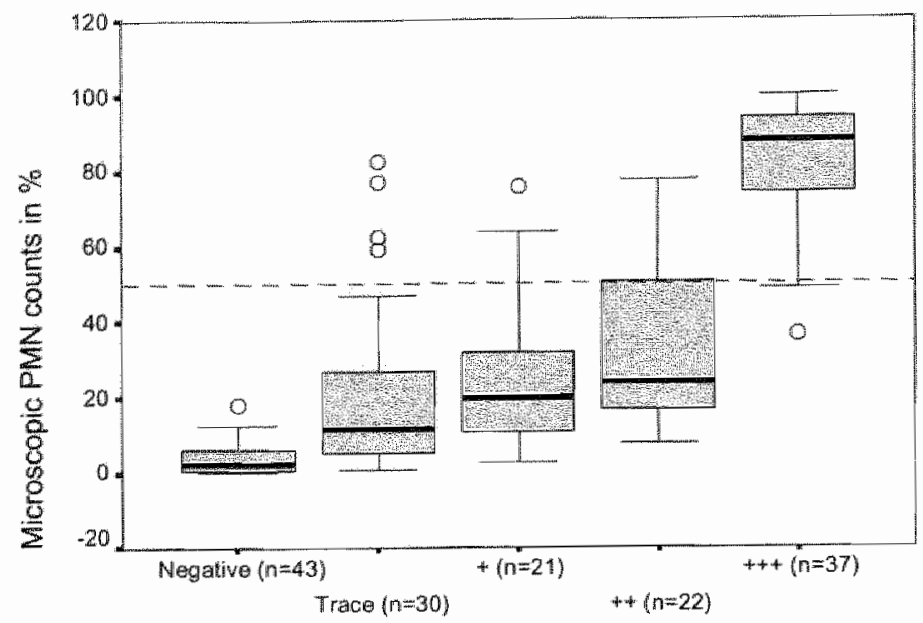

Multistix Leukocyte Esterase strip category

Figure 1. Box-plot graph representing the semi-quantitative leukocyte esterase categories generated by the reagent strips for the 153 bronchoalveolat lavage fluid samples, plotted against the percentages of polymorphonuclear neutrophils (PMNs) counted microscopically. The dorted line represents the $50 \%$ PMN count.

the "trace" category $(p=0.003)$ and the " ++ " and " +++ " categories $(p<0.001)$. Assignment of a BAL fluid to the "negative" LE category consistently predicted a PMN count of less than $20 \%$. Conversely, the mean PMN count of the " +++ " LE category $(81.8 \% \pm 16.3 \%, \mathrm{n}=37)$ largely exceeded the mean PMN counts of any other category $(p<0.001)$. At a threshold of $50 \%$ PMNs, the " +++ " LE category predicted the BAL fluid samples to the correct group (PMNs above versus below $50 \%$ ) with a sensitivity of $70.8 \%$ and a specificity of $97.1 \%$. Given the prevalence of $31.4 \%$ for a PMN count $>50 \%$ in the present study, the "+++" LE category had a positive predictive value of $91.9 \%$ and a negative predictive value of $87.9 \%$.

With respect to the $50 \%$ PMN count, 17 out of 153 LE categories were inconsistent with the microscopic findings. Three BAL fluid samples assigned to the "+++" LE category but showed PMN counts $<50 \%$, resulting in a $2.9 \%$ false-positive ratio. In two of these BAL fluids, borderline PMN counts were noted $(48.0 \%$ and $49.2 \%$ respectively), for the remaining BAL fluid (with a PMN count of $36.2 \%$ ) no explanation for this false-positive event was found. Another $14 \mathrm{BAL}$ fluid specimens showed PMN counts $>50 \%$ but were assigned to LE categories " $++"(n=6), "+"(n=4)$ and "trace" $(n=4)$. A part from three BAL fluid samples (in the "++" category) with a borderline PMN count, four BAL fluid samples with an elevated protein level ( $>300 \mathrm{mg} / \mathrm{L}$ ) were noted. For the remaining seven BAL fluid samples, no cause for the false-negative result was found. 
The LE categories that were visually read on 40 BAL fluid samples corresponded well with those generated by the Clinitek 50 reader, except for an occasional discrepancy in the "trace" or the "+ categories. By contrast, accurate timing proved to be critical for obtaining reliable results, as the readings of the BAL fluid samples shifted from the LE " + category to the "+++" category when the delay of entering the reagent strip into the Clinitek 50 reader reached 120 seconds. Likewise, visual readings at less or longer than two minutes after dipping caused false results into a too low or a too high LE category respectively.

\section{DISCUSSION}

Urine reagent strips have been used for semi-quantitation of PMNs in other body fluids with varying results. ${ }^{10-13}$ To our knowledge, they have not been evaluated in BAL fluid samples before. The present prospective study demonstrated that the Multistix 7 reagent strip provided a rapid method for the prediction of low (< $20 \%$ ) and high (>50\%) PMN counts in BAL fluid samples, by the "negative" and the "+++" LE categories respectively.

One might argue that the present study population was heterogenous, comprising BAL fluid samples obtained from ventilated patients as well as from patients that were immunosuppressed or suffering from interstitial lung diseases. However, the aim of this study was the validation of the Multistix 7 reagent strip as a prediction for the BAL fluid PMN count, irrespective of the conditions affecting these counts. Elevations of the BAL fluid PMN count may occur in several clinical conditions, and the relative numbers of PMNs are associated with disease severity in disorders such as Pneumocystis carinii pneumonia, sarcoidosis, the Adult Respiratory Distress Syndrome (ARDS) and VAP. 4,6,14,15 In diagnostic practice, rapid estimation of the BAL fluid PMN count will be of most diagnostic gain in the intensive care setting, i.e. when VAP and ARDS are suspected. BAL fluid specimens obtained in this setting are generally processed in the microbiological laboratory, where cytological expertise is not always available. Furthermore, in cases of VAP and ARDS, high BAL fluid PMN counts are to be expected and the need for prompt administration of antibiotics in case of VAP calls for a rapid test. ${ }^{15-17}$ In addition, in our experience, up to $40 \%$ of BAL fluid specimens sampled in the intensive care unit arrive at the laboratory during weekends or off-hours. For these reasons, a rapid and reliable screening test for the prediction or the exclusion of high BAL fluid PMN counts is mandatory.

For a screening test to be adopted in the diagnostic laboratory, both a high sensitivity and a high specificity are required. ${ }^{18}$ Considering the LE " +++ " category in its ability to predict a $>50 \%$ PMN count, it is clear that the Multistix 7 reagent strip only fulfils the specificity criterion. This will be of particular importance when the reagent strip will be used in a setting with a high prevalence of elevated BAL fluid PMNs, such as in the intensive care unit. In that case, the posi- 
tive predictive value, or the chance that a BAL fluid assigned to the " +++ " LE category actually will display a $>50 \%$ PMN count, will increase. However, the negative predictive value, or the chance that a BAL fluid assigned to one of the other categories (except the "negative" category) actually has PMN counts $<50 \%$ will decrease. By consequence, the low predictive value in the exclusion of high PMN counts will be the limiting factor of the reagent strips in this circumstance.

Given the concern on the moderate sensitivity, we looked for explanations for the false-negative events with respect to the 50\% PMN threshold. For urinary samples, factors that may contribute to false-negative results include high protein levels, and, according to the Multistix 7 package insert, elevated glucose concentrations, the presence of cephalosporins or tetracyclines in high concentrations, and the presence of coloured substances such as nitrofurantoin. ${ }^{10}$ In the present study, elevated protein levels were found in three out of four false-negative specimens of the "trace" category, but they were equally observed among the correctly predicted samples. Although we presently did not score the use of antibiotics prior to bronchoscopy, we do not expect these agents to be responsible for false-negative readings, as BAL fluid generally represents a 1:10 to 1:100 dilution of the alveolar epithelial lining fluid. ${ }^{19}$ Furthermore, no readings that were obscured by heavily blood stained specimens were presently found, and we repeatedly observed that high eosinophil counts $(>40 \%)$ did not interfere with the reagent strip readings. For increase of the sensitivity of the Multistix 7 reagent strip in the prediction of high PMN counts, further investigation on the possible causes of false-negative readings is required. In addition, we suggest further technical developments of the LE reagent strip area to include an extension of the reading scale, in an attempt to differentiate and grade the PMN counts of the "trace", the "+" and the "++" categories.

In the present study, we did not intend to evaluate the other reagent areas of the Multistix 7 reagent strip. In retrospect, most of these tests proved either not to be reliable nor clinically useful, except for the $\mathrm{pH}$ and the protein tests. The nitrite test, which points to the presence of Gram-negative bacteria, may not be used in this setting because dietary nitrate is not present in BAL fluid specimens. For purposes of the present study, the reagent strip could be simplified to the area of interest. One might equally consider the addition of areas for estimation of the other BAL fluid cell populations, e.g. an area detecting non-specific esterase enzyme activity, which in BAL fluid is confined to the alveolar macrophage population. ${ }^{20}$

We further found the Multistix 7 reagent strips convenient to use. The readings were easy to perform, although accurate timing proved to be essential for obtaining reliable results. Visual readings that were consistent with the instrumental readings and a long package shelf-life made the occasional use of the strips easier. The Clinitek 50 reader was a reliable a pparatus that required little maintenance and that was easy to calibrate. 
In conclusion, the Multistix 7 reagent strip designed for urinalysis may be used as a rapid test for semi-quantitative esrimation of the relative PMN count in BAL. fluid samples, in those conditions where facilities for cytological examination are not available. The LE categories generated by the reagent strip may distinguish BAL fluid samples displlaying elevated (>50\%) PMN count with a high specificity but at the cost of a low sensitivity. Further study on the false-negative events and refinements of the reading scale are desired for optimal use of this reagent strip in the present setting.

\section{REFERENCES}

1. Drent M, Nierop van MAMF, Gerritsen FA, Wouters EFM, Mulder PGH. Computer program using BALF analysis results as a diagnostic tool in interstitial hung diseases. Am ] Respir Crit Care Med 1996;153:736-741.

2. Allaouchiche B, Jaumain $H$, Dumontet $C$, Motin J. Early diagnosis of ventilator-associated pneumonia. Is it possible to define a cutoff value of infected cells in BAL fluid? Chest $1996 ; 110: 1158-1165$.

3. Jacobs JA, De Brauwer EIGB, Ramsay G, Cobben NAM, Wagenaar SiSc, Ven van den AJJ, et al. Detection of non-infectious conditions mimicking pneumonia in the intensive care setring: usefulness of BAL fluid cytology. Respir Med 1999;93:571-578.

4. Drent M, Jacobs JA, Vries de J, Lamers RJS, Liem, IH, Wouters EFM. Does the cellular bronchoalveolar lavage fluid profile reflect the severity of sarcoidosis? Eur Respir I $1999 ; 13: 1338-344$.

5. Kirtand SH, Corley DE., Winterbaner RH, Springmeyer SC, Casey KR, Hampson NB, et al. The diagnosis of ventilator-associated pneamonia. A comparison of histologic, microbiologic, and clinical criteria. Chest 1997;112:445 457 .

6. Meduri G, Reddy R, Stanley T, El Zeky F. Pneumonia in acute respiratory distress syndrome. Am J Respir Crir Care Med 1998;158:870-875.

7. Jacobs $1 \mathrm{~A}$, De Brauwer ElGB. Applicarions of BAL fluid cyrology for the assessment of infectious lung disease. Hosp Med 1999;60:550-556.

8. De Brawwer EIGB, Drent M, Mulder PGH, Bruggeman CA, Wagenaar SjSc, Jacolss JA. Differential cell analysis of cytocentrifuged BAL Ihid samples affected by thearea counted. Anal Quant Cytol Histol; in press.

9. Timsit JF, Misset B, Goldstein IFW, Vaury P, Carlet J. Reappraisal of distal diagnositic testing in the diagnosis of ICU-acguired pneumonia. Chest $1995 ; 108: 1632-1639$.

10. Smalley DL, Doyle VR, Duck worth JK. Correlation of leukocyte esterase detection and the presence of leukocytes in body fluids. Am, Med Technol 1982:48:135-137.

11. Moosa AA, Quortum HA, Ibrahim MD. Rapid diagnosis of meningitis with reagent strips. Lancet 1995;345:1290-1291.

12. Molyneux $E$, Walsh $A$. Caution in the use of reagent strips to diagnose acute bacterial meningitis. Lancer 1996;348:1170.1171. 
13. Bonev V, Gledhill RF. Use of reagent strips to diagnose bacterial meningitis. Lancet $1997 ; 349: 287-288$.

14. Azoulay E, Partot A, Flahault A, Cesari D, Lecomte I, Roux P, et al. AIDS-related Pnewwocystis carinit pneumonia in the era of adjuncrive steroids. Am J Respir Crit Care Med 1999:160:493-499.

15. Weiland JE, Davies WB, Holter JF, Mohammed JR, Dorinsky PM, Gadek JE. Lung neutrophils in the adult respiratory distress syndrome. Clinical and pathophysiologic significance. Am Rev Respir Dis 1986;133:218-225.

16. Cobben NAM, Jacobs JA, Diejjen-Visser van MP, Mulder PGH, Wouters EFM, Drent $M$. Diagnostic value of bronchoalveolar lavage fluid cellular profile and enzymes in infectious pulmonary disorders. Eur Respir J 1999;14:496-502.

17. Luna CM, Vujacich P, Niederman MS, Vay C, Gherardi C, Matera Js et al. Impact of BAL data on the therapy and outcome of ventilator-associated pneumonia. Chest 1997;11: 676-685.

18. Sacker DL, Haynes $R B$, Tugwell $\mathbb{P}$. Clinical epidemiology. A basic science for clinical medicine. Boston/Toronto: Little Brown and Company, 1985,307-309.

19. Baselski VS, Wunderink RG. Bronchoscopic diagnosis of pneumonia. Clin Microbiol Rev 1994;7:533-558.

20. Baughman R, Strohofer S, Kim K. Variation of differential cell counts of bronchoalveolar lavage fuid. Arch Pathol Lab Med 1986;110:341-343. 
CHAPTER 7

\title{
Detection of non-infectious conditions mimicking pneumonia in the intensive care setting: usefulness of bronchoalveolar lavage fluid cytology
}

\author{
Jan Jacobs \\ Els De Brauwer \\ Graham Ramsay \\ Nicole Cobben \\ Sjoerd Wagenaar \\ André van der Ven \\ Cathrien Bruggeman \\ Marjolein Drent
}




\begin{abstract}
Objective: The present study inwestigated the usefulness of BAL fluid cytology in the identification of non-infectious pumonary conditions in patients hospitalised in the intensive care unit (ICU) and suspected of pneumonia.

Study design: A total of 182 BAL. fluid samples obtained during a 27-month period from $130 \mathrm{ICU}$ patients with suspected pneumonia were quantitatively cultured and investigated for opportunistic parhogens. Cytocentrifuged preparations stained with the May-Grünwald-Giemsa and Perls' methods were reviewed. A non-infectious aetiology was considered when cultures yielded micro-organisms in quantities $<10^{3}$ colony forming units per $\mathrm{ml}$, in the absence of any other parhogen, and in conjunction with one or more of the following cytological findings: $>20 \%$ haemosiderin macrophages, $>10 \%$ lymphocytes, the presence of activated lymphocytes, plasma cells, > $5 \%$ eosinophils, a preponderance of foamy macrophages, reactive type II pneumocytes or malignant cells. Patients" clinical records were reviewed to identify a clinical diagnosis for these episodes.

Results: Thirty-five $(19.2 \%)$ BAL. fluid samples from 26 parients were considered as of non-infectious origin. An alternative diagnosis was ascertained in 20 of 26 parients. Diagnoses included drug-induced pnetmonitis $(n=7)$, aspitation of gastric contents $(n=2)$, pulmonary emboli ( $\mathrm{n}$ $=3), \operatorname{ARDS}(\mathrm{n}=4)$, lung contusion $(\mathrm{n}=1)$, cardiogenic pulmonary oedema $(\mathrm{n}=$ 1), and carcinomatous lymphangitis $(n=2)$.

Conchusion: The BAL fluid cytological findings were readily discernible and proved to be useful in the diagnostic work-up of samples obtained from ICU patients with suspected pnetmonia.
\end{abstract}




\section{INTRODUCTION}

Pneumonia is common in patients in intensive care units (ICUs), especially in mechanically ventilated patients. Establishing the diagnosis of pneumonia in these patients is notoriously difficult as clinical and radiological parameters offer a high sensitivity at the cost of an unacceptably low specificity. ${ }^{1}$ Adding the results of quantitative cultures of bronchoalveolar lavage (BAL) fluid increases the diagnostic specificity but preliminary and definitive culture results take 24 hours and up to 72 hours, respectively. ${ }^{2}$

Apart from infectious pneumonia, a number of non-infectious pulmonary conditions may explain the clinical symptoms of the ICU patient with suspected pneumonia. Such conditions include pulmonary haemorrhage, malignancy, drug-induced toxicity, the Adult Respiratory Distress Syndrome (ARDS) and cardiogenic pulmonary oedema. It is important to distinguish these conditions from pneumonia as the management and prognosis of these entities is quite different. ${ }^{3,4}$ Distinctive findings in BAL fluid cy tology, such as lymphocytosis, the presence of activated lymphocytes, plasma cells and eosinophils or the preponderance of foamy macrophages point to drug-induced pulmonary disease, and the presence of reactive type II pneumocytes has been described in association with ARDS. ${ }^{5-7}$ BAL fluid cytological findings in ARDS are characterised by a marked predominance of neutrophils in the early phase and a recruitment of macrophages, lymphocytes and eosinophils in the late phase. ${ }^{8}$ A number of $>20 \%$ haemosiderin macrophages thas been demonstrated to be indicative for alveolar haemorrhage. ${ }^{9}$ Until now, however, the usefulness of BAL fluid cytology in the diagnosis of these non-infectious pulmonary conditions in ICU patients has received little attention in the literature. In daily practice, the use of BAL fluid cytology is limited to the enumeration of infected cells and to the identification of squamous epithelial cells which are indicative of oropharyngeal contamination. 10,11

In our hospital, bronchoscopy with BAL is routinely used in the diagnosis of pneumonia in the ICU setting. ${ }^{2}$ Recently, we introduced a standardised protocol for the cytocentrifugation process and included the differential cell count as part of the routine microbiological work-up of BAL fluid specimens. As we collected a series of consecutive BAL fluid samples performed in ICU patients with suspected pneumonia, we decided to evaluate the usefulness of BAL fluid cytology in the prediction of non-infectious pulmonary conditions. We therefore retrospecrively looked for the diagnosis in those BAL fluid samples that showed cytological findings consistent with a non-infectious condition. 
MATERIALS AND METHODS

\section{Study population}

Over a 27-month periad (January 1996 to April 1998), BAL fluid samples from ICU parients in the University Hospital Maastricht were obtained. All patients were suspected of having pneumonia as defined by clinical and radiological criteria. $^{2}$

\section{Sampling technique}

A fiberoptic bronchoscope (Pentax FB 15H/FB-15X, Pentax Medicals, Tokyo, Japan) was introduced through a special adaptor (Swivel connector, Gibeck Respiration, Upplands Väsby, Sweden) and "wedged" into the affected segmental or subsegmental bronchus. The fluid was instilled into the subsegment through the biopsy channel of the bronchoscope in four aliquots of $50 \mathrm{ml}$ sterile saline $(0.9 \% \mathrm{NaCl}$, room temperature) and immediately aspirated and recovered. The BAL fluid samples were transported to the laboratory within 15 minutes of collection and analysed within 1 hour of arrival in the laboratory.

\section{Processing of BAL fluid specimens}

The volume of the recovered BAL fluid was recorded. The first fraction, representing the bronchial fraction, was separated for mycobacterial culture and the remaining fractions were pooled for further analyses. The total cell count was performed in a Fuchs Rosenthal hemocytometer chamber. BAL fluid samples were quantitatively cultured for bacteria and yeasts by means of a calibrated loop technique. ${ }^{12}$ They were also cultured for filamentous fungi and mycobacteria and, if clinically indicated, for viruses and Legionella spp. In addition, stains for detection of Preumocystis carinii and Legionella pneumophila (immunofluorescent monoclonal antibody stainings), filamentous fungi (Methenaminesilver stain) and acid-fast bacteria (auramine-rhodamine stain) were performed on cytocentrifuged preparations. When a community-acquired pneumonia was suspected, serology for detection of viral pathogens was done and polymerase chain reactions for detection of Chlanydia pneumoniae and Mycoplasma pnewmoniae were performed.

Gytocentrifugation was done with the Cytospin 3 apparatus (Shandon Scientific Ltd, Astmoor, U.K.) as previous described. ${ }^{13}$ Differential cell counts were made on May-Grïnwald-Giensa (MGG) stained preparations, by the first or second author examining 500 nucleated cells. Both macrophages and neutrophils were screened for the presence of intracellular organisms and the number of infected cells was expressed as a percentage of the 500 -cell aliquot counted. The preparations were sealed (Xylene substitute mountant, Shandon) and stored at 
room temperature. When basophilic granules were seen in macrophages or neutrophils, Perls" stain for haemosiderin visualisation was performed. 14

\section{Rejection criteria}

BAL fluid samples were excluded if the retriewed wolume was less than $20 \mathrm{ml}$, if the cytocentrifuged preparations showed excessive amounts of red blood cells, intercellular debris or damaged nucleated cells, or if the differential cell count yielded $1 \%$ squamous epithelial cells or $\geq 5 \%$ ciliated cells.

\section{Defintions}

BAL fluid samples were categorised into four groups based on the following diagnostic criteria.

Group I, pneumonia microbiologically confirmed: this group consisted of samples for which quantitative cultures yielded micro-organisms in quantities $z$ $10^{4}$ colony forming units per millimetre (cfu/ml), or for which obligatory respiratory pathogen such as $P$. carinit was demonstrated.

Group II, pneumonia not conclusive: BAL fluid samples were categorised as "not conclusive" when they had borderline quantitative cultures results, $i_{\text {. }}$. counts $\geq 10^{3} \mathrm{cfu} / \mathrm{ml}$ and $10^{4} \mathrm{cfu} / \mathrm{ml}$.

Group IIT, pneumonia excluded, no cytological abnormalities: infectious pneumonia was considered as microbiologically excluded at a culture threshold of $<10^{3} \mathrm{cfu} / \mathrm{ml}$ and $<2 \%$ infected cells, and with no obligatory respiratory pathogen demonstrated. On cytological examination of the BAL fluid, none of the findings cited for Group IV was observed.

Group IV pneumonia excluded, non-infectious aetiology: BAL fluid samples were considered as of "non-infectious aetiology" when pneumonia was microbiologically excluded (criteria as for Group III) in the absence of previous (within 72 hours) antimicrobial therapy, and when one or more of the following cytological findings were observed: the presence of malignant cells, a count of $>$ $10 \%$ lymphocytes, a count of $>5 \%$ eosinophils, the presence of activated lymphom cytes or plasma cells, and the preponderance of foamy macrophages. A number of $>20 \%$ haemosiderin laden macrophages was considered as diagnostic for alveolar haemor hage.

\section{Review of clinical records}

The patients' clinical records were reviewed for clinical radiological and laboratory evidence to identify diagnoses of non-infectious aetiology. 


\section{R VSULTS}

During the study period, 1721 patients were admitced to the ICU and 228 bronchoscopies with BAL. were performed (Figure 1). Forty-six BAL fluid samples were excluded from analysis, resulting in 182 BAL fluid samples obtained from 130 patients.

Seventy-seven BAL fluid samples were considered as microbiologically proved pneumonia and allocated to Group I. L. pnemmophila was identified as the pathogen in one BAL fluid sample, $P$. carmit in four BAL fluid samples (three patients), and a viral pneumonia was detected in three BAL fluid samples obtained in two patients (RSV and parainfluenza virus respectively). At a threshold of $10^{4}$ cfuml, infectious pneumonia was further confirmed in $69 \mathrm{BAL}$ fluid samples. Group II (pneumonia not conclusive) consisted of 23 BAL fluid samples were included in Group III (pneumonia microbiologically excluded, no cytological abnormalities).

Based on the exclusion of a microbiological pathogen and on the presence of one or more of the cytological findings, $35 \mathrm{BAL}$ fluid samples were assigned to Group IV ("non-infectious aetiology"). These 35 BAL fluid samples accounted for $19.2 \%$ of the 182 included BAL fluid samples and were obtained from 26 $(20 \%)$ of 130 patients ( 9 patients underwent repeat bronchoscopy with BAL).

Table I lists the non-infectious conditions identified by review of the clinical records in the 26 patients, and the differential cell counts together with the cytological findings in the corresponding BAL fluid samples.

The patients mean age was $62.8 \pm 1.4 .2$ years, and the male to female ratio 1.36:1. Half of the patients were admitted from the community, one patient was admitted from a nursing home and twelve patients were transferred from another hospital ward." 3

Bronchosicopy was performed after 11.2.13.9 days of $1 \mathrm{CU}$ admission (range 1. -57 days), with seven BAL. fluid samples obtained on the day of the patient's admission to the ICU. Twenty-six of 35 BAL fluid samples were obtained from ventilated patients, in 21 samples the parient was ventilated for more than $72 \mathrm{~h}$ prior to suspicion of pneumonia. For two BAL fluid samples, no data on ventilation were retrieved upon chant review.

Three patients demonstrated amiodarone pneumonitis, which was confirmed histologically in one case. Nortriptyline pulmonary toxicity was obserwed after an accidental overdose in a psychiatric patient. Carbamazepine induced pneumonitis occurred due to self-poisoning. Methotrexate-induced pneumonitis occurred in a partent treated because of rheumatoid arthritis. Mefloquine-induces pneumonitis was seen in a patient with hemizygote glucose-6-phosphate-dehydrogenase deficiency. Aspiration of gastric contents was documented in a patient during surgical treatment for achalasia and in another patient who aspirated enteral feeding during a prolonged ICU stay. Pulmonary emboli were found at autopsy in two patients and third patient developed multiple pulmonary emboli after surgical 


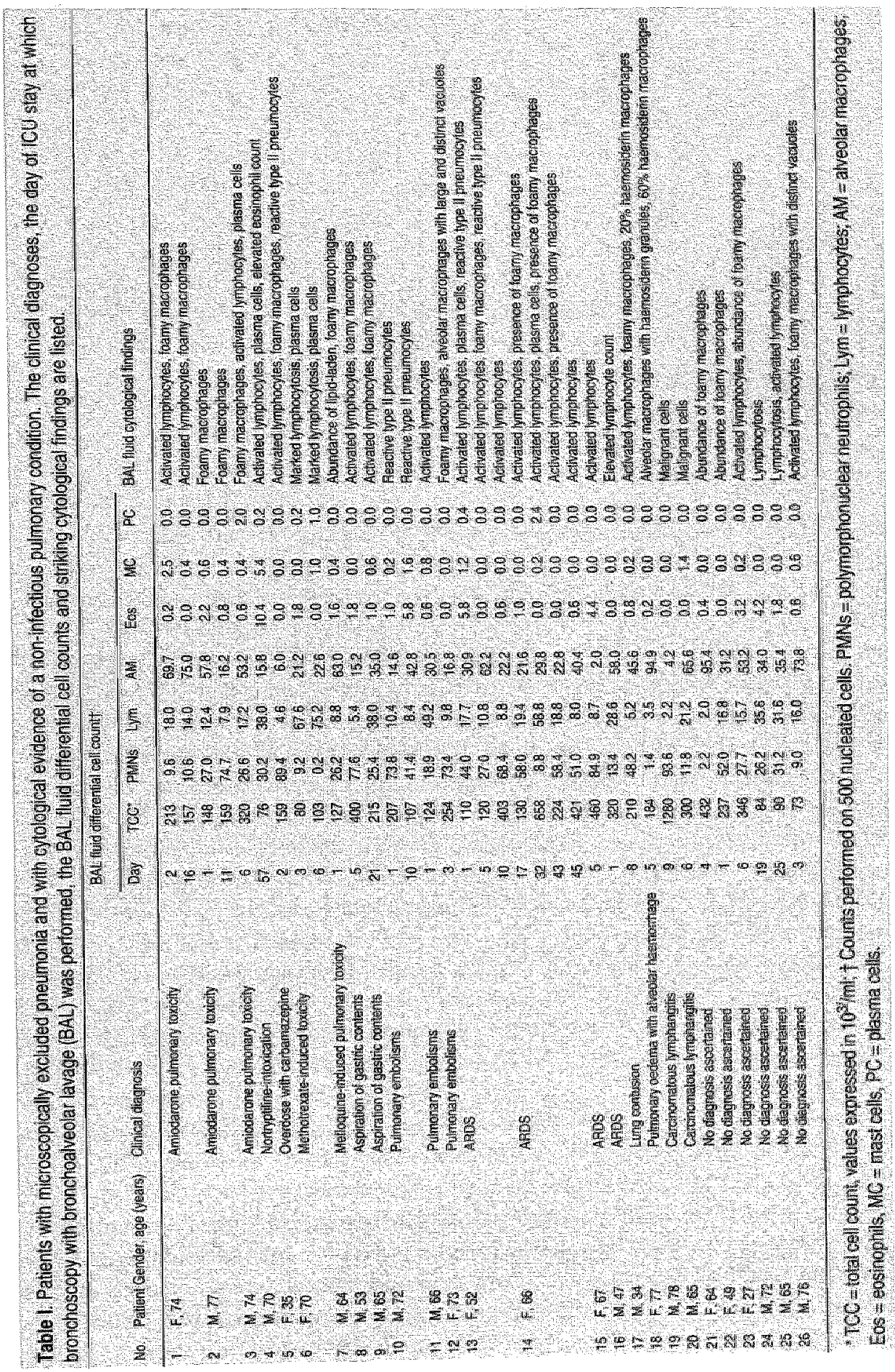



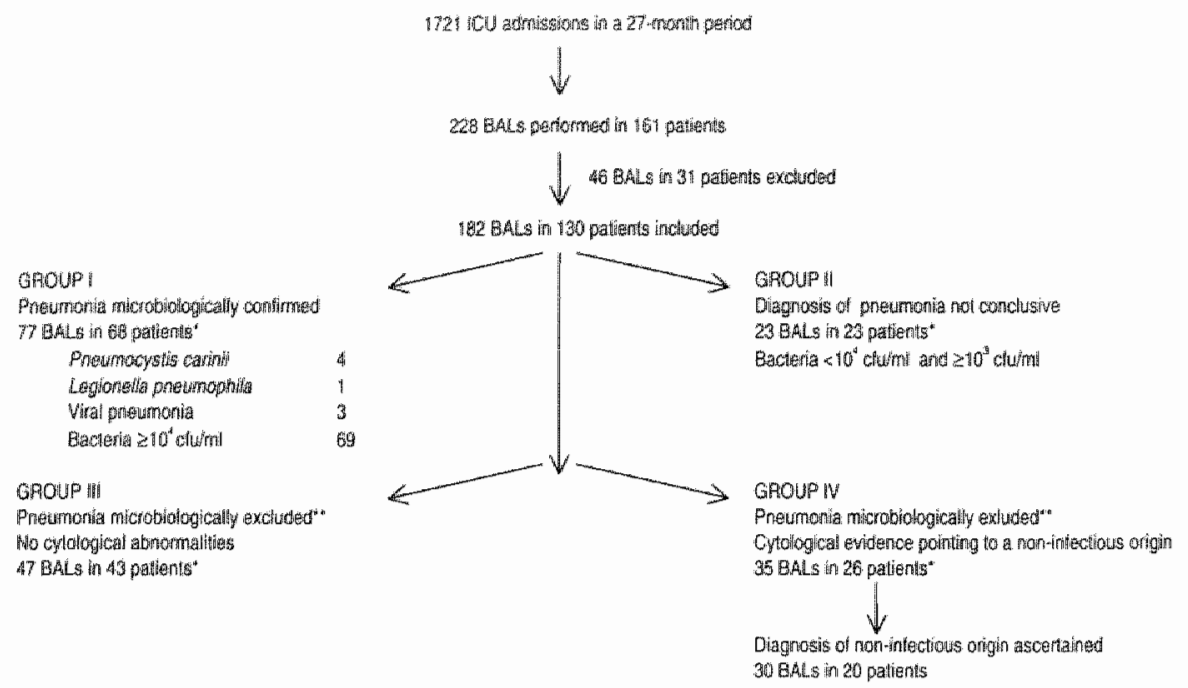

Figure 1. Flow chart of bronchoalveolar lavage (BAL) fluid selection and definitions.

Numbers exceed the total number of patients included as several patients underwent repear bronchoscopy with BAL.* Bacteria $<110 \% \mathrm{~m}$. and $<2 \%$ cells containing intracellular organisms.

revision of a hip prothesis. Based on respiratory parameters and a clinical picture, the diagnosis of ARDS was assessed in four patients; in one of them the diagnosis was confirmed on histological examination at post-mortem. Numerous iron-laden macrophages were seen in one patient with lung contusion and in another patient with severe cardiogenic pulmonary oedema. Malignant cells originating from a disseminated lung adenocarcinoma were seen in two patients; in one of them, the BAL fluid cytology findings provided the first suspicion of malignancy.

Overall, in seven patients the etiological diagnosis was established by histology obtained by biopsy or autopsy and in 13 patients the diagnosis was supported by clinical, radiological and laboratory findings. In the six remaining patients, data regarding the clinical status were not conclusive.

\section{DISCUSSION}

Based upon the absence of a microbiological pathogen and upon cytological evidence present in MGG stained cytocentrifuged preparations, in this study we classified 35/182 (19.2\%) BAL fluid samples as of non-infectious origin. These BAL fluid samples were obtained in $26 \mathrm{ICU}$ patients with suspected pneumonia. 
Retrospectively, we identified a diagnosis explaining the non-infectious condition in 20 of the 26 patients.

We realise that one of the major limitations of this study was its retrospective design. This design did not allow tracing of all cases of non-infectious lung conditions. As the use of antimicrobial agents prior to bronchoscopy was not systematically documented, reliable exploration of Group II (pneumonia not conclusive, BAL fluids with border line quantitative culture results) and Group III (pneumonia excluded, no cytological abnormalities) was not possible. Neither were we able to identify a diagnosis in all non-infectious BAL fluid samples. In particular, difficulties were encountered in the retrospective diagnosis of ARDS and drug-induced pneumonitis. In the case of a suspected drug-induced pneumonitis, a definite role for a particular drug can not be proven in the absence of rechallenge. In the present series, rechallenge supported the diagnosis of carbamazepine-induced toxicity as the patient was readmitted with a second autointoxication. The role of mefloquine was confirmed by restarting of the drug prior to the drug being suspected. Both cases have been described elsewhere in detail. ${ }^{15}, 16$ Among others, amiadarone, methotrexate and anti-depressants are known to be capable of causing drug-induced pneumonitis. ${ }^{17-19}$ In the cases presently described, these drugs were considered as causative because withdrawal of the drug resulted in clinical and radiological improvement.

Reviewing a large number of studies, Timsit et al. concluded that about two-thirds of the episodes of suspected pneumonia in ventilated patients do not meet quantitative culture criteria but are related to other conditions. The authors however admitted that no data definitely supported their conclusion, as many of these episode were believed to be false-negative pneumonia's in which bacterial growth was suppressed by the administration of antimicrobial agents prior to bronchoscopy. 20 In view of their supposition, it is striking that few studies list an alternative diagnosis for those episodes with no microbiological evidence of pneumonia $^{3,4,21,22}$ The reported incidences of non-infectious conditions in these studies were higher than in the present study, but non-infectious BAL fluid samples were defined at a culture threshold of $<10^{4} \mathrm{cfu} / \mathrm{ml}$, whereas in the present study a threshold of $<10^{3} \mathrm{cfu} / \mathrm{ml}$ was applied to exclude BAL fluid samples with borderline quantitative culture results. The low culture threshold in the present study was combined to a threshold for infected cells of $2 \%$, which is the lowest cited cut-off value. ${ }^{23}$ By using these stringent criteria, we aimed to minimise the diagnosis of false-negative infectious pneumonia but probably may have underestimated the number of non-infectious conditions. Second, the authors of previous studies looked for alternative diagnoses in all non-infectious BAL fluid samples, irrespective of the BAL fluid cytological findings. In this way, their alternative diagnoses included more cases of atelectasis, pleural involvement and pulmonary oedema, which are conditions for which, to our knowledge, no specific cytolog ical BAL fluid findings have been described. Although the present study did not intend to search an alternative diagnosis in Groups II and III, we assume that 
conditions such as atelectasis and pleural involvement may have been present in at least part of these episodes. The exact incidences and nature of the non-infectious conditions in this setting should however be addressed by a prospective study.

In contrast to previous studies, we added the findings of the cytological examination to direct the investigation to a non-infectious condition. Retrospectively, we were able to demonstrate an alternative diagnosis for infectious pneumonia in $20(77 \%)$ out of the 26 patients that were selected based on well-defined cytological criteria. Most microbiological laboratories are reluctant to perform BAL differential cell counts as these counts are not always unequivocal and cannot differentiate bronchial infection from lung infection. 24,25 Moreover, performing BAL fluid differential cell counts requires skilled microscopists and is looked upon as laborious and time-consuming in times of limited sources and tendencies to automation. The cytological findings looked for in the present study are, however, easily discernible on MGG stained cytocentrifuged preparations. The processes of cytocentrifugation, MGG staining and cell differentiation as described here can be achieved within a two hours period, making the results of the BAL fluid cytology available within a very short delay. The MGG stain (or an equivalent one) with the differential cell count can be conveniently incorporated into the routine microbiological work-up of BAL fluid samples. Other advantages of the MGG stain are its ability to detect $P$. carinii and its reliability for enumeration of intracellular organisms. ${ }^{12,13}$ The sensitivity of the cytological findings for the detection of a non-infectious origin together with the feasibility and the low turn-over time of the procedure make us to recommend BAL fluid cytology as part of the routine work-up in cases of ICU patients with suspected pneumonia.

One should note that the cytological findings under consideration are not pathognomonic. They point to the possibility of a non-infectious condition, which has to be confirmed and identified by clinical, radiological, or laboratory findings. In our experience, the above-listed cytological findings were not specific for the non-infectious BAL fluid samples. In this way, we also observed alveolar haemorrhage in seven of the 69 bacterial pneumonia's, in agreement with the association between alveolar haemorrhage and infection reported by others. ${ }^{9}$ Moreover, seven of the patients in whom a non-infectious aetiology was diagnosed developed a pneumonia during their further ICU stay. In BAL fluid samples from patients with $P$. carinii pneumonia, we occasionally observed foamy macrophages and plasma cells similar to cases of drug-induced toxicity (unpublished observations), and we have noted elevated numbers of lymphocytes in BAL Fluids obtained from patients with tuberculosis, in line with the findings of others. ${ }^{26,27}$ These observations emphasise the importance of a thorough microbiological investigation, even if BAL fluid cytology at first glance points to a non-infectious condition.

Further, it should be noted that the presence of foamy macrophages in the case of amiodarone intake may represented amiodarone-impregnation and does not necessarily imply toxicity. ${ }^{6}$ 
From table I, it is clear that, apart from malignancy, none of the cyrological findings was confined to a particular non-infectious aetiology. This may partly be explained by an overlap between the distinct conditions, i.e., both lung contusion and aspiration of gastric contents are well-known risk factors for the development of ARDS, and non-infectious processes may co-exist with pneumonia. ${ }^{28,29}$ It is clear that the discriminative power of the cytological findings will be augmented if the number of BAL fluid samples included for comparison increases. For this reason, we are presently conducting a prospective study that will investigate the predictive value of the different cytological parameters and their combinations.

In conclusion, the present study demonstrated the value of the BAL fluid cytological findings for the diagnosis of non-infectious conditions in ICU patients with suspected pneumonia. We recommend incorporating BAL fluid cytology as part of the routine work-up of BAL fluid samples obtained in the ICU serting. A prospective study should address the exact incidence and aetiologies of non-infectious pulmonary conditions in the ICU setting, and allow refinement of the cytological description. In that way, cytology may further improve the diagnostic accuracy of BAL fluid analysis in ICU patients with suspected pneumonia.

\section{REFERENCES}

1. Johanson WG Jr, Seidenfeld JJ, Gomez P, Los Santos de R, Coalson JJ. Bacteriologic diagnosis of nosocomial pneumonia following prolonged mechanicall vencilation. Am Rev Respir Dis 1988;137:259-264.

2. Bonten MJM, Bergmans DCJJ, Stobberingh EE, varn der Geest S, De Leeuw PW, van Tiel $\mathrm{FH}$, et al. Implementation of bronchoscopic techniques in the diagnosis of ventilator-associated pneumonia to reduce antibiotic use. Am J Respir Crit Care Med $1997 ; 156: 1920-1924$.

3. Guera LF, Baugham RP. Use of bronchoalve olar lavage to diagnose bacterial pneumonia in mechanically wentilated parients. Crit Care Med 1990;18:169-172.

4. Timsit JF, Misset B, Goldstein FW, Vaury P, Carlet J. Reappraisal of distal diagnostic testing in the diagnosis of $1 \mathrm{CU}$-acquired pneumonia. Chest 1995; 108:1632-1639.

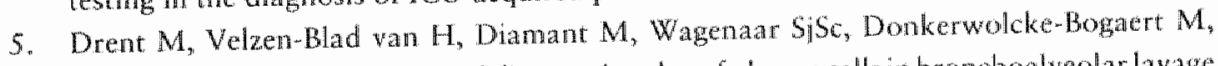
Bosch van den JMM. Differential diagnostic value of plasma cells in bronchoalveolar lavage fluid. Chest 1993;103:1720-1724.

6. Rosenow EC III, Martin W] II. Drug-induced interstitial lung disease. Im. Schwarz MI, King TE (eds.). Interstitial lung disease. 2nd edition, 1993:255-270.

7. Grotte D, Stanley MW, Swanson PE, Henry-Stanley J, Scott D. Reactive Type II pneumocytes in bronchoalveolar lavage fluid from adult respiratory distress syndrome can be mistaken for cells of adenocarcinoma. Diagn Cytopathol 1990;6:317-322.

8. Nakos $G$, Kirsiouli EL, Tsangaris L, Lekka MD. Bronchoalweolar lavage fluid characteristics of early intermediate and late phases of ARDS. Intensive Care Med 1988;24:296-303. 
9. Lassence de A, Fleury-Ferth J, Escudier E, Beane J, Bernaudin JF, Cordonnier C. Alveolar hemorihage. Diagrostic criteria and results in 194 immuno-compromised hosts. Am J Respir Crit Care Med 1995;151:157-163.

10. Kahn FW, Jones JM. Diagnosing bacterial respiratory infection by bronchoal weolar lavage. JInfect Dis 1987;155:862-869.

11. Chastre J, Fagon JY, Soler P, Domart Y, Pierre J, Dombret MC, etal. Quantification of BAL calls containing intracellular bacteria rapidly identifies ventilated patients with nosocomial pneumonia. Chest 1989,95:190-192.

12. Easelskiki VS, El-Torky M, Coalson JI, Griffin JP. The standardisation of criteria for processing and interpreting laboratory specimens in patients with suspected ventila. tor-associated pneumonia. Chest 1992;102:574.579.

13. De Brauwer EIGB, Jacobs JA, Nieman FH, Bruggeman CA, Drent M. Test characteristics of Acridine Orange, Gram and May-Grunwald-Giemsa stains for the detection of intracellular organisms in bronchoalveolar lavage fluid. I Clin Microbiol 1999:37: 427.429

14. Dacie JV, Lewis SM (eds.). Practical Haematology. $6^{\text {th }}$ Edition, Edinburgh: Churchill Livingstone 1984.

15. Wilschut FA, Cobben NAM, Thunissen FBJM, Laners RJS, Wouters EFM, Drent M. Acute interstitial pneamonitis due to single overdose with carbamazepine. Eur Respir J $1997 ; 10: 2163-2165$.

16. Drent M. Drug-induced pneumonia associated with hemizygote glucosem-phosphate dehydrogenase deficiency. Eur J Haematol 1998;61:218-220.

17. Cooper AD, White DA, Matthay RA. Drug induced pulmonary disease. Part 1: cytotoxic drugs. Am Rev Respir Dis 1986:133:321-340.

18. Cooper AD, White DA, Matthay RA. Drug-induced pulmonary disease. Part 2: noncytoroxic drugs. Am Rev Respir Dis 1986;133:488-505.

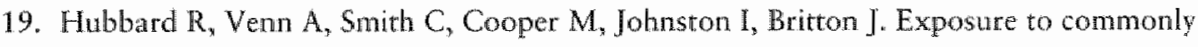
prescribed drugs and the aetjology of cryptogenic fibrosing alveolitis. Am J Respir Crit Care Med 1998:157:743-747.

20. Timsit JF, Chevret S, Vallcke J, Misset B, Renaud B, Goldstein FW, et al. Mortaliry of nosocomial pneumonia in wentilated patients: influence of diagnostic tools. Am I Respir Crit Care Med 1996;154:116-123.

21. Aubns $\mathbf{S}$, Aubas P, Capdevila X, Darbas H, Rouscan J-P, Cailar du J. Bronchoalweolar lawage for diagnosing bacterial pneumonia in mechanically ventilated patients. An J Respör Crit Care Med 1994:149:860-866.

22. Meduri GU, Maudin GL, Wunderink RG, Leeper KV, Jones CB, Tolley E, et al. Causes of fever and pulmonary densities in parents with clinical manifestations of ventilaw tor-associated pneumonia. Chest 1994;106:221-233.

23. Allaouchiche $B$, Janmain $H$, Dumonter $C$, Motin J. Early diagnosis of ventilator-associated pneumonia. Is it possible to define a cut-off value of infected cells in BAL fluid? Chest $1996 ; 110: 1158-1165$.

24. Banghman RP, Strohofer $S$, Kim $C K$. Variation of differential cell counts of broncholveolar lavage fluid. Arch Parhol Lab Med 1986;110:341-343. 
25. Thorpe JE, Baughman RP, Frame PT, Wesseler TA, Staneck JL. Bronchoallveolar lawage for diagnosing acute bacterial pneumonia. I Infect Dis 1987;155:855-861.

26. Baughman RP, Dohn MN, London RG, Frame PTI. Bronchoscopy with bronchoalveolar lavage in tuberculosis and fungal infections. Chest 1991;99:92-97.

27. Drent M, Wagenaar SjSc, Mulder PHC, Velzen-Blad wan H, Bosch van den JMM. Bronchoalveolar lavage fluid profiles in sarcoidosis, cuberculosis, non-Hodgkin's and Hodgkin's disease: an evaluation of differences. Chest 1994;105:514-520.

28. Steinberg KP, Milberg JA, Martin TR, Mauncer RJ, Cockill BA, Hudson LD. Exolution of bronchoalveolar cell population in the Adult Respiratory Distress Syndrome. Am J Respir Crit Care Med 1994;150:11.3-122.

29. Marquette CH, Chopin M-C, Wallet F, Marquette Chopin Wallet F, Neviere R, Saulier F, Matrhic D, et al. Diagnostic tests for pneumonia in verrilated partents: prospective evaluation of diagnostic accuracy using hisrology as a diagnostic gold standard. Am. I Respir Crit Care Med 1995;151:1878-1888. 



\section{CHAPTER 8}

\section{Summary and general discussion}

Pulmonary diseases have traditionally been evaluated by laboratory tests, lung function tests, imaging procedures and tissue biopsies. 'Bronchoalveolar lavage (BAL) represents an additional tool in assessing the health status of the lung. BAL is a procedure in which the bronchoalveolar region of the respiratory tract is lavaged with an isotonic salt solution. It samples cells and solutes from the epithelial layer of the lower respiratory tract. After its introduction as a research tool, BAL has been appreciated extensively for clinical applications in the field of infections and interstitial lung diseases. Diagnostic application of BAL fluid analysis is mainly based on cellular characteristics of the fluid, therefore, appropriate cellular analysis is mandatory. Normally, BAL fluid samples from healthy non-smoking controls contain alveolar macrophages, lymphocytes, and, to a lesser extent, polymorphonuclear neutrophils (PMNs), eosinophils and mast cells.

Although the value of BAL fluid cytology in the assessment of interstitial lung disease and pulmonary infections is apparent, it should be realised that the actual determination of the cell types does require technical skill and training, and that the entire BAL fluid processing requires considerable time and effort.

The procedure of cytocentrifugation has been used for many years in haematology and cytology laboratories, as it enables excellent observation of cell morphology in specimens of low volume. During the past decades, applications of cytocentrifugation have been developed for diagnostic microbiology. Among others, these applications included screening for urinary tract infections, visualisation of bacteria in normally sterile body fluids, and detection of acid-fast bacilli in sputum preparations. ${ }^{2-4}$ Despite encouraging results, cytocentrifugation has failed to become a widespread technique in diagnostic microbiology.

The diagnostic value of cytology largely depends on the possibilities for standardising the procedures of cytocentrifugation. Indeed, technical factors interfering with the cytocentrifugation process may cause distortion of the BAL. fluid differential cell count. Such errors include the "bull's eye" appearance of the cytocentrifuge spot (due to low sample volumes in the cytospin chamber), and the "crescent shaped" appearance of this spor (due to a delayed start of the centrifuge after loading of the chambers)..$^{5}$

Although progress has been made in non-morphologic diagnosis (e.g. flow cytometry and polymerase chain reaction-techniques), the microscopic identification of cells and pulmonary parhogens constitutes the cornerstone of BAL fluid analysis in the daily practice of the diagnostic laboratory, and it is likely to remain so in the near future. Indeed, analysis of the cellular profile in BAL fluid samples 
can give more insigh into the underlying lung disease. The use of refined techmiques of specimen processing and microscopy not only offers fast and reliable diagnosis, but also fits the needs for cost-accountable specimen management and round-the-clock patient care.

Despite the recommendations of the European Society of Pneumonology and those of the American Thoracic Society, 6,7 further study on standardisation of the cytocentrifugation process is necessary.

Chapters 2 and 3 were conceived as a spin-off of this search for standardisation. In these chapters, the influence of the cytocentrifugation parameters on the differential cell count of BAL fluid samples was investigated. In chapter 2 , the impact of three cytocentrifugation parameters (i.e. speed, time and acceleration rate) on the BAL fluid differential cell count was investigated. As cytocentwifugation entalls selective loss of lymphocytes, the recovery rate of these cells at various cytocentrifugation conditions was of special interest. $8,9 \mathrm{~A}$ cytocentrifugation speed of 1200 revolutions per minute ( $\mathrm{rpm}$ ), and a duration of 10 minutes ascertained the highest recovery rate of lymphocytes. Ar intermediate (1200 rprot) and high speed (2000 rpm) conditions however, morphological cell damage became apparent, and thus we elected to use the low cytocentrifugation speed as the one preferred for BAL fluid cytology. In chapter 3 , it was concluded that lymphocytes and alveolar macrophages were not randomly distributed on the cytocentrifuge spot, and that the centre of the cytocentrifuge spot appeared to be the most reliable area for performance of the differential cell count. Although the findings in both chapters were statistically significant, their clinical significance remains debatable. The mean absolute differences in lymphocyte percentages for the different quadrants (chapter 3 ) and for the different cytocentrifugation conditions (chapter 2) were small, but there were many individual BAL fluid samples for which the absolute difference exceeded $10 \%$. Although no tolerance limits have been clefined for interassay variability of BAL fluid differential cell counts, a $10 \%$ difference is considered technically significant when assessing interlaboratory variabilities. ${ }^{10}$ Further investigation on the limits for interassay variability of $B A L$ fluid differential cell count, without clinical impact, should be done and will increase the application of BAL fluid cytology in the daily practice.

Chapters 4 and 5 present refinements of the previously published recommendations on the number of BAL fluid cells to be differentiated. In chapter 4 , it was demonstrated that a 200-cell count (which the American Thoracic Society proposed as the minimum number of cells to be enumerated $)^{6}$, only warranted a reliable count of PMNs and alveolar macrophages. When increasing the number of cells counted to a total of 300 , the lymphocytes and eosinophils were also reliably enumerated. However, the percentages of mast cells, plasma cells, squamous and bronchial epithellial cells were not reliably estimated, even at a counc of 500 cells by one observer. On May-Grunwald-Giemsa stained preparations, it appeared that reliable counting of mast cells was not possible, and therefore caution should be exercised when interpreting mast cell percentages. Extended 
microscopic screening of BAL fluid cytocentrifuged preparations was recommended, in order to evaluate the presence of epithelial cells and plasma cells. Chapter 5 demonstrated that $M G G$ stained preparations offered a more reliable counting of infected cells than did the Gram and the Acridine Orange stained preparations. Reliable estimation of the percentage of infected cells was achieved at a count of 200 cells. The results obtained in chapters 4 and 5 may be regarded as a further attempt to standardise the BAL fluid differential cell count. The studies presented in chapters 4 and 5 should be complemented by a detailed investigation of inter-laboratory differences in the processing of BAL fluid samples, in order to achieve a better standardisation of the BAL differential cell counts. ${ }^{11}$

From the scope of instrumentation and automation, several attempts have been made to simplify the processing of BAL fluid samples in the diagnostic setting. Calibration of a Coulter Counter: D apparatus enabled fast and accurate electronic measurement of the total cell count of BAL fluid samples, and a commercial Dip Slide method compared favourably to conventional quantitative culture methods. ${ }^{12,13}$ In line with these evolutions, a commercial Leakocyte esterase strip, designed for urinalysis, was evaluated for its ability to detect elevated numbers of PMNs in BAL fluid samples. The results of this study, presented in chapter 6 , showed that the Multistix 7 reagent strip proved to be usefull as a rapid screening test for the BAL fluid PMNs percentage. However, from the viewpoint of diagnostic and analytical sensitivity, further study on the false-negative readings and refinements of the reading scale are needed. Furthermore, adaptations of the other Multistix parameters to the BAL fluid ranges are desired. Although BAL fluid samples on their own do not represent a large field of application (and sale) for such reagent strip, they would be a useful adjunct to conventional microscopy in those situations where trained cytologists are not available.

In chapter 7, the usefulness of BAL fluid cytology was assessed in intensive care patients suspected of having pneumonia. In these patients, pulmonary densities noted on chest radiograph are numerous, and non-infectious disorders may be just as prevalent as those produces by organisms. ${ }^{14}$ From the study presented in chapter 7 , it was clear that BAL fluid cytology may offer valuable information in the detection of at least part of these non-infectious conditions. Readily discernible cytological findings such as haemosiderin loaden macrophages, eosinophils and malignant cells clearly pointed to a non-infectious condition such as aspiration of gastric contents, the Adult Respiratory Distress Syndrome, diffuse alveolar haemorrhage and lymphangitis carcinomatosa. It is important, however, to realise that none of these findings was exclusive, a reason why thorough microbiological examination of the BAL fluid samples is still required in order to rule out an infectious origin. 


\section{In summary}

1. Optimal recovery of the different BAL fluid cell types combined with excellent cytomorphology can be achieved by cytocentrifugation at intermediate speed $(650 \mathrm{rpm})$, for a duration of 10 minutes and at the low accelleration rate.

2. For reliable estimation of the BAL fluid lymphocyte and alveolar macrophage numbers, the differential cell count of cytocentrifuged BAL fluid samples should be performed in a circular pattem around the center of cytocentrifuge spot.

3. Reliable estimation of the number of PMNs, alveolar macrophages, lymphocytes and eosinophils in cytocentrifuged BAL fluid samples is reached at a count of 300 cells by one observer. Extended microscopic screening is recommended to evaluate the presence of epithelial cells (low magnification) and plasma cells (high magnification).

4. For enumeration of the infected cells in cytocentrifuged BAL fluid samples, the MGG stain is the preferred stain, and reliable enumeration by a single observer is achieved at a count of 200 cells.

5. For estimation of the BAL fluid PMN count, the leukocyte esterase reagent (LE) Multistix 7 reagent strip (designed for urinanalysis) can be of adjunct value: negative LE radings consistently predict a BAL fluid PMN count of < $20 \%$, and the " +++ " LE category predict PMN counts above and below $50 \%$ with a sensitivity of $71 \%$ and a specificity of $97 \%$.

6. In intensive care patients suspected of having pneumonia, BAL fluid cytological findings such as $>20 \%$ haemosiderin loaden macrophages, the presence of activated lymphocytes, plasma cells, > 5\% eosinophils, a preponderance of foamy macrophages, reactive type II pneumocytes and malignant cells, point to a non-infectious origin of the symptoms.

Further refinements of these findings in a prospective study will increase the diagnostic accuracy of the BAL fluid cytology in the prediction of non-infectious as well as infectious conditions. The studies in the previous chapters illustrated the value of a multidisciplinary approach in the processing and interpretation of $\mathrm{BAL}$ fhid cytology. Fxcellent technical and statistical support enabled to tefine BAL fuid processing. However, appropriate clinical information is mandatory to improve the diagnostic accuracy of BAL fluid analysis. When applied according to standardized protocols, and consiclered in the context of other diagnostic tests and appropriate climical information, BAL appears to be useful in the diagnosis of cettain lung diseases. Attempts have to be made to further improve the procedure and explore the value of the procedure for clinical as well as research application. 


\section{REFERENCES}

1. Drent M, Jacobs JA, Wagenaar SjSc. Bronchoalweolar lavage. Eur Respir Mon 2000;5: $63 \times 78$.

2. Lampert $F$, Brandl A, Daschner F. Urinalysis with the cytocentrifuge: a method to supplement quantitatiwe bacterial culture. J Stud Trear Infect 1975;3:40-43.

3. Shanholzer CJ, Schaper PJ, Peterson LR. Concentrared gram stain smears prepared with a cytospin centrifuge. J Clin Microb 1982;16:1052-1056.

4. Saceanu CA, Pfeiffer NC, McLean T. Evaluation of sputum smears concentrated by cytocentrifugation for detection of acid-fast bacilli. J Clin Microb 1993;31:2371-2374.

5. Grover $\mathrm{ML}$, Blee E, Stokes BO. Effect of sample volume on cell recovery in cytocentrifugation. Acta Cytol 1995;39:387-390.

6. Klech $\mathrm{H}$, Pohl W. Technical recommendations and guidelines for bronchoalveolar lavage (BAL): report of the European Society of Pneumonology Task Group on BAL. Eur Respir] 1989;2:561-585.

7. Goldstein R. Clinical role of bronchoalveolar lavage in adults with pulmonary disease. Am Rev Respir Dis 1990;142:481-486.

8. Saltini $C$, Hance AJ, Ferrans VJ, Basset F, Bitterman PB, Crystal RG. Accurate quantification of cells recovered by bronchoalve olar lavage. Am Rev Respir Dis 1984;130:650-658.

9. Laviolette M. Lymphocyte fluctuation in bronchoalveolar lavage fluid in normal volunteers. Thorax 1985;40:651-656.

10. Kleykamp BO, Baughman R.P. Who should perform bronchoalveolar lavage analysis? Am J Respir Crit Care Med 1998;157:67.

11. Baughman RP. Is bronchoalveolar lavage clinically useful for every day practice in interstitial lung disease? J Bronchol 1999;6:211-216.

12. Heaney LG, McKirgan J, Stanford CF, Ennis M. Electronic cell counting to measure rotal numbers in bronchoalveolar lavage fluid. Eur Respir ] 1994;7:1527-1531.

13. Speich R, Wüst J, Hess T, Kayser F, Russi EW. Prospective evaluation of a semi-quantitative dip slide method compared with quantitative bacterial cultures of BAL fluid. Chest $1996 ; 109: 1423-29$.

14. Santos $\mathrm{E}$, Talusan A, Brandsteter RD. Roentgenographic mimics of pnewnonia in the critical care unit. Crit Care Clin 1998; 14:91-104. 



\section{Samenvatting}

De introductie van de flexibele bronchoscoop door Ikeda in 1968 betekende een belangrijke diagnostische en therapeutische aanwinst voor de pneumologie. Via de flexibele bronchoscoop kan er een spoeling van het distale deel van de long plaatsvinden, de bronchoalveolaire lavage (BAL) genaamd. Door onderzoek van het spoelvocht, verkregen met de BAL, heeft men meer inzicht gekregen in de morfologische, microbiologische, immunologische en chemische aspecten van processen in de kleine luchtwegen en de alveolaire ruimten. De onderzoeksresultaten hebben geleid tot een ruimer toepassingsgebied van de BAL in de diagnostiek van zowel niet-infectieuze als infectieuze long-aandoeningen.

In de spoelvloeistof var gezonde personen komen alveolaire macrofagen 180 tot $90 \%$ van de totale celtelling), lymfocyten ( 5 tot $10 \%$ ), polymorphonucleaire neutrofielen (PMN) (1 tot $2 \%)$, eosinofielen en mast cellen $(1$ tot $2 \%)$ voor. Plaveisel-, trilhaarepitheelcellen, plasma cellen en maligne cellen zijn onder normale omstandigheden niet aanwezig in de spoelvloeistof. Door de bepaling van de differentiatie van de cellen a anwezig in de spoelvloeistof is het mogelijk een inzicht te krijgen in het ziekteproces van de long. De cytocentrifugatietechnick, in het bijzonder de Cytospin (Shandon Ltd.), is de meest gebruikte methode voor het maken van cytologische preparaten. De cellen aanwezig in de spoelvloeistof worden door het cytocentrifugatieproces geconcentreed op een rond oppervlak met $6 \mathrm{~mm}$ diameter, de cytocentrifugatiespot genaamd. Wanneer een juiste hoeveelheid vocht wordt gecytocentrifugeerd komen de cellen juist naast elkaar te liggen op de cytocentrifugatiespot en is er een uitstekende morfologie van de verschillende cellen. Een aantal factoren interfereert met het cytocentrifugatieproces waardoor de kwaliteit van de preparaten, c.q. de cytomorfologie, wordt aangetast. Een van de factoren is het gebruik van een te kleine hoeveelheid materiaal in de cytospinkamer. De cellen komen aan de rand van de cytocentrifugatiespot te liggen met in het midden een celarm deel, het "bull's eye" effect genaamd. Een andere factor is de tijd tussen het vullen van de cytocentrifugatiekamer en het starten van het cytocentrifugatieproces. Indien de tijd te lang is, ontstaat er cen onregelmatige verdeling van de cellen op de cytocentrifugatiespot, de "crescent" genaamd.

De cytologie eist ervaren en getrainde microscopisten en is een arbeidsintensieve en dure bepaling. Voor de toepassing van de cellulaire analyse in de diagnosriek van zowel niet-infectieuze als infectieuze longaandoeningen, is het belangrijk dat de techniek waarop de BAL vloeistof verwerkt wordt in het laboratorium betrouwbaar en reproduceerbaar is. Ondanks het bestaan van aanbevelingen van o.a. de European Society of Pneumonology en de American Thorax Society wordt voor het cytologisch onderzoek van de BAL-vloeistof niet altijd aan deze voorwaarden voldaan. Er is een noodzaak naar verdere standaardisatie van zowel de 
cytocentrifugatietechnek, dan de differentiele celtelling van BAL-voeistof. Dit proefschrift heeft als doel zowel de cytocentrifugarietechniek als de differentiatie van de cellen in een BAL-voeistof te optimaliseren, en de diagnostische meerwaarde van een BAL bijeen beadem de patiënt met een infiltraat op de röntgenfoto van de thorax an te tonen.

In hoofdstuk 2 werd de invloed van de 3 cytocentrifugatie-parameters: snelheid, tijd en acceleratie op de celdifferentiatie van de BAL-wloeistof nagegaan. De aandachtging vooral uit naar de opbrengst van de lymfocyten bij de verschillende cytocentrifugatie-snetheden. Er werd aangetoond dat de opbrengst van de lymfocyten het hoogst is bij een cytocentrifugatie-snelheid van $1200 \mathrm{rpm}$. Aangezien bij de hogere snelheden (1200 rpm en $2000 \mathrm{rpm}$ ) morfologisch meer celbeschadiging werd waargenomen, wordt een cytocentrifugatie-snelheid van $650 \mathrm{rpm}$ aanbevolen. Deze snelheid werd gebruikt in dit proefschrift. Het onderzoek beschreven in hoofdstuk 3 toonde aan dat de lymfocyten en de alveolaire macrofagen niet ad random verdeeld zijn op de cytocentrifugatiespot. De meest betrouwbare plaats woor een celdifferentiatie was rond het centrum van de cytocentrifugatiespot. Ondanks dat het verschil, zowel in het percentage lymfocyten als in het percentage alveolaire macrofagen, voor de verschillende cy tocentrifugatie-parameters (hoofdstuk 2 ) en de verschillende $k$ wadranten (hoofdstuk 3 ) in een aantal gevallen statistisch significant was, bliff de klinische betekenis controversieel. Tot heden werden geen criteria gedefinieerd over de grenzen waartussen een differentiële celtelling van een BAL, zonder dat de klinische diagnose beinvloed wordt, kan wariëren. Het is interessant om na te gaan of de beoogde criteria vastgelegd kummen worden met behulp van verder onderzoek.

In hoofdstuk 4 en 5 werd aandacht besteed aan de standaardisatie van het aantal te differentiëren cellen. In hoofdstuk 4 werd aangetoond dat voor een representatieve telling van PMN en alveolaire macrofagen minimaal 200 cellen, zoals a anbevolen door de American Thorax Society, dienen te worden geteld. Indien ninimal 300 cellen door 1 observer werden geteld, bleck de celtelling ook betrouwbar te zijn voor de lymfocyten en de eosinofielen. Voor de mast cellen, plasma cellen, trilhaar- en plaveiselepitheelcellen was het niet mogelijk het minimaal antal cellen te bepalen om een betrouwbare celtelling te krijgen. Derhalve is het van belang cen uitgebreide screening van de preparaten naar plasma cellen, trillarar-en plaveiselepitheelcellen te doen. De herkenning van de mast cellen op May-Grünwald-Giemsa (MGG) gekleurde preparaten is erg moeilijk. De identificatie van de mast cellen op MGG gekleurde preparaten dient met alle voorzichtig heid te gebeuren. In hoofdstuk 5 werd aangetoond dat voor de bepaling van het aantal geinfecteerde cellen, de MGG kleuring betrouwbarder is dan de Gram en de Acridine Oranje kleuring. De telling van het aantal geinfecteerde cellen was reeds betrouwbar bijeen telling van 200 cellen door 1 observer. In hoofdstuk 4 en 5 werd angetoond dat door een differentiatie van minimaal 300 cellen gecombineerd met een uitgebreide screening van de preparaten een betrouwbare cellulaire analyse verkregen wordt. Om de resultaten van de cellulaire analyse van verschil- 
lende laboratoria te kunnen vergelijken, is het belangrijk dat de laboratoria dezelfde techniek gebruiken. Vervolgens is het interessant na te gaan hoe groot de verschillen in de celtelling tussen de verschillende laboratoria kunnen zijn en of dat gevolgen heeft voor de klinische diagnose.

In hoofdstuk 6 werd onderzocht of de commerciële Leukocyte esterase strip kan gebruikt worden om op een semi-kwantitatieve wijze de hoeveelheid PMN in BAL-vloeistof te bepalen. De studie toonde aan dat de strip, Multistix 7 reagent strip genoemd, bruikbaar is. Doch, de afleesschaal dient verfijnd te worden en verder onderzoek dient te gebeuren naar de kans op vals-negatieve aflezingen. Het toepassingsgebied wan de strip is beperkt tot die situaties waar geen getrainde analist beschikbaar is. De semi-kwantitatieve bepaling biedt dan een uitkomst als aanvulling op de conventionele microscopie.

In hoofdstuk 7 werd aangetoond dat de cytologie van een BAL-vloeistof een aanvullende diagnostische waarde heeft bij beademde intensive care patiënten met een infiltraat op de röntgenfoto van de thorax. De oorzaak van het infiltraat kan zowel infectieus als niet-infectieus zijn. De cytologie heeft vooral een meerwaarde voor de diagnose van niet-infectieuze aandoeningen, waardoor onnodig antibioticagebruik zoveel mogelijk voorkomen kan worden. Indien in de lavagevloeistof haemosiderine beladen macrofagen, eosinofielen en/of maligne cellen worden aangetroffen, kan dit een aanwijzing zijn voor niet-infectieuze aandoeningen, zoals aspiratie van maagzuur, adult respiratory distress syndrome, diffuus alveolaire haemorrhagie en lymphangitis carcinomatosa. Echter steeds dient aanvullend microbiologisch onderzoek een infectieuze oorzaak uit te sluiten.

\section{Samenvatterd}

1. De meest ideale opbrengst van de verschillende celsoorten aanwezig in een BAL-vloeistof gecombineerd met een uitstekende cytomorfologie wordt bereikt bij een cytocentrifugatie proces met een gemiddelde snetheid \$650 $\mathrm{rpm})$, gedurende 10 minuten bij een lage acceleratie.

2. Voor een betrouwbare telling van het aantal lymfocyten en alveolaire macrofagen is het aan te bevelen een celtelling te doen rond het centrum van de cytocentrifugatiespot van de preparaten.

3. Een betrouwbare telling van het aantal polymorphonucleaire neutrofielen, alveolaire macrofagen, lymfocyten en eosinofielen wordt verkregen bij een differentiatie van 300 cellen door 1 observer. Uitgebreide screening van de cytocentrifugatie preparaten is aan te bevelen om de aanwezigheid van epitheelcellen (lage vergroting) en plasma cellen (hogere vergroting) te evalueren.

4. De bepaling van het aantal geinfecteerde cellen in BAL-vloeistof is betrouwbaar bij een differentiatie van 200 cellen door 1 observer op MayGrünwald-Giemsa gekleurde preparaten. 
5. Voor de bepaling van het aantal polymorphonucleaire neutrofielen (PMN) in BAL-vloeistof, kan de leukocyte esterase (LE) Multistix 7 reagent strip (ontworpen voor urinanalysis) een toegevoegde waarde hebben. Een negatieve $\mathrm{LE}$ aflexing voorspelt een BAL-vloeistof met een PMN aantal < $20 \%$, en een " +++ " LE categorie voorspelt een PMN telling boven de $50 \%$ met een sensitiviteit van $71 \%$ en een specificiteit van $97 \%$.

6. Bij intensive care patienten verdacht van een pneumonie wijzen de cytologische bevindingen in een BAL-vloeistof zoals $>20 \%$ haemosiderine beladen macrofagen, de aanwezigheid van geactiveerde lymfocyten, $>5 \%$ cosinofielen, een meerderheid van schuimmacrofagen, reactief type II pneumocyten en maligne cellen in de richting van een niet-infectieuze oorzaak.

De studies beschreven in dit proefschrift benadrukken de waarde van een multidisciplinaire aanpak in de verwerking en interpretatie van de cytologie van BAL-vloeistof. Het onderzoek heeft geleid tot een meer gestandaardiseerde verwerking van BAL-vloeistof. Het onderzoek zal de diagnostische waarde van BAL-yloeistof cytologie voor zowel infectieuze als niet-infectieuze condities doen toenemen. Doch, de cytologie van BAL-vloeistof is arbeidsintensief en tijdrovend. Er wordt uitgebreid onderzoek gedaan naar de toepasbaarheid van snelle, geautomatiseerde technieken, zoals de flow-cytometrie om een differentiële celteelling uit te voeren of de toepassing van de polymerase chain reactie voor een snelle diagnose van een Legionella pneumophila pneumonie, op de BAL-vloeistof. Het onderzoek naar de mogelijkheid van automatisering in de verwerking van BAL-vloeistof in de laboratoria zal zowel de standaardisatie als de toepasbaarheid van BAL-vloeistof in de diagnostiek van longziekten doen toenemen. Een goede samenwerking tussen long- en intensive care artsen biedt de mogelijkheid om de cytologie in een klinisch kader te plaatsen. Op deze manier neemt de cytologie van een BAL-vloeistof een unieke plaats in, zowel in de dagelijkse patiëntenzorg als in het onderzoeksgebied. 


\section{Dankwoord}

Danken is een woord ontstaan rond 901-1000 na Christus en is afgeleid van het werkwoord "denken". De cryptische omschrijving van het woord is goede gezindheid jegens iemand van wie men iets goeds ondervonden heeft en het blijk daarvan. Tegen het einde van een onderzoek dat resulteert in een proefschrift wil je iedereen danken en dit als gevolg van de opluchting dat je de eindstreep bijna gehaald hebt. Ik wil enkele personen in het bijzonder noemen.

Allereerst will ik Jan Jacobs bedanken, mijn co-promotor, de initiatiefnemer van dit onderzoek. Beste Jan, de hematologische kennis - die we beide hebben verkregen tijdens de opleiding Klinische Biologie te Leuven - bracht ons samen in dit onderzoek. Jouw interesse en kennis op het gebied van de microbiologie en de bronchoalveolaire lavage zijn enorm. Jouw heldere kijk op de resultaten was zeer relevant voor de voortgang van het onderzoek. Mijn dank!

Mijn promotor Prof. Dr. C. A. Bruggeman, Cathrien, bewonder ik vooral om haar goed relativerend vermogen. Haar vriendelijke aard, eenvoud en toegankelijkheid bleken van grote waarde in de begeleiding en de totstandkoming van het proefschrift. Mijn dank!

De samenwerking in de laatste fase van het proefschrift was hoofdzakelijk met Marjolein Drent. Beste Marjolein, jouw drijflracht om alles tot cen goed einde te brengen zal ik niet vergeten. De adviezen, hulp en tenslotte het constructief leiden van de voor bereiding van de verdediging. Je begrip dat kinderen krijgen en promoveren niet altijd evident is, stel ik zeer op prijs. Mijn dank!

Henken Lisette wil ik zeker niet vergeten. De stille, harde werkers in de tweede linie. Dankzij hun hulp verliep het onderzoek vlot, zelfs tijdens mijn werkzaamheden als assistent in opleiding. Henk, jouw technisch inzicht is te bewonderen. De wijze waarop je meedacht tijdens het oplossen van problemen is een compliment waard. Jouw drijvende kracht om iets bij te leren en proefondervindelijk te ervaren zal je helpen in de verdere opbouw van je loopbaan. Nog veel succes! En dan Lisette, zij was het rustgevend punt in de ploeg. Nooit was haar iets teveel. Ze werkte steeds op haar ritme en ons humeur kon de hare niet ondermijnen. Mijn dank!

Voor de cellulaire analyse kreeg ik de ondersteuning wan Monique. Monique, bedankt voor de nauwkeurigheid waarmee je de celtellingen uitwoerde.

De analisten van de bacteriologie werkten zeer vlijtig en met veel nauwkeurigheid mee aan het onderzoek. Zelfs tijdens de avonddienst en 's nachts waren ze bereid om langer te werken. Dit om dat extra carrouselletje met preparaten te draaien. Mijn dank!

Voor het leveren van de bronchoalveolaire lavages (BAL's) will ik de afdeling longziekten, in het bijzonder de mensen van de behandelkamer, danken. Dankzii 
hun snelheid werden de BAL's bimen de twee ur na afname naar het laboratorium gebracht.

Voor de statistische werwerking van de gegevens deed ik beroep op twee ervaren statistici, Paull en later Fred. Jullie wisten mij op een eenvoudige manier wegwijs te maken in de doolhof van de statistiek. Mijn dank!

Als "young" doctors wisten Daisy en Nico wat promoveren betekent. Ze waren steeds bereid te luisteren op moeilijke momenten. Mijn dank!

Ondertussen heb ik mijn opleiding tot arts-microbioloog afgerond en ben ik verhuisd naar het Atrium medisch centrum te Heerlen. Ik ben daar hartelijk ontvangen door Hans, Jo, het secretariaat en de analisten. Ik dank hen, in het bijzonder Jo en Saskia, voor het begrip dat ze hadden voor het feit dat ik nog tijd nodig had om mijn promotie voor te bereiden. Dankzij de morele ondersteuning van Jo en het handige type-en e-mailwerk van Saskia was de continuitteit gewaarborgd, zells tijdens mijn zwangerschaps- en bevallingsverlof.

De finale van een promotie kan niet zonder paranimfen. Leen en Daisy bedankt dat jullie bereid zijn mij te begeleiden tijdens de verdediging van het proefschrift en te helpen bij de organisatie van het feest.

Mijn lieve ouders wil ik bedanken voor de kans die ze me gegeven hebben om te studeren en me volledig te ontplooien.

Tenslotte, mijn Ger. Ger, alhoewel je zelf aan een proefschrift werkt en een drukke baan hebt, zette je op de goede momenten een stapje terug. Je was mijn praatpaal en uitlaatklep. Ik vind het fijn dat je visie is dat vrouwen zich ook moeten kunnen ontwikkelen. Ik moet dan ook altijd lachen om de reclame die je voor mij maakt. Ger, samen met Astrid, onze kleine waterval, en sinds kort Clara, weet je van ons huis een gelukkig en warm thuis te maken. Mijn dank! 


\section{Curriculum Vitae}

Els De Brauwer werd geboren op 20 september 1967 te Hasselt (Bellgië). In 1985 werd het diploma klassieke talen Grieks met Wiskunde behaald aan het Humaniora Virga Jesse te Hasselt. In dat jaar startte ze de studie geneeskunde aan het Limburgs Universitair Centrum te Diepenbeek. In 1988 werd het kandidaatsdiploma behaald met onderscheiding. De doctoraatsjaren volgde ze aan de Katholieke Universiteit Leuven, alwaar ze in 1992 met onderscheiding haar artsendiploma behaalde. Van 1992 tot 1995 doorliep ze de opleiding Klinische Biologie aan het Stedelijk Ziekenhuis te Roeselare en het Algemeen Ziekenhuis $S t$. Jan te Brugge. Hetzelfde jaar besloot ze zich verder te bekwamen in de microbiologie en startte de opleiding tot arts-microbioloog in het Academisch Ziekenhuis Maastricht. De registratie tot arts-microbioloog volgde in september 1999. Sinds 1 oktober 1999 is ze werkzaam in het Atrium medisch centrum te Heerlen. De in dit proefschrift beschreven studies werden aangevangen gedurende de opleiding tot arts-microbioloog. Els is gehuwd met Ger Koek en moeder van twee dochters Astrid en Clara. 



\section{List of publications}

1. Coene J, De Brauwer E, Gordts B, Van Landuyt H. Vancomycin-resistant Enterococous faecalis: now also in Belgimm. Acta Clin Belg 1995;50:46 47.

2. De Brawwer $\mathrm{E}$, Van Landuyt HW, Gordts B and Boelaert JR. In witro acquisition of iron from the iron-desterrioxamine complex by Aeromonas bydrophila. Clin Microbiol inf $1996 ; 4: 273-274$.

3. Lin SH, Shick SD, Lin YF, De Brauwer E, Van Landuyt HW, Gordts B, Boelaert JR. Fatal Aerownonas bydrophila bacteremia in a patient treared with deferoxamine. Am J Kidnay Dis $1996 ; 27: 733-735$.

4. De Brauwer EIGB, Jacobs JA, Nieman FH, Bruggeman CA, Drent M. Test characteristics of Acridine Orange, Gram and May-Grunwald-Giemsa stains for the detection of intracellular organisms in bronchoalveolar lavage fluid. J Clin Microbiol 1999;37: 427-429.

5. Jacobs JA, De Brauwer EIGB. BAL fluid cytology in the assessment of infectious lung disease. Hosp Med 1999;60:550-555.

6. Jacobs $\ A$, De Brauwer EIGB, Ramsay G, Cobben NA, Wagenaar SS, van der Ven A., Bruggeman CA, Drent M. Detection of non-infectious conditions mimicking pneumonia in the intensive care setting: usefulness of BAL fluid cytology. Respir Medicine $1999 ; 93: 571-578$.

7. De Brauwer EIGB, Drent M, Mulder PGH, Bruggeman CA, Wagenaar SiSc, Jacobs JA. Differential cell counts in cytocentrifuged BAL fluid preparations are influenced by the area used for counting. Analyt Quant Cytol Histol 2000;22:143-149.

8. De Brauwer EJGB, Jacobs JA, Nieman F, Bruggeman CA, Wagenaar SjSc, Drent M. Cyrocentrifugation conditions affect the differental cell count in bronchoalweolar lavage fluid. Analyt Quant Cytol Histol 2000; in press.

9. Jacobs JA, De Brawwer EIGB, Conelissen EI, Drent M. Corretation of leukocyte esterase. detection by reagent strips and the presence of neutrophils: a study in bronchoalveolat lavage fluid. Chest 2000 ; in press.

10. Jacobs JA, De Brauwer EIGB, Comelissen EI, Drent M. Accuracy and precision of quantitative calibrated loops in transfer of BAL fluid. J Clin Microbiol 2000;38:2117-2121. 